\title{
Euro Area Policies: 2007 Article IV Consultation-Staff Report; Staff Supplement; Public Information Notice on the Executive Board Discussion; and Statement by the Executive Director for Member Countries
}

Under Article IV of the IMF's Articles of Agreement, the IMF holds bilateral discussions with members, usually every year. In the context of the 2007 Article IV consultation with member countries forming the euro area, the following documents have been released and are included in this package:

- $\quad$ The staff report on euro area policies (including the trade policies of the European Union), prepared by a staff team of the IMF, following discussions that ended on June 4, 2007, with the officials at EU institutions in the context of the Article IV consultations with countries forming the euro area. Based on information available at the time of these discussions, the staff report was completed on July 10, 2007. The views expressed in the staff report are those of the staff team and do not necessarily reflect the views of the Executive Board of the IMF.

- $\quad$ A staff supplement of July 20, 2007 updating information on recent developments.

- $\quad$ A Public Information Notice (PIN) summarizing the views of the Executive Board as expressed during its July 25, 2007 discussion of the staff report that concluded the Article IV consultation.

- $\quad$ A statement by the Executive Director for Germany, on behalf of the euro-area Member States and the European Community.

The document listed below has been or will be separately released.

Selected Issues Paper

The policy of publication of staff reports and other documents allows for the deletion of market-sensitive information.

To assist the IMF in evaluating the publication policy, reader comments are invited and may be sent by e-mail to publicationpolicy@imf.org.

Copies of this report are available to the public from

International Monetary Fund • Publication Services

$70019^{\text {th }}$ Street, N.W. • Washington, D.C. 20431

Telephone: (202) 623-7430 • Telefax: (202) 623-7201

E-mail: publications@imf.org • Internet: http://www.imf.org

Price: $\$ 18.00$ a copy

\section{International Monetary Fund Washington, D.C.}





\title{
INTERNATIONAL MONETARY FUND
}

\section{EURO AREA POLICIES}

\section{Staff Report for the 2007 Article IV Consultation with Member Countries}

\author{
Prepared by the European Department \\ Approved by Michael Deppler and Michael Hadjimichael
}

July 10, 2007

\section{EXECUTIVE SUMMARY}

There was broad agreement between staff and authorities on most issues. The main points are as follows:

- $\quad$ The outlook is the best in years. The economy is poised for a sustained upswing, partly because of cyclical considerations, but also because of policies, which have up to now had a forward-looking cast. The area's external position and the real effective exchange rate of the euro are within range of medium-term equilibrium.

- Stabilizing inflation below 2 percent might well require a further gradual tightening of monetary policy.

- $\quad$ Fiscal outturns and policies have been strong, and intentions are for this to continue; but there are concerns that past accomplishments together with benign prospects will prompt some letting down of the guard, particularly in countries still some distance from their medium-term objectives.

- With structural policies representing the area's main contribution to an orderly resolution of global imbalances, staff welcomed the renewed impetus behind the Lisbon Agenda. Labor market developments continue to surprise on the upside, but much remains to be done to increase participation rates. Product market policies have been moving into higher gear, but 50 years after the signing of the Treaty of Rome, contestability in sheltered sectors remains problematic and is central to reversing the weak performance of productivity.

- Increased contestability and integration in the financial sector is also key to improving performance, and significant initiatives to strengthen markets and the stability framework to that end are underway, but how to proceed is controversial. 
Contents

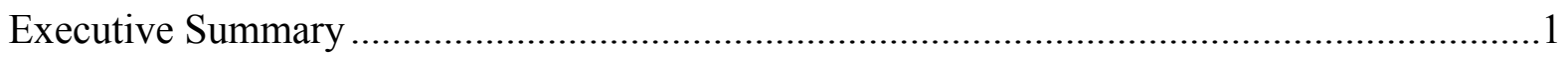

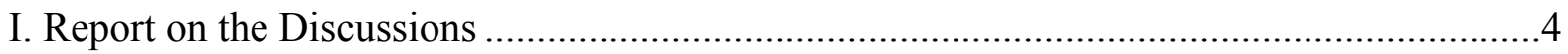

A. Cyclical Developments and Prospects ...................................................................

B. Inflation and Monetary Policy: Removing Policy Accommodation...........................

C. Fiscal Policy: Adjusting During the Upswing …………........................................

D. Structural Policies: Integrating Europe and Raising Labor Utilization ...................11

E. Financial Sector Integration and Stability ……………........................................14

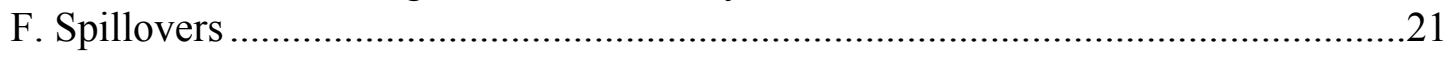

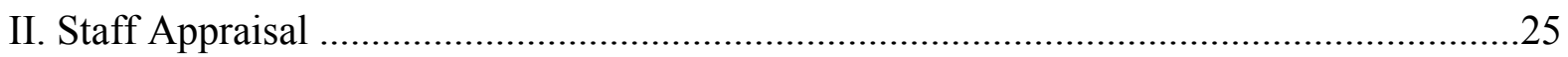

Tables

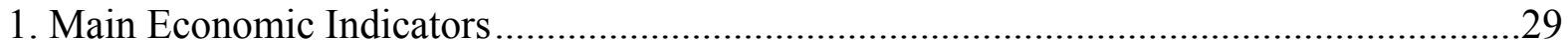

2. Financial Conditions of Large Complex Banking Groups in the Euro Area........................30

3. Euro Area: Policy Progress and Plans Relevant to the IMFC Strategy ..................................31

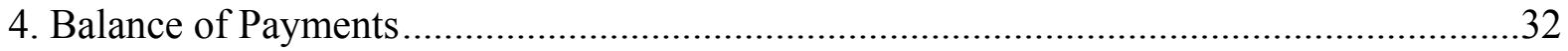

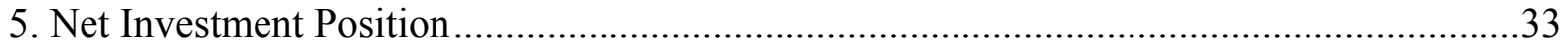

Figures

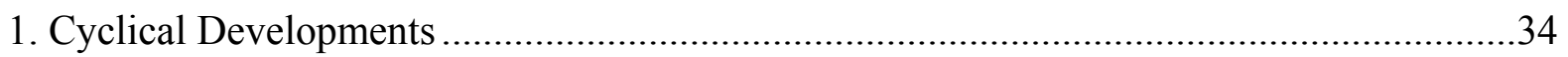

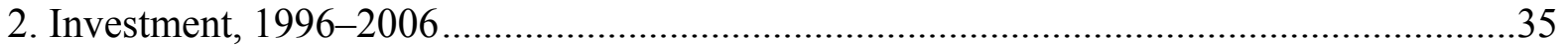

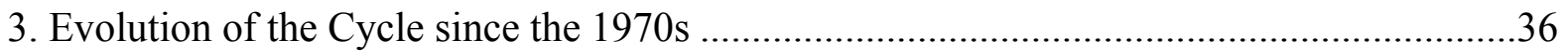

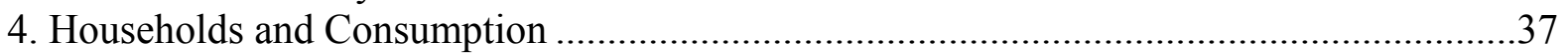

5. Indicators of Capacity and Labor Constraints ....................................................................

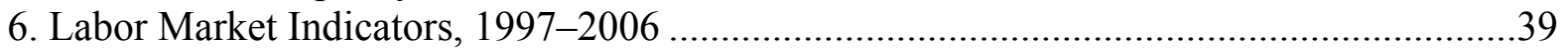

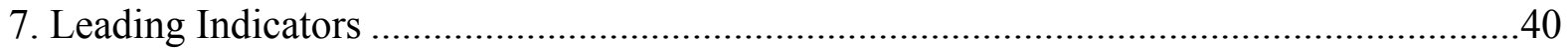

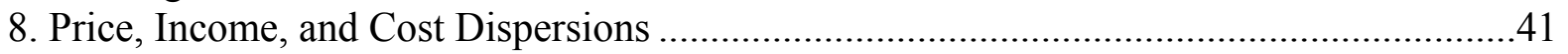

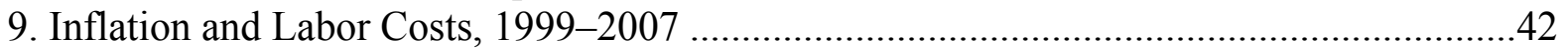

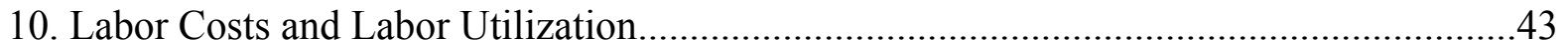

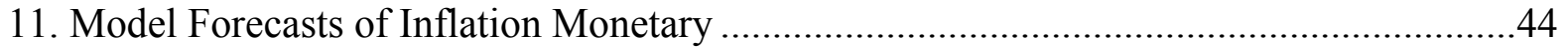

12. Monetary Policy and Market Expectations, 1999-2007 ..................................................45

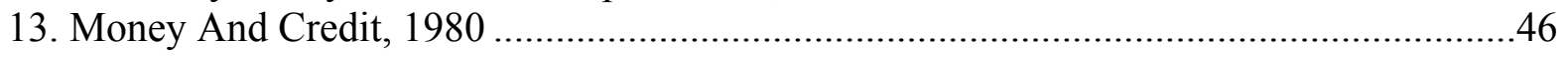

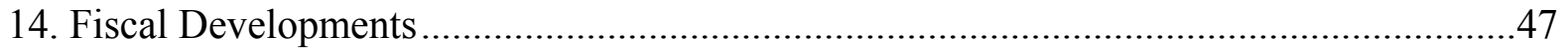

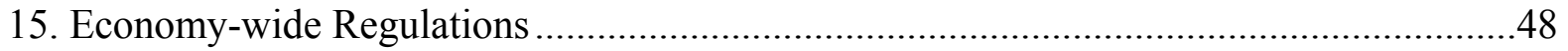

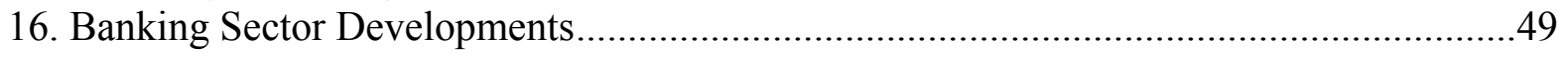

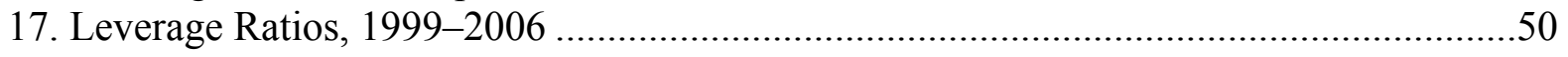

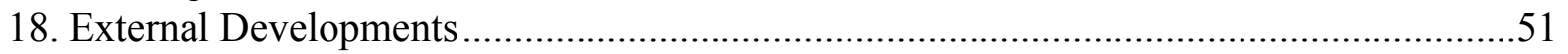




\section{Boxes}

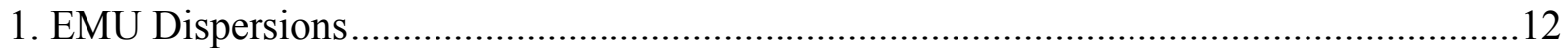

2. Spillover Risks Among the Major European Union Banks ............................................19

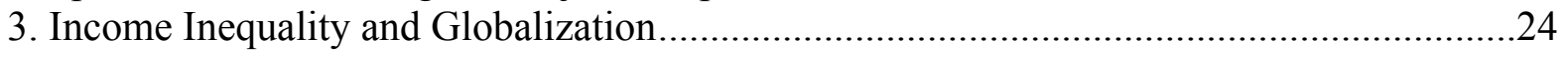

Appendixes

Appendix-Statistical Issues 


\section{REPORT ON THE DISCUSSIONS}

\section{A. Cyclical Developments and Prospects}

1. The economy is moving from recovery to upswing and the fundamentals are improving (Figure 1, Table 1). Real GDP growth is running around 2 $1 \frac{1}{2}$ percent; fiscal deficits are markedly lower than a few years ago; and strong export growth, improving profitability and balance sheets, and accommodative financial conditions have fostered a broad based upswing of investment and employment (Figures 2-4).

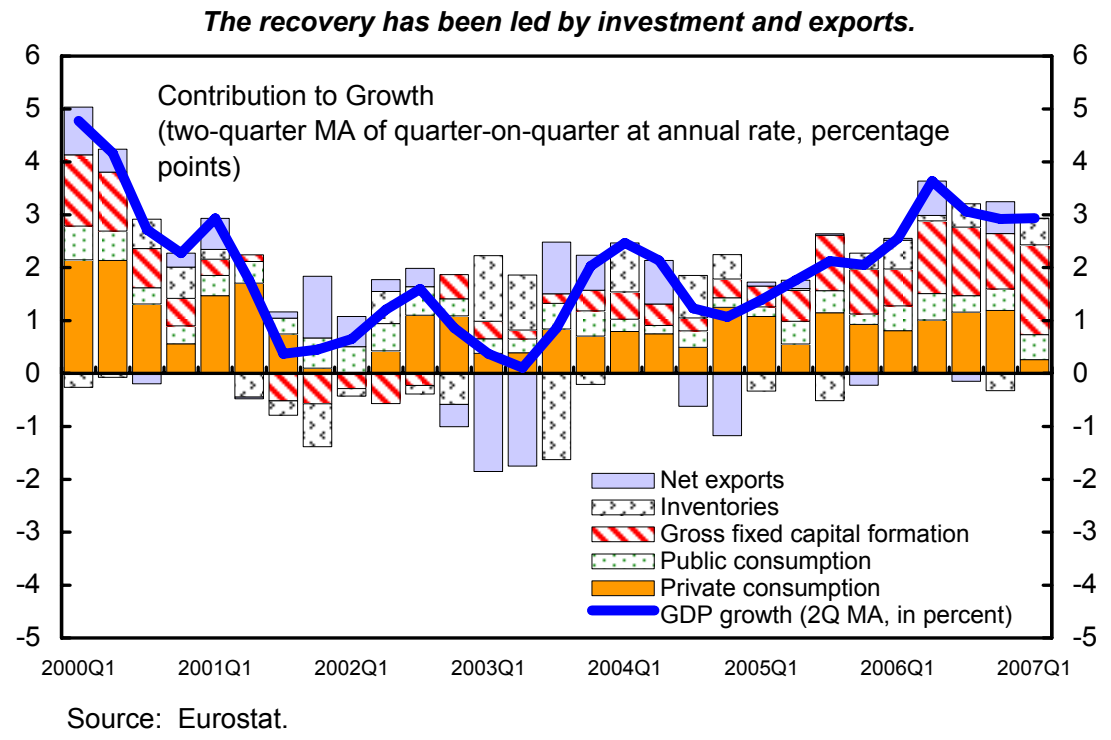

2. The external setting is generally considered propitious. Specifically:

- Import demand growth in partner countries is projected to slow down only moderately, from about $7 \frac{1}{2}$ percent annually over the past couple of years to around $6 \frac{1}{2}$ percent through 2008 .

- The area's external current account is broadly balanced and export growth has been dynamic, notwithstanding the recent appreciation of the euro's real effective exchange rate $(\$ 32)$.

- $\quad$ Financial market volatility and risk premia remain historically low. 
Growth momentum is robust...

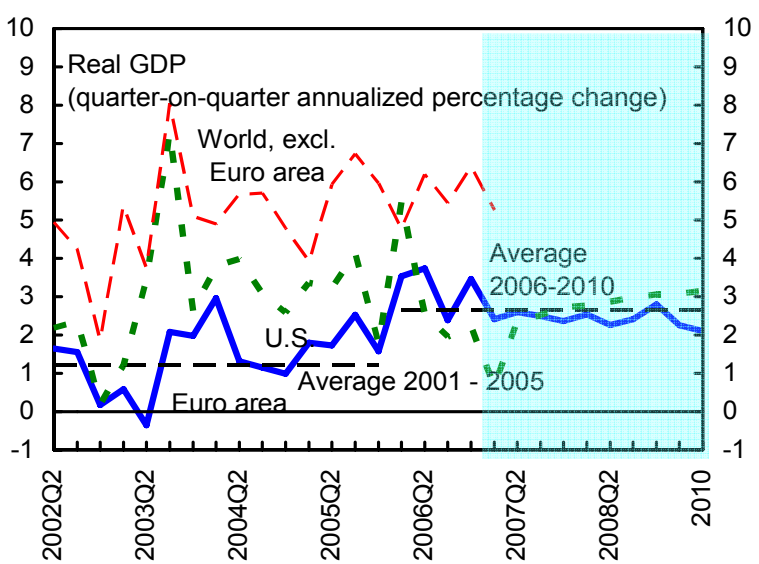

...its fiscal deficit has declined...

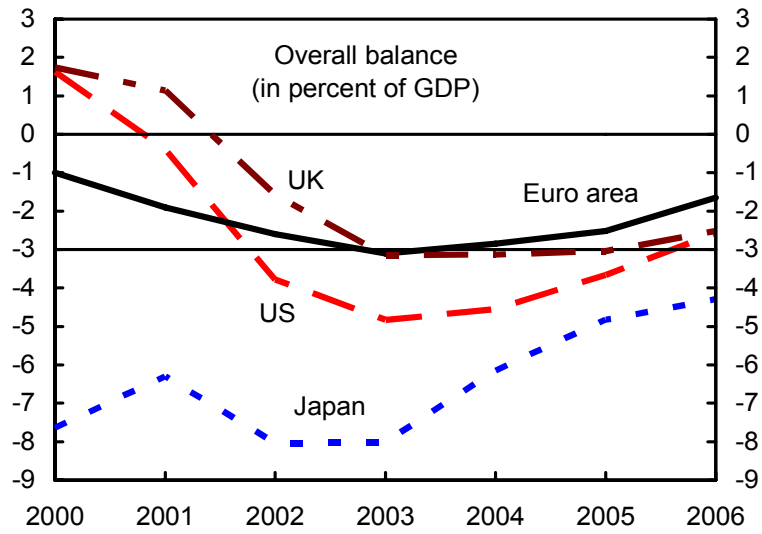

...and the area's external position is close to balance...

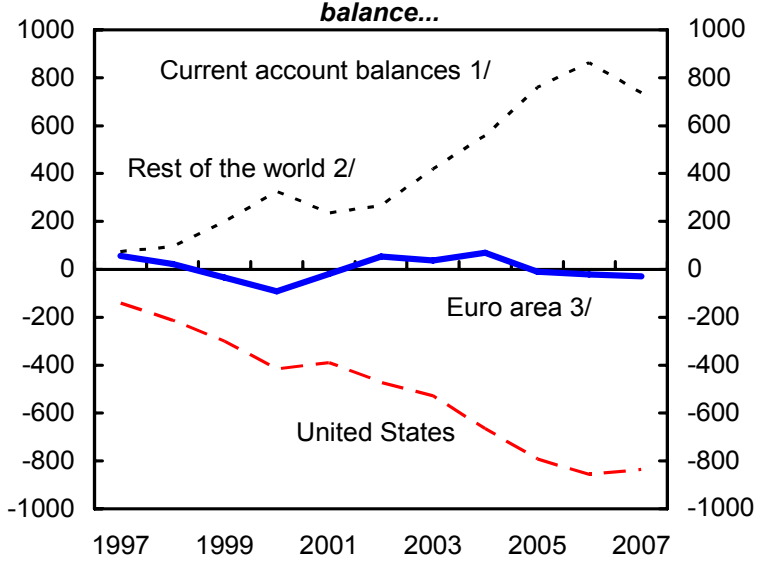

...but low productivity and labor utilization are weighing

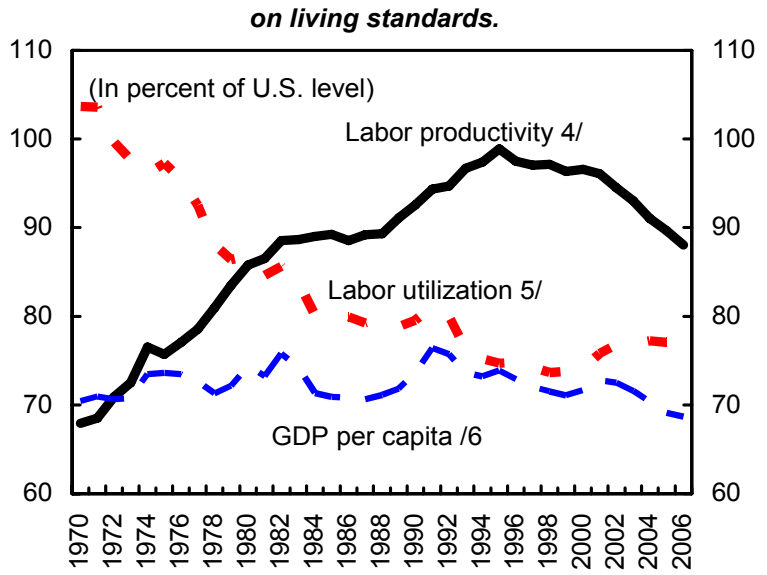

Sources: IMF, World Economic Outlook; European Commission; OECD; and Fund staff calculations. $1 /$ In billions of U.S. dollars.

2/ Rest of the world calculated as residual (excludes global discrepancy).

3/ Excludes intra-area trade (ECB data).

4/ Nominal PPP GDP per hour.

5/ Total hours worked per capita.

6/ Nominal PPP GDP per capita.

\section{Accordingly, projections are for} growth around $2 \frac{1}{2}$ percent through 2008 .

This represents a slowdown from the recent pace, which was just over 3 percent over the four quarters to 2006:Q4 and 2007:Q1. This reflects the unwinding of the German VAT, the tightening in macroeconomic policies during 2006-07, and the fading of exceptionally favorable export performances observed in 2006.
The recovery is expected to continue.

\begin{tabular}{|c|c|c|c|c|c|c|}
\hline & & \multicolumn{3}{|c|}{ Real GDP 1/ } & \multicolumn{2}{|c|}{ Oil Prices } \\
\hline & \multirow[b]{2}{*}{ Vintage } & \multicolumn{5}{|c|}{ (in percent) } \\
\hline & & 2006 & 2007 & 2008 & 2007 & 2008 \\
\hline WEO & June & & 2.6 & 2.5 & -0.8 & $7.83 /$ \\
\hline ECB 2/ & June & & 2.6 & 2.3 & -0.8 & 7.5 \\
\hline $\mathrm{EC}$ & May & & 2.6 & 2.5 & 2.3 & $6.24 /$ \\
\hline Consensus & June & & 2.7 & 2.3 & $\ldots$ & $\ldots$ \\
\hline Actual & April & 2.7 & & & & \\
\hline
\end{tabular}

$1 /$ Not adjusted for working days.

2/ Mid-point.

3/ Based on a simple average of spot prices of UK Brent, Dubai, and West Texas Intermediate crude oil.

4/ Based on Brent crude oil prices. 
4. With potential growth rate estimates currently just above 2 percent, the projections imply a gradual increase in resource utilization. All capacity utilization indicators are moving up and some are already close to previous cyclical peaks. However, labor does not appear to be a major constraining factor thus far, even at the level of individual countries

(Figure 5). While unemployment rates have fallen below the 2000 trough, equilibrium rates are likely to have fallen even further and labor force participation and population are on the rise (Figure 6). Key developments include: (i) the deregulation-enabled shift of employment toward part-time and temporary jobs; (ii) the rising labor force participation of women and older workers; (iii) high immigration; and (iv) less generous welfare. ${ }^{1}$
The decline in population growth has reversed owing to

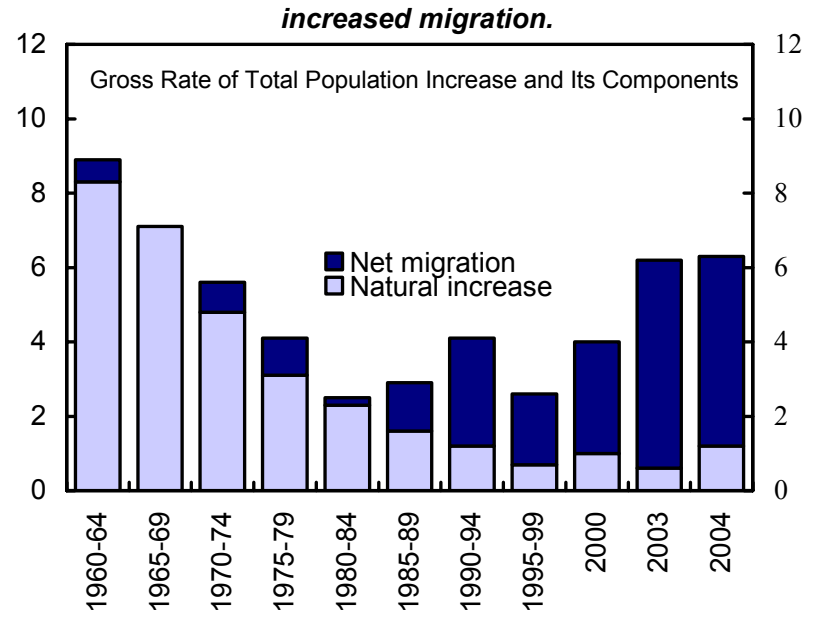

Source: European Commission.

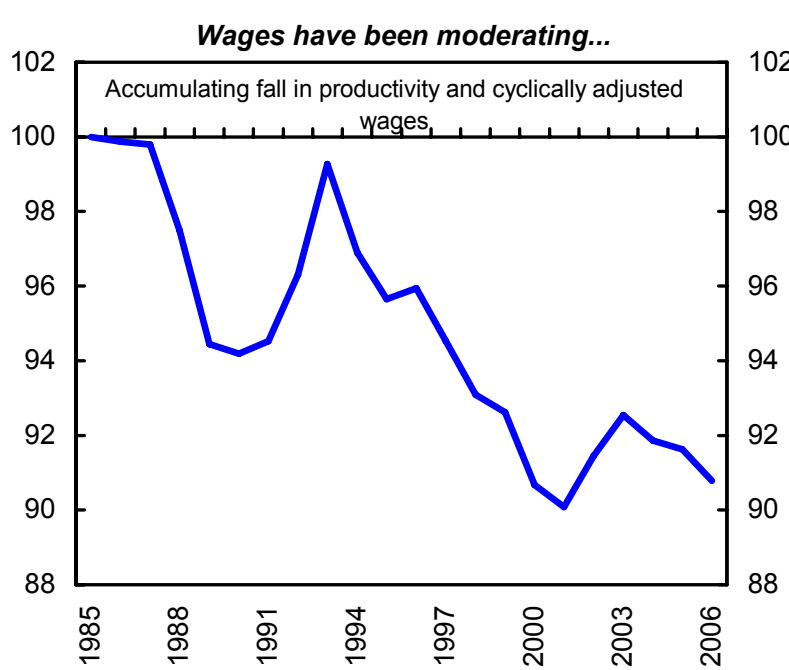

Source: EC-AMECO database.

1/ See IMF Country Report No. 04/235, Chapter 1.

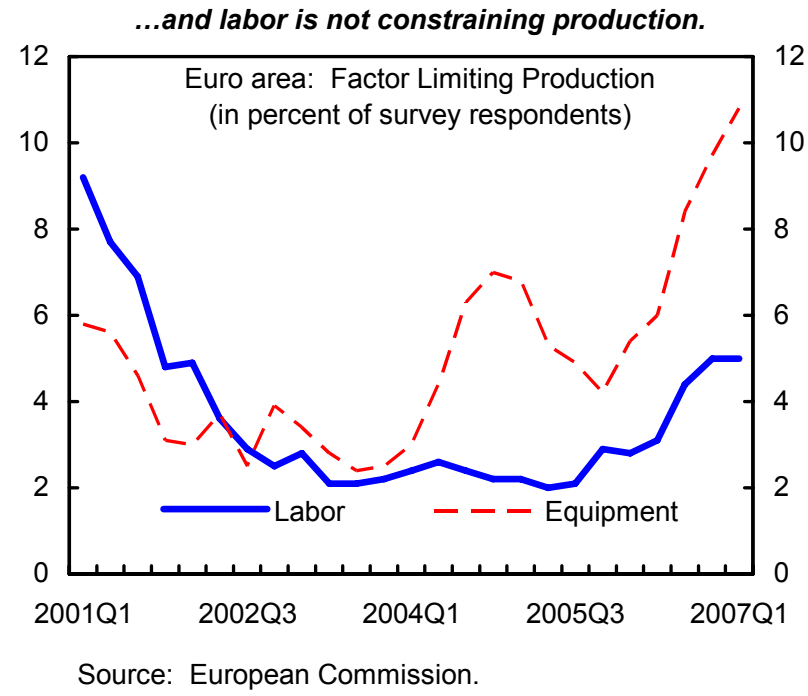

Source: European Commission.

\footnotetext{
${ }^{1}$ See IMF Country Report No. 04/235, Chapter I. Staff has marked up area-wide potential output growth estimates from 1.8 percent for 2004 to 2.1 percent starting 2008 - rates that are similar to those estimated by EC and ECB staff - projecting that the output gap would close in 2008. Upward revisions mainly reflect higher investment and capital stocks as well as growing labor force participation in response to improving employment prospects.
} 


\section{The risks to growth were generally seen to be small and to the upside in the} short run but widening and moving to the downside over the medium run. The external risks were viewed as on the downside and increasing over time. They relate mainly to renewed upward pressure on oil prices, a hard landing of the US economy, a malign unwinding of global imbalances, and flight from risk. Domestic risks were seen to be on the upside over the coming year but broadly balanced over the medium run. In the short run, consumer spending could accelerate faster than anticipated, as consumer confidence is relatively strong and employment and other conjunctural indicators are in expansionary territory (Figure 7). Moreover, equity markets are more fairly valued and corporate balance sheets stronger than at the peak of the previous boom. With emerging equipment capacity constraints, investment could grow more than expected. Regarding the medium run, household saving rates might stabilize rather than rise again in 2008, as assumed in WEO projections. But there are also domestic medium-run weaknesses, notably those related to stretched housing sectors and, to a lesser extent, insufficient competitiveness in some significant parts of the area (Figure 8).

Risks to growth are tilted to the upside in the near term and downside over the long term.

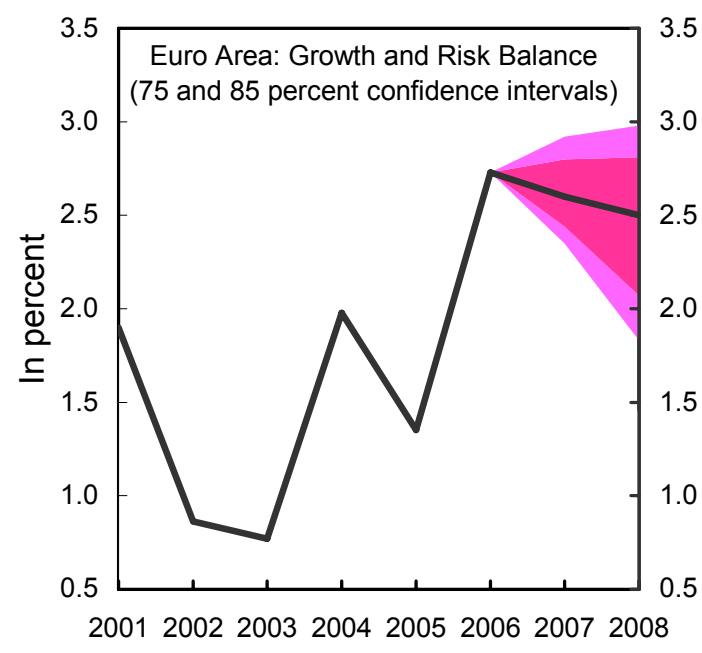

\begin{tabular}{|c|c|c|}
\hline & Near Term & Medium Term \\
\hline Upside & \begin{tabular}{|l} 
Stronger domestic growth \\
momentum \\
- Higher growth in EMCs
\end{tabular} & $\begin{array}{l}\text { - Higher growth in EMCs } \\
\text { - Lower-than-projected saving }\end{array}$ \\
\hline Downside & $\begin{array}{l}\text { Slower growth in the US } \\
\text { - Financial market risk } \\
\text { - Renewed oil price increase } \\
\text { - Disorderly unwinding of global } \\
\text { imbalances }\end{array}$ & $\begin{array}{l}\text { - Slowdown in construction in the } \\
\text { euro area } \\
\text { - Financial market risk } \\
\text { - Slower growth in the US } \\
\text { Renewed oil price increase } \\
\text { - Disorderly unwinding of global } \\
\text { imbalances }\end{array}$ \\
\hline
\end{tabular}

\section{B. Inflation and Monetary Policy: Removing Policy Accommodation}

6. While headline inflation has been somewhat volatile, measures of underlying inflationary pressures have been inching up. Financial market-based measures, analysts expectations, and various indicators of underlying inflation (core, trimmed means, etc.) have been rising gradually since the troughs of 2005
Inflation is seen close to 2 percent in 2008.

\begin{tabular}{|c|c|c|c|c|c|c|c|}
\hline & \multirow[b]{3}{*}{ Vintage } & \multicolumn{3}{|c|}{$\mathrm{HICP}$} & \multicolumn{3}{|c|}{ Oil Prices } \\
\hline & & \multicolumn{6}{|c|}{ (in percent) } \\
\hline & & 2006 & 2007 & 2008 & 2007 & 2008 & \\
\hline WEO & June & 2.2 & 2.0 & 2.0 & -0.8 & 7.8 & $2 /$ \\
\hline ECB 1/ & June & 2.2 & 2.0 & 2.0 & -0.8 & 7.5 & \\
\hline EC & May & 2.2 & 1.9 & 1.9 & 2.3 & 6.2 & $3 /$ \\
\hline Consensus & June & 2.2 & 2.0 & 2.0 & $\ldots$ & $\ldots$ & \\
\hline \multicolumn{2}{|c|}{ Admin. Price effects 4/ } & 0.4 & 0.4 & 0.2 & $\ldots$ & & \\
\hline \multicolumn{8}{|c|}{ 1/ Mid-point. } \\
\hline \multicolumn{8}{|c|}{$\begin{array}{l}\text { 2/ Based on a simple average of spot prices of UK Brent, Dubai, and West } \\
\text { Texas Intermediate crude oil. }\end{array}$} \\
\hline \multicolumn{8}{|c|}{ 3/ Based on Brent crude oil prices. } \\
\hline \multicolumn{8}{|c|}{$\begin{array}{l}\text { 4/ Fund staff estimates. ECB projection assumes } 0.5 \text { percentage point for } \\
2007 \text { and none for } 2008 \text {. }\end{array}$} \\
\hline
\end{tabular}


(Figure 9). The euro-area headline HICP has been running just under the 2 percent threshold. The effects of the January 2007 VAT increase in Germany, which may have added around $1 / 4$ percentage point at the area-wide level, have been masked by stabilizing oil prices.

7. Although still quite moderate, wage demands are expected to firm somewhat more than productivity over the projection horizon. Backward looking indicators show subdued wages through 2006 and wage settlements-lately in Germany's metal sector-continue to surprise on the downside. Amid supply side-driven moderation, the cyclical response of wages appears to have diminished (Figure 10). Nonetheless, continued high oil prices and improving labor market conditions were seen to provide ground for higher pay, notably in

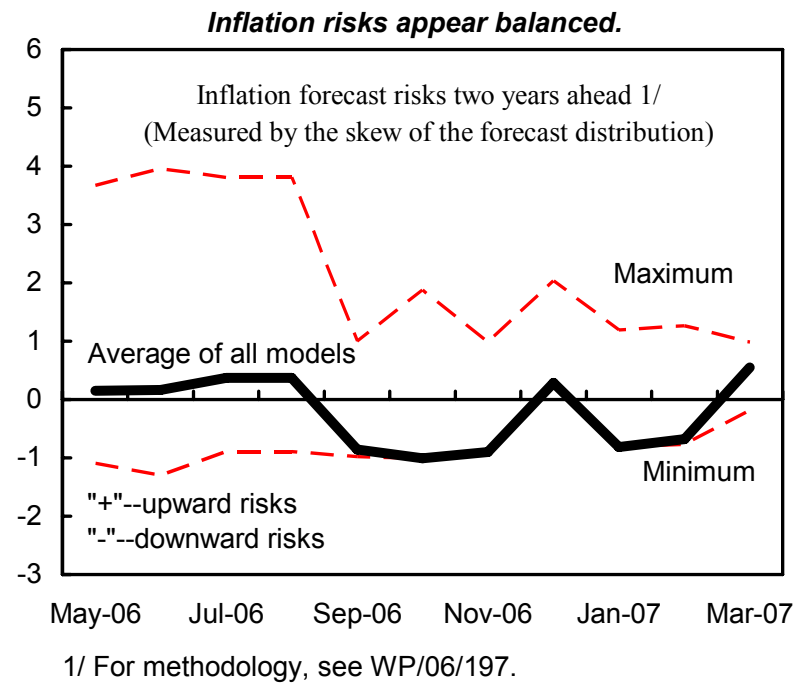
Germany where compensation had been exceptionally subdued. With firms already wellplaced to increase margins somewhat further, cost increases would likely translate into price increases as well.

\section{Looking ahead, the central view} was therefore that underlying inflation would gradually firm. Staff and ECB forecasts are for HICP inflation hovering around 2 percent through 2008, implying that an acceleration in costs would make up for the unwinding of the effect of the VAT on year-on-year inflation. Staff models point to roughly balanced risks (Figure 11), although fully capturing upside risks related to indirect taxes as well as administrative and oil prices with these models is difficult. The ECB put greater emphasis on the upside risks, including those related to wages and ample liquidity. Credit to nonfinancial corporations is increasing rapidly but that to households, notably for mortgages, is slowing down noticeably, suggesting that
Taylor rules suggest rates need not move much above 4 percent.

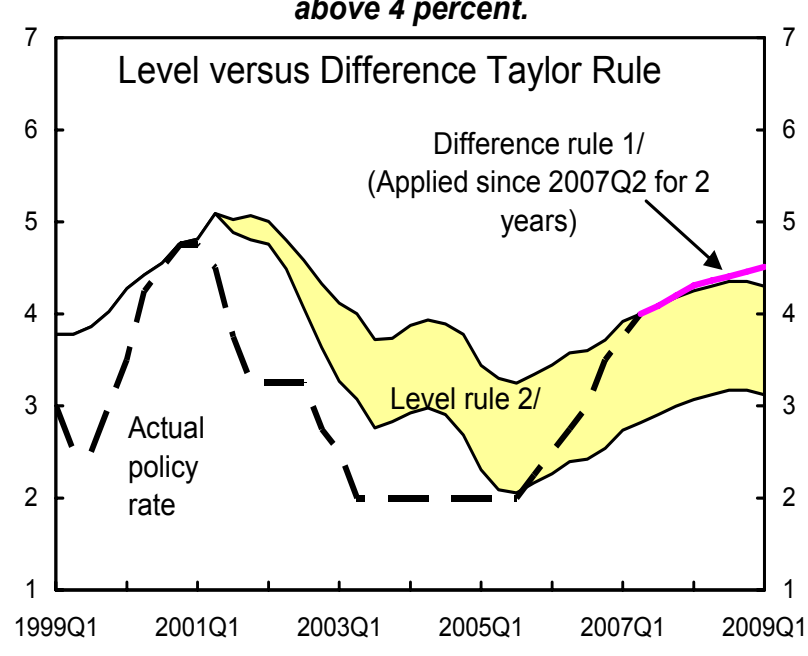

$1 /$ The coefficients on the changes in inflation and unemployment are 0.5 and 1.25 correspondingly.

$2 /$ The formula gives equal weight $(0.5)$ to the deviation from the inflation target and the output gap; the nominal natural rate is assumed to be 4.15 percent. 
past rate hikes are feeding through (Figures $12-13) .{ }^{2}$ Nonetheless, M3 continues to expand at a brisk pace (lately increasingly on account of less liquid components), although its recent dynamism may currently overstate somewhat the robust underlying rate of monetary expansion, according to ECB staff. Fund staff is skeptical about M3 as an indicator of shortto medium-run inflation. ${ }^{3}$

9. Some further monetary policy action is likely to be necessary. As expected, following the mission the ECB raised rates to 4 percent on June 6, 2007, and markets foresee rates just under $4 \frac{1}{2}$ percent by the end of this year. Concurrently, long-term interest rates have moved up noticeably as of late, implying some tightening of monetary conditions. With the area's growth projected to remain close to or above potential, and the possibility of some further upward pressure on factor utilization and prices, staff thought that (aside from global inflation trends) the scope and timing of further action would need to depend on (i) the extent to which reforms and demographics have improved labor supply; (ii) the extent to which the incipient acceleration of productivity is structural or cyclical; and (iii) the evolving distribution of (mainly demand-side) risks - including those related to the exchange rate ( $(32)$ - to activity further out, which are presently seen to be on the downside.

\section{Fiscal Policy: Adjusting During the Upswing}

\section{Fiscal policy surprised on}

the upside in 2006. Standard measures suggest that the area's cyclically-adjusted fiscal deficit fell by almost 1 percentage point of GDP in 2006 - exceeding staff's $1 / 2$ percent of GDP benchmark for countries at a significant distance from their medium-term objectives (MTO). This was led by large reductions in Germany, France, and (upon considering the expiration of one-off measures), Italy. Other EDP countries have also met their commitments and, more generally, higher-thanbudgeted revenues have been allocated to debt reduction, even if not to the full extent by all countries.

\begin{tabular}{|c|c|c|c|c|c|c|}
\hline \multicolumn{7}{|c|}{ Fiscal Developments, 2005-09 } \\
\hline & \multirow[t]{2}{*}{2005} & \multicolumn{2}{|c|}{2006} & \multirow{2}{*}{$\begin{array}{r}2007 \\
\text { proj. }\end{array}$} & \multirow{2}{*}{$\begin{array}{l}2008 \\
\text { proj. }\end{array}$} & \multirow{2}{*}{$\begin{array}{r}2009 \\
\text { proj. }\end{array}$} \\
\hline & & SP 2005 & est. & & & \\
\hline Overall fiscal balance & \multicolumn{6}{|c|}{ (In percent of GDP) } \\
\hline Euro area & -2.5 & -2.3 & -1.7 & -1.0 & -1.0 & -0.8 \\
\hline of which: & & & & & & \\
\hline Revenue & 45.2 & 45.1 & 45.8 & 45.6 & 45.4 & 45.3 \\
\hline Expenditure & 47.7 & 47.4 & 47.4 & 46.6 & 46.3 & 46.1 \\
\hline \multicolumn{7}{|l|}{ Structural fiscal balance } \\
\hline $\begin{array}{c}\text { Euro area }{ }^{1 /} \\
\text { of which: }\end{array}$ & -1.9 & -1.7 & -1.0 & -0.8 & -0.8 & -0.8 \\
\hline Revenue & 45.7 & $\ldots$ & 46.1 & 45.7 & 45.5 & 45.5 \\
\hline Expenditure $^{1 /}$ & 47.6 & $\ldots$ & 47.1 & 46.5 & 46.3 & 46.3 \\
\hline EDP countries ${ }^{2 /}$ & -3.1 & -3.1 & -1.8 & -1.3 & -1.5 & -1.3 \\
\hline Non-EDP countries & -0.7 & -0.3 & -0.1 & -0.2 & -0.2 & -0.2 \\
\hline Germany & -2.4 & -2.8 & -1.3 & -0.7 & -0.9 & -0.6 \\
\hline France & -2.7 & -1.6 & -1.9 & -1.6 & -1.6 & -1.6 \\
\hline Italy ${ }^{1 /}$ & -3.4 & -3.1 & -2.3 & -1.8 & -2.0 & -2.2 \\
\hline
\end{tabular}

Sources: WEO, ECFIN and Fund staff projections.

${ }^{1}$ Excludes net deficit increasing one-off measures in Italy in 2006 (1.5\% of GDP).

${ }^{2}$ Germany, Greece, Italy and Portugal, as of May 31, 2007.

\footnotetext{
${ }^{2}$ Relatedly, house prices have been moderating but still climbed at an annual pace just under 7 percent until lately.

${ }^{3}$ See IMF Country Report No. 05/266, Chapter II.
} 


\section{Spurred by these strong outcomes and buoyant prospects, the Eurogroup} Ministers announced their intention to accelerate the consolidation of the area's public finances. Specifically, they committed to achieve their (country-specific) MTO at the latest by 2010 and agreed, notwithstanding a still negative output gap according to agreed measurement techniques, that "good times" prevail. Under the Stability Growth Pact (SGP) rule book, this implies a commitment to adjust by more than $1 / 2$ percent of GDP annually for those countries that have not yet reached their MTO.

\section{There was agreement at staff levels, therefore, that the reformed SGP had worked well thus far, but also concerns that the true test of its preventive arm still lay} ahead. The challenges remain sizeable, particularly in some countries. Despite progress under the SGP's dissuasive arm, cyclically-adjusted fiscal positions today are not appreciably different from those attained in 2000. Moreover, recollections of the very large negative corrections made ex post to the structural positions estimated for 2000 prompted caution about relying unduly on current estimates. Indeed, there was agreement that the standard cyclical adjustment might overstate the true structural adjustment that occurred in 2006 because it did not allow for the potential procyclicality of revenue elasticities. The shared view was that, pending deeper analysis, it would be prudent to consider only about half of the observed reduction in the deficit ratio as structural, a figure that is broadly consistent with the decline in the cyclicallyadjusted expenditure ratio (adjusted for one-off operations). In addition, while significant progress had been made in preparing for the effect of the aging of the population on public expenditures, ${ }^{4}$ conservatively estimated increases of $3 \frac{3}{4}$ percent of GDP by 2050 remained in the pipeline. ${ }^{5}$ Staff therefore argued that, even if growth was likely to be stronger, a repeat

EU: Aging-related Expenditure, 2004-2050 (In percent of GDP)

\begin{tabular}{|c|c|c|c|c|c|c|}
\hline & \multicolumn{2}{|c|}{2004} & \multicolumn{2}{|c|}{2030} & \multicolumn{2}{|c|}{2050} \\
\hline & EU25 & Euro area & EU25 & Euro area & EU25 & Euro area \\
\hline & \multicolumn{2}{|c|}{ Level } & \multicolumn{4}{|c|}{ Increase over 2004} \\
\hline Pensions & 10.6 & 11.5 & 1.3 & 1.6 & 2.2 & 2.6 \\
\hline Health care & 6.4 & 6.3 & 1.0 & 1.0 & 1.6 & 1.5 \\
\hline Long-term care & 0.9 & 0.7 & 0.9 & 0.2 & 0.6 & 0.5 \\
\hline Gross expenditure & 17.9 & 18.5 & 3.2 & 2.8 & 4.4 & 4.6 \\
\hline Plausible alternative $1 /$ & $\ldots$ & $\ldots$ & $\ldots$ & $\ldots$ & 5.8 & 6.0 \\
\hline Education & 4.6 & 4.4 & -0.7 & -0.7 & -0.6 & -0.6 \\
\hline Unemployment benefits & 0.9 & 1.0 & -0.3 & -0.3 & -0.3 & -0.3 \\
\hline Net expenditure & 23.4 & 23.9 & 2.2 & 1.8 & 3.5 & 3.7 \\
\hline Plausible alternative & $\ldots$ & $\ldots$ & $\ldots$ & $\ldots$ & 4.9 & 5.1 \\
\hline
\end{tabular}

Source: AWG Report, European Policy Committee.

1/ Assumes that healthcare costs rise in line with wages rather than per-capita GDP; and that the probability of receiving formal long-term care rises gradually.

of the damaging SGP debates of 2002-04 was a distinct possibility. The reason is that some countries - Italy, and to a lesser extent France and Greece-would remain uncomfortably

\footnotetext{
${ }^{4}$ See European Commission, Special Report No 1/2006, Table 3.13.

${ }^{5}$ For further details, see IMF Country Report No. 06/288, Box 4.
} 
close to the 3 percent ceiling given the stage of the cycle, a view that was shared by EC and ECB staff.

Structural Balance Medium-term Objectives and Adjustments Needed

\begin{tabular}{|c|c|c|c|c|c|c|c|c|c|c|c|c|c|}
\hline \multicolumn{2}{|c|}{ Euro Area } & Aus & $\mathrm{Bel}$ & Fin & Fra & Ger & Gre & Ire & Ita & $\mathrm{Net}$ & Por & Spa & Slo \\
\hline MTO & 0.1 & 0.0 & 0.5 & 2.0 & 0.0 & 0.0 & 0.0 & 0.0 & 0.0 & $\begin{array}{l}-0.5 \text { to } \\
-1.0\end{array}$ & $?-0.5$ & 0.0 & -1.0 \\
\hline $\begin{array}{l}\text { Adjustment } \\
\text { needed }^{11}\end{array}$ & 1.1 & 1.3 & 1.2 & - & 1.9 & 1.3 & 3.1 & - & 2.3 & - & 2.5 & - & - \\
\hline
\end{tabular}

${ }^{1 /}$ Based on Fund staff estimates for the 2006 structural balance.

\section{Staff therefore pressed for full adherence to the SGP's norm of at least} $1 / 2$ percent of GDP adjustment per annum by countries that remained short of their MTOs. On present budgetary plans, staff thought that little adjustment was in the offing through 2008, particularly in some key countries, a concern that was shared by Commission and ECB representatives (Figure 14). There was broad agreement that various institutions, from independent ad-hoc committees to fiscal rules to medium-term expenditure budgeting are useful means to overcome political economy distortions to fiscal policy, depending on a country's institutional setting. The Commission observed that euro-area countries were making appreciable progress on this front, pointing to greater emphasis on medium-term planning, spending rules, and enforcement mechanism in stability programs (SPs). Staff welcomed these measures as they could help bring forward the credibility gains from adopting complementary fiscal and structural policies, but noted that peer pressure within the framework of the SGP would also need to play an important role.

\section{Structural Policies: Integrating Europe and Raising Labor Utilization}

\section{Advancing economic integration in the currency union}

14. The currency union countries have been integrating rapidly since EMU but structural reforms and more financial integration would help reduce remaining country dispersions and alleviate their repercussions on households and firms. Areawide shocks now explain the bulk of growth and inflation developments in individual member countries (Box 1), suggesting that the union has been integrating at considerable speed. As a result, the share of shocks that is country-specific is no longer high by international standards for currency unions. However, their persistence is still a concern, partly explaining appreciable divergences in national competitiveness (Figure 6). There was agreement that adjustments in national competitiveness needed to proceed more rapidly, notably through wage flexibility, and that continued labor and product market reform was critical to that effect. In addition, further financial integration could contribute to income smoothing among EMU members. 


\section{Box 1. EMU Dispersions}

Under EMU, common shocks explain a much larger portion of member countries' output and inflation developments than before, and the transmission of shocks has become increasingly similar. In particular, common factors are driving around 60 percent of growth and inflation during EMU, up from around 20 percent for growth and 30 percent for inflation before EMU. To a small extent, common shocks still trigger different responses across countries, accounting for some 20 percent of growth and inflation dispersions, down from 60 percent for growth and 30 percent for inflation dispersions before EMU. Remaining country-specific shocks to growth and inflation,
Euro Area: Contribution of Common Shocks Before and After EMU (In percent)

Growth

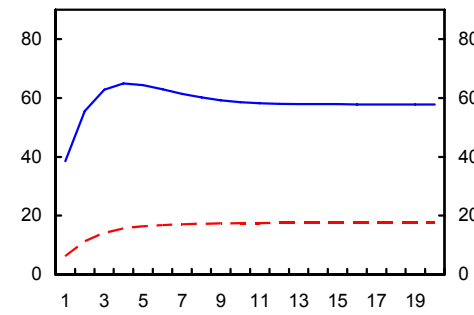

Growth dispersions
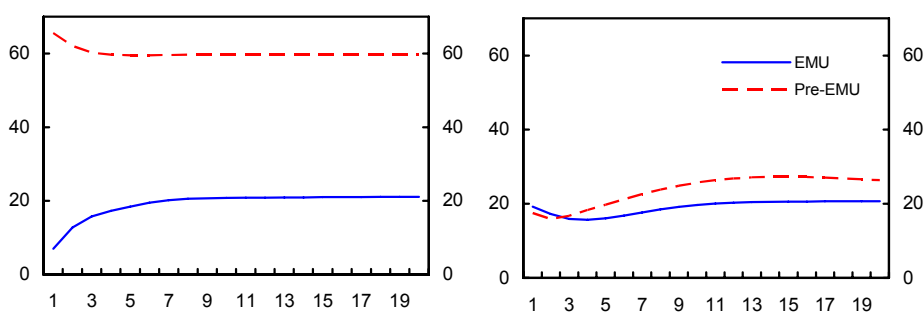

Source: IMF Staff calculations.

however, have a fairly large persistent component. Partly these shocks are driven by one-off factors that take time to unwind, notably the EMU-related declines of interest rates and increases in real estate valuations in various countries that featured high pre-EMU real interest rates. Partly they reflect income and price convergence. These two developments are difficult to account for separately, because the relatively less-wealthy countries were also those with relatively high pre-EMU interest rates. Staff research suggest that they can account for a large proportion of remaining country-specific shocks (see "Growth and Inflation Dispersions in EMU: Reasons, the Role of Adjustment Channels, and Policy Implications," forthcoming IMF Working Paper).

\section{Further integration of the financial system could increase risk sharing and income} smoothing in response to remaining country-specific shocks. Staff research suggests that the financial system has played a role as a shock absorber however, it is still far from achieving its full potential. The results indicate that its role for risks sharing has not increased substantially over time. Findings in the literature suggest that the contribution of the financial sector to income smoothing could be increased significantly — by up to 20 percentage points — if its level of integration reached that of the United States. ${ }^{1 /}$

\footnotetext{
${ }^{1 /}$ See Marinheiro, C. F., 2003, "Output Smoothing in EMU and OECD: Can We Forego Government Contribution? A Risk Sharing Approach,” CESIFO Working Paper No. 1051.
} 
15. Beyond reducing dispersions, all saw further market integration also as a boon for euro-area productivity. Euro-area productivity compares well internationally on tradables and poorly on nontradables, notably wholesale and retail trade and financial services. Similarly, among EU countries those with less regulated product markets have tended to post better growth performances over the past couple of decades, without necessarily experiencing larger social inequities. Indeed, staff analysis suggests that successful reformers focused on increasing labor supply through benefit reform and lowering tax wedges and government consumption. Greater labor supply translated into employment growth more effectively in the presence of liberal labor and product markets. ${ }^{6}$ There was broad agreement among staff, EC, and ECB officials on the synergies between labor and product market reform and hence on the benefits from eliminating remaining barriers to the

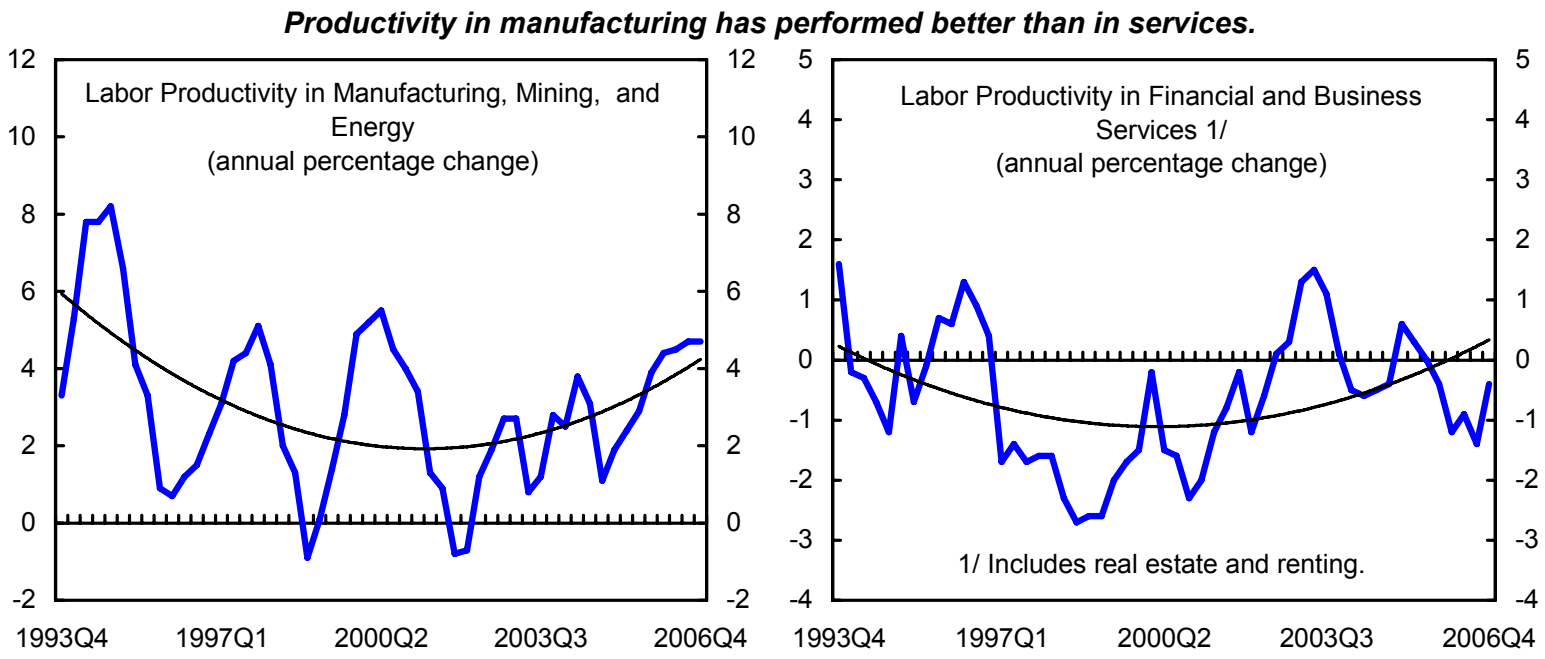

full integration of goods and services markets (Figure 15), including obstacles to foreign entry. Accordingly, the discussions focused on the key EU policy initiatives that seek to advance integration and market contestability, including the Lisbon Agenda, the Services Directive, and the Financial Services Action Plan (EU FSAP).

\section{The Lisbon Agenda and the Services Directive}

16. The implementation of the Lisbon Strategy is improving, as evidenced by the renewed issuance of country-specific economic policy recommendations. The Strategy was adopted by EU heads of state in 2000 to make Europe more dynamic and competitive and relaunched in Spring 2005, after initially disappointing results. Some estimates put the Lisbon Agenda's growth impact at about $1 / 2-3 / 4$ percentage points of GDP over the medium

\footnotetext{
${ }^{6}$ See Annett, 2007, "Lessons from Successful Labor Market Reformers in Europe," IMF Policy Discussion Paper No. 07/1.
} 
run. EC officials explained that aside from product, services, and financial market reform, as well as R\&D, priorities under the Strategy include several additional measures, notably improving flexibility and security on labor markets as well as education and training. Within these broad priorities, countries define their own National Reform Programs (NRP) that the Commission evaluates, making recommendations that are submitted for endorsement by the European Council.

17. Staff argued NRP under the Lisbon Strategy still needed to better harness the synergies between reforms and become more transparent. The NRP are helpful in harnessing synergies between reforms that boost labor supply, which are typically nationallyled, and those that liberalize product and services markets, which are increasingly EU-led. While there are some signs of progress, in the staff's view, too many countries are still not using the NRP to those effects and too many NRP are too vaguely specified to be monitorable and hence as credible as they might be.

\section{The Commission countered that the Agenda had already fostered a closer} dialogue between Ministries within countries in designing NRP. Furthermore, work is underway to improve the analysis of growth bottlenecks and their linkages to specific structural reforms as well as the monitoring and quantification of such reforms. Commission officials were particularly keen on improving coordination between national reforms and Community-led initiatives, including areas covered by EU structural and social policies. Staff agreed on the need for more coordination but pressed for the country-specific recommendations to place greater emphasis on improving the monitorability and domestic governance of NRP.

\section{Member states are to implement the Services Directive through national laws,} regulations, and administration by December 2009. The mission pressed for an early and good faith implementation of the Directive (meaning no abuse of the its public interest exemptions), which could be fostered by publishing country-specific transposition status timetables and scheduling a formal mid-term review by the European Commission. The liberalization of the services markets would also need to be extended to sectors not covered by the Directive, notably professional services. Commission staff explained that the transposition of the Directive would be a complex undertaking with different requirements for different countries.

\section{E. Financial Sector Integration and Stability}

20. Financial sector integration is a key avenue to boosting Europe's growth prospects. National accounts data suggest that: (i) about half of the euro area's just under 1 percent annual productivity growth gap during 1996-2003 relative to the United States can be traced back directly to the financial sector (excluding insurance); (ii) labor productivity in business and financial services has been moving broadly sideways since 1993; and (iii) the 
euro area is doing much better with respect to productivity in insurance, which at the level of major financial institutions appears more European and global than banking. While productivity data on financial services are not without problems, it is clear that the direct growth benefits of integration may well be large; that indirect benefits, notably from financial-sector-enabled restructuring and innovation, may be larger still; and that financial integration will foster more cross-border risk sharing and a better pass-through of monetary policy.

Banking is the least "Europeanized" of activities.
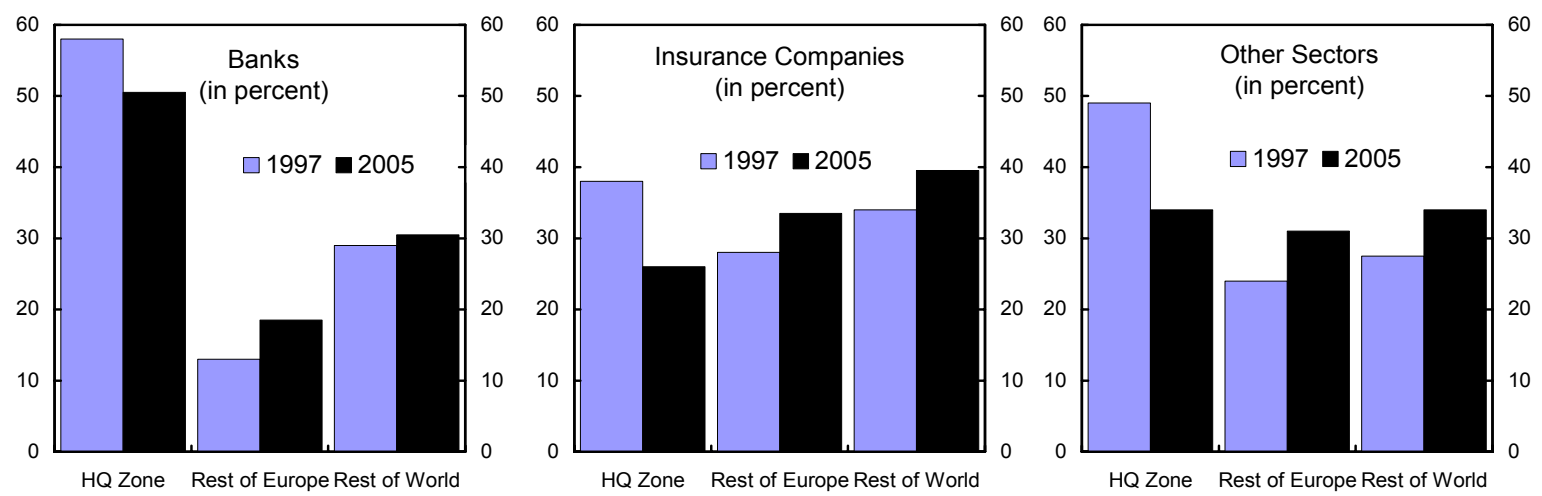

Source: Veron (2006).

Geographical distribution of activity (topline indicator, generally revenue or operating income) for a sample of 55 among Europe's 100 largest companies by market capitalization.

\section{Financial integration and development}

\section{The achievements to date are} major but so are the remaining obstacles.

In terms of progress on the ground, wholesale markets are now relatively wellintegrated, notably interbank and corporate bond markets, but less so equity and securitization markets and there is considerable scope to further develop armslength financing. Retail market integration is lagging, particularly in banking — on some measures the least "Europeanized" sector of the economy. Europe has put in place a strong policy framework to advance integration, comprising the EU's Financial Services Action Plan (EU FSAP) and the

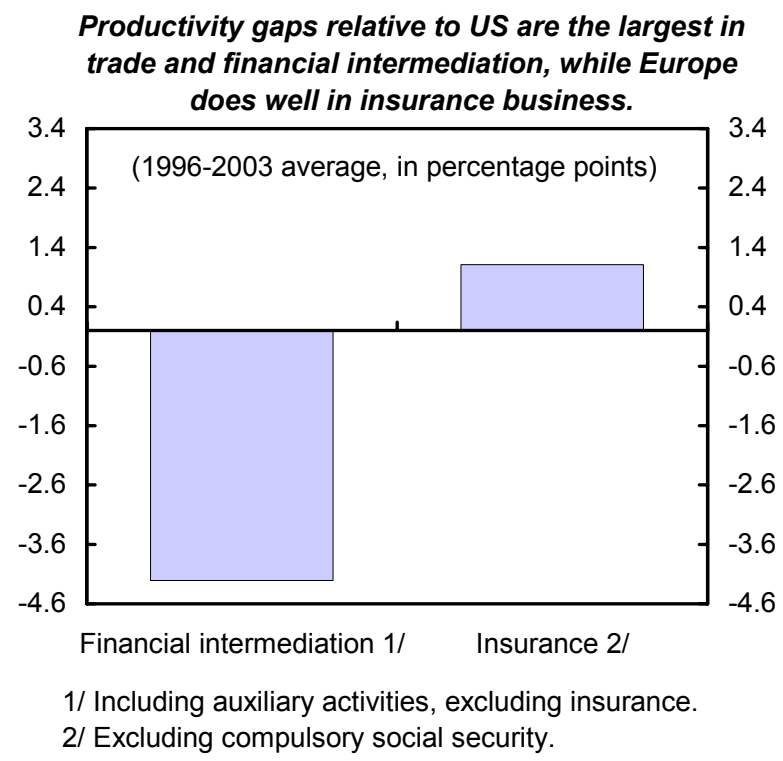
Lamfalussy process, with its several levels that focus on the development and implementation of legislation. On the regulatory front, the policy achievements within this framework are major: there has been much legislative and regulatory convergence, pushed forward in particular by the 2006 Capital Requirements Directive (CRD) for banks and 
investment firms, the forthcoming Solvency II Directive for insurance companies, and the Markets in Financial Instruments Directive for financial markets. The key challenge is to ensure the uniform implementation of the directives by national prudential authorities, which is the responsibility of the Level 3 (committees of supervisors) and 4 (enforcement by the Commission) of the Lamfalussy framework. Progress in this regard as well as with respect to supervision and crisis prevention, management, and resolution is mixed, however.

\section{Financial integration and development}

\section{Major initiatives are underway to develop European capital markets and "arms- length" finance as well as to promote retail market integration.}

- Transposition into national laws of the Markets in Financial Instruments Directive (MiFID). This will radically reshape the investment services landscape in Europe and has, for example, already led several major banks to plan a trading platform to compete with domestic stock exchanges in Europe. MiFID establishes a comprehensive regulatory regime for regulated financial markets, other trading systems, and investment firms. It simplifies and extends the "single passport" system for investment firms, enabling them to do business anywhere in the EU on the basis of home-country authorization, with a minimum of red tape. The Directive also enables investment firms to process client orders outside regulated markets. Overall, the Directive is expected to lead to major changes in the architecture of capital markets and financial intermediation in Europe both via increased competition and faster technological change. ${ }^{7}$

- Work is underway to integrate securities clearing and settlement systems, which is central to integrating Europe's capital markets. In particular, key post-trading services providers signed a Code of Conduct in November 2006 committing them to (i) price transparency; (ii) interoperability; and (iii) unbundling of services, by January 2008. Progress will be monitored and, if deemed insufficient, could lead to renewed work on a directive. Additionally, the ECB is evaluating opportunities to provide efficient settlement services in central bank money for securities transactions, processing securities and cash legs on a single platform (Target 2-Securities).

- $\quad$ Other policy initiatives cover bank mergers and acquisitions; the integration of payments systems (SEPA); retail products (e.g., mortgages, bank accounts); and investment funds.

It will take some time before these and other initiatives yield their full benefits. The mission welcomed the progress and encouraged work on converging national securitization markets.

\footnotetext{
${ }^{7}$ See Selected Issues paper, Chapter I.
} 
Securitization can play a major role in developing capital markets, spreading risks, and reducing economic divergences. It can also foster a more efficient, market-driven division of tasks between capital markets and banks.

\section{The financial stability dimension}

\section{The financial system is}

viewed as relatively healthy. Equity

markets have returned close to

previous highs or above; and

volatility and risk premia remain

unusually low, notwithstanding

recent turbulence. Bank profitability

has strengthened through 2006 (Table

2, Figure 16), although it remains

structurally low in parts of the area, and the insurance sector has benefited from recovering asset prices. Balance sheets are generally strong

(Figure 17), as reflected also in

relatively benign developments of

market-based indicators, such as

distance to default for large European

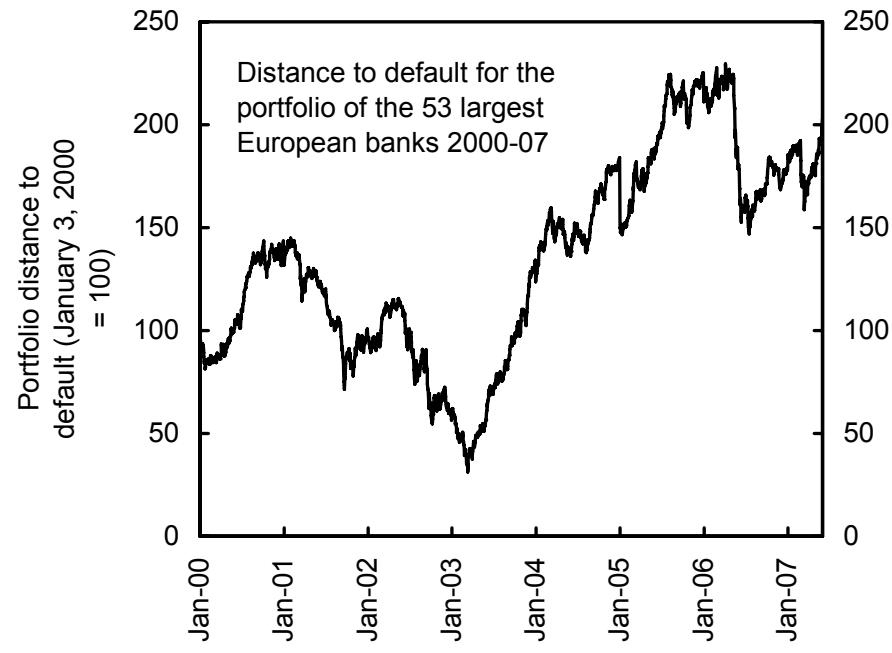

Sources: Staff calculations based on data from Datastream. Note: Distance to default is the difference between the expected value of assets at maturity and the default threshold, which is a function of the value of the liabilities. A higher distance to default is associated with a lower probability of default.

banks. While concerned about rapid growth of credit (especially in foreign currency) in various NMS, officials did not see significant vulnerabilities for euro-area financial institutions as a whole.

24. Financial indicators may have peaked, however. There are signs that the credit cycle is gradually turning: nonfinancial corporate rating downgrades have been more frequent than upgrades and leverage in parts of the corporate and household sectors may have become excessive. Also, ECB analysis suggest that the vulnerability of the financial system to an abrupt and unexpected loss of market liquidity appears to be increasing. Other concerns are the external downside risks; the rising complexity of financial instruments; and, to a lesser extent, the activities of highly leveraged nonbank financial institutions. ${ }^{8} \mathrm{EC}$ and ECB staff discounted worries about "subprime-like" mortgage products, a market that is far less developed in Europe than in the United States. They thought that few of the large euroarea banks have significant direct exposures to subprime activity in the United States. EC and ECB officials agreed on the desirability of stress testing to gauge potential cross-border

\footnotetext{
${ }^{8}$ High-yield bond issuance has increased significantly but related risks are better spread than during earlier times.
} 
vulnerabilities in Europe but observed that differences in supervisory data and confidentiality issues need to be addressed first. In the meantime, they implement less sophisticated stress tests using publicly available data on financial products and large crossborder financial institutions (LCFI). These had confirmed the robustness of the financial system.

25. Turning to the stability framework, Europe has for years sought to establish the right balance between the impulse to strengthen integration on the one hand and to preserve national accountability for financial stability on the other. In 1993, the Second Banking Directive introduced home-country control and mutual recognition, resulting in a "single passport" that enabled any bank licensed in any EU country to open branches (not subsidiaries) in other EU countries on the basis of its home license. However, branching entails a loss of control of host countries over domestic financial stability, for which they remain accountable, and often is less attractive than market entry via subsidiaries. Accordingly, the single passport has not delivered a single "rules book" of prudential policies and practices. A new impetus toward reform of the financial stability framework came with the 1999 Financial Services Action Plan (FSAP), which had as one of its objectives the introduction of state-of-the-art prudential rules and supervision. To support this objective and pursue convergence of supervisory practices, the FSAP was complemented with the Lamfalussy framework, a tiered process that relies on committees of national supervisors to effect convergence of national rule books and practices. Combined, the FSAP and Lamfalussy process have achieved major progress but less so in key areas, notably crossborder crisis prevention, management, and resolution. In the meantime a number of LCFI have begun to dominate the European banking landscape and crossborder consolidation is accelerating, even though it remains behind other sectors of the euro-area economy. ${ }^{9}$ As a result, the importance of crossborder bank linkages and the potential for contagion among the major European banks are increasing (Box 2). Against this background, the authorities have initiated various stock-taking exercises.

\section{The core problem, which is widely recognized, is that national authorities'} fiduciary responsibilities are toward national treasuries, and this limits their incentives to work toward a common EU-wide stability framework. The dominant strategy for supervisors in an LCFI crisis will likely be to look out for the national treasury, using informational advantages to that effect, notwithstanding MoUs on information sharing and cooperation. A scramble for assets in an LCFI crisis is thus likely and would have significant crossborder spillovers, preventing efficient and effective crisis management and resolution.

\footnotetext{
${ }^{9}$ ESCB work shows that some 46 LCFI hold about 68 percent of EU banking assets.
} 


\section{Box 2. Spillover Risks Among the Major European Union Banks}

The scope for cross-border spillovers among the major European banks can be examined using the Extreme Value Theory framework, which analyzes co-movements between extreme events ("co-exceedances"), specifically the co-movement of extreme negative (left-tail) realizations of banks' soundness measures. The soundness measure chosen in this analysis is the distance-to-default (DD), defined as the difference between the expected value of assets at maturity and the default threshold, which is a function of the value of the liabilities. A higher DD is associated with a lower probability of the bank's default. It is generally a useful proxy for default risk if stocks are traded in liquid markets.

The DD for 27 of the largest European Union banking groups were computed for May 2000-April 2007 using daily stock price and annual balance sheet data. A binomial logit model was used to estimate the probability of a bank experiencing a large negative DD change in response to large negative shocks to the DD changes of other banks. Large negative shocks were defined as those falling in the $10^{\text {th }}$ percentile of the left tail of the common distribution of the changes in the DD across all banks. Four control variableschanges in the slope of the term structure, and the volatility of the domestic, regional and world stock market indices - were also included in the model to account for common factors affecting all EU banks.

Significant Co-Exceedances among EU Banks, May 2000-April 2007

\begin{tabular}{lcccccc}
\hline & \multicolumn{2}{c}{ May 2000 - Apr 2007 } & & \multicolumn{2}{c}{ May 2000 - Nov 2003 } \\
\cline { 2 - 3 } & Domestic & Cross-border & & Domestic & Cross-border \\
\hline Number of significant links 1/ & 19 & 57 & & 14 & 50 \\
Percent of all possible links 2/ & 39.6 & 8.7 & & 28.6 & 7.6 \\
\hline
\end{tabular}

Source: IMF staff calculations, based on data from Bloomberg LP; and @ Bureau van Dijk Electronic Publishing - BankScope.

$1 /$ The number of bank pairs for which co-exceedances were found significant at the 5 percent level in the given period.

2/ The number of significant links (in the previous line), in percent of all possible contagion channels (i.e., as percent of all possible domestic and cross-border pairings of banks, respectively).

The results (see table) suggest that although spillovers within domestic banking systems generally remain more likely, the potential for extreme events to spill over from one bank to another appears to have increased, both among domestic banks and across the border. The number of significant cross-border links is already larger than the number of significant links among domestic banks, adding another piece of empirical evidence supporting the need for greater cross-border supervisory cooperation in the EU. 
In this set-up, it is natural for national prudential authorities to fear loss of control over domestically-active financial players. The desire to maintain control to better protect national financial stability is a factor contributing to customization and "goldplating" of EU directives, which risks delivering a collection of national rather than a single set of best EU prudential policies and practices; opposition to a framework for systematic multilateral supervisory data sharing: ${ }^{10}$ and, perhaps most importantly, a reluctance to agree to EU principles and procedures for crossborder financial crisis prevention, management, and resolution.

\section{While it is generally acknowledged that Europe's financial stability framework} needs to be strengthened further, views differ considerably on priorities. Some policymakers see a burden sharing agreement as the cornerstone of a reformed framework and thus a natural entry point toward more joint responsibility. These representatives argue that such an agreement is a condition for prudential authorities to fully internalize any spillovers of domestic actions - essential to minimize the EU-wide collective costs of LCFI failures (and therefore moral hazard) — and for advancing key reforms across a broad range of issues (e.g., more information sharing). Others consider talk about ex-ante mechanisms to share costs of LCFI failures as premature and entailing moral hazard and risks of forestalling practical steps towards financial integration. In their view, a host of other issues need to be settled first. Nonetheless, some proposals to instill more joint accountability and responsibility of national prudential authorities have been tabled, notably: (i) introducing EU-related references in the mission statements of national supervisors and qualified majority voting (in lieu of unanimity) in Lamfalussy Level 3 committees; and (ii) elaborating LCFI-specific MoUs covering crisis prevention, management, and resolution, including agreement on EU principles and procedures that these MoUs should incorporate.

\section{Staff pressed for imparting to the system a greater sense of joint responsibility} and accountability, considering it essential to meaningful progress in the prevention and the efficient and effective handling of LCFI solvency crises. In this regard, staff views the issue not as one of centralized versus decentralized supervision but about finding the right balance between the national and system-wide priorities. One possibility would be to couple proposals to introduce a European orientation into the mandates of prudential authorities and qualified majority voting at Level 3 committees with a parallel mandate for these and other authorities to elaborate principles and procedures seeking efficient and effective LCFI oversight as well as crisis prevention, management, and resolution. These principles and procedures would have to aim at minimizing collective costs of potential LCFI failures facing EU states. While such an approach might eventually have to address the allocation of costs across states, agreement at this juncture on a mandate to minimize

\footnotetext{
${ }^{10}$ Specifically, no entity in Europe (including the ECB) has a deep knowledge over what is going on in all of the key LCFI at any point in time.
} 
collective costs could be expected to accelerate work toward a balanced strengthening of Europe's financial stability framework, notably through establishing a database for sharing supervisory information on LCFI, including with the ECB; reducing differences in supervisory powers; enhancing pre-crisis sanctions and tools; harmonizing and improving the operations of deposit insurance; and understanding and improving the operation of bank insolvency laws in an area-wide context. ${ }^{11}$

\section{F. Spillovers}

\section{Euro adoption}

29. With the Maastricht criteria for NMS are driving exports of euro-area countries. entry having been controversial, staff asked how euro adoption for the NMS would be managed. The inflation and exchange rate criteria, if taken to their limit, amount to a real income convergence criterion. ${ }^{12}$ While this has not been much of an issue thus far, per capita incomes in most NMS are appreciably lower than in the euro area. Hence, higher inflation or nominal exchange rate appreciation in these NMS can (but need not) be consistent with medium-term equilibrium. With real income convergence set to extend over a horizon stretching significantly beyond current

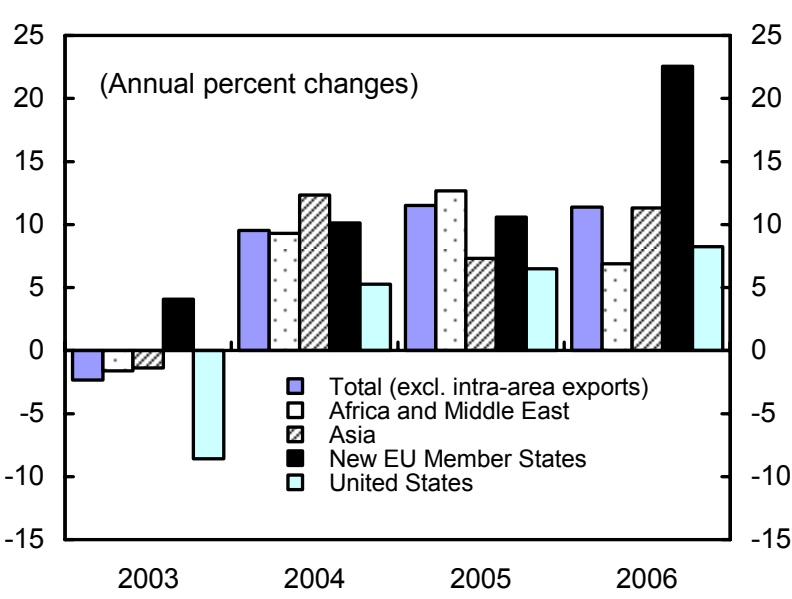

Source: IMF, Direction of Trade Statistics and Fund staff calculations. Growth rates refer to exports of goods denominated in euros. market expectations on official plans for euro adoption, staff asked how the euro-adoption process - notably the emphasis on sustainability with respect to inflation convergencewould be managed. Clarification is particularly important in view of the fact that financial positions and transactions in NMS suggest that economic agents have expectations of euro adoption within the next 5-7 years.

\footnotetext{
${ }^{11}$ With many of these steps requiring extensive harmonization across national legislation, an alternative approach would be to put in place a specific EU-level prudential regime (which could, for example, be elaborated within the Lamfalussy process). See "The Case for a European Banking Charter," forthcoming IMF Working Paper.

${ }^{12}$ See Selected Issues paper, Chapter II.
} 

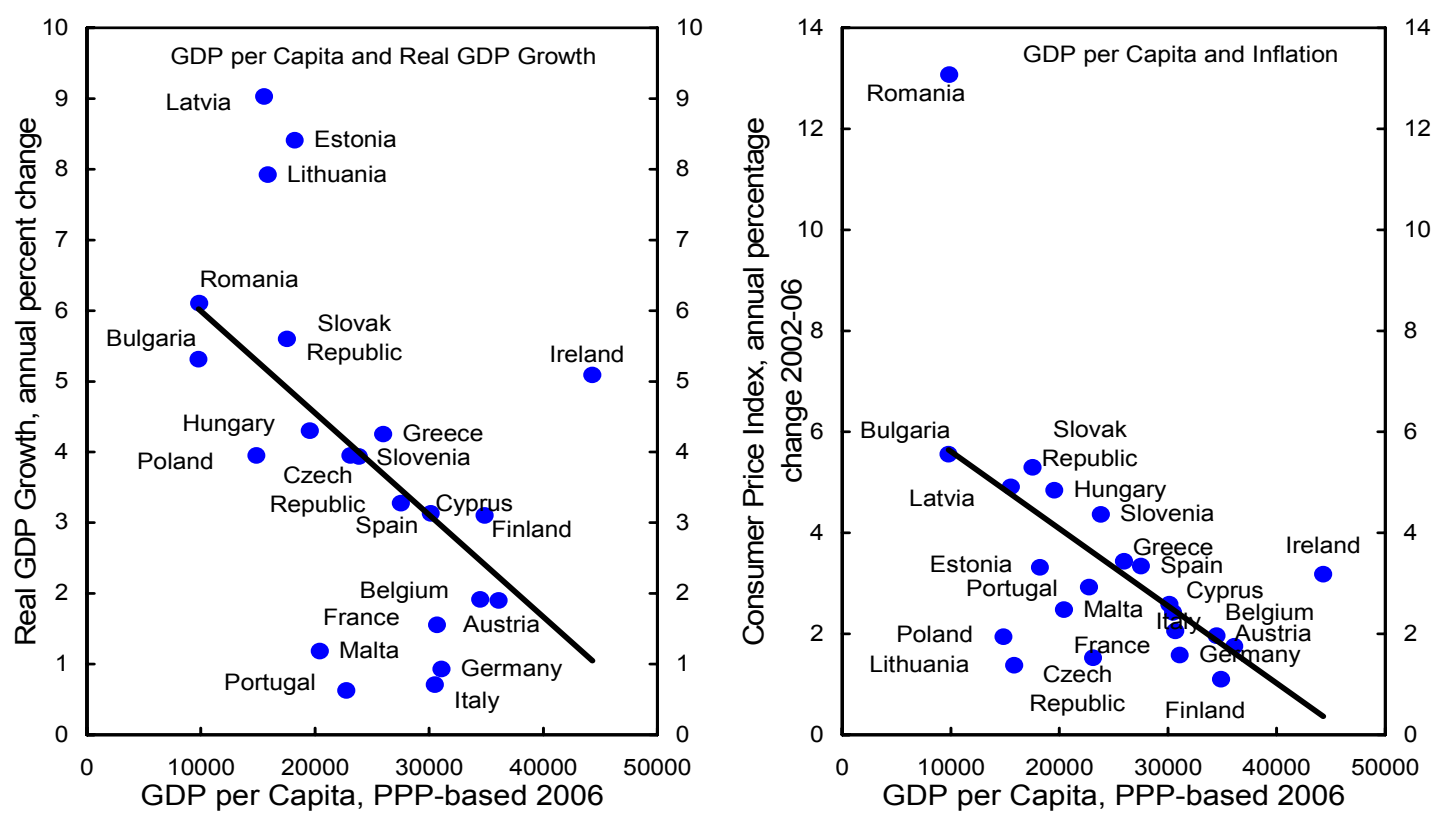

Sources: Eurostat; National Statistical Offices; and IMF staff estimates.

30. Interlocutors responded that while the Treaty did embody an expectation to join, the timing was open and the euro-adoption process was well understood.

Expectations of early entry had over time been replaced by much more cautious statements by all involved, especially over the past year, without causing market tensions. Furthermore, EC officials stressed that the "real income convergence" argument was overstated. They clarified that "sustainability" in the context of the price stability criterion meant that inflation had to be within Maastricht bounds without reliance on one-off factors, with the assessment involving backward-looking analysis as well as a forward-looking assessment with a prudent use of forecasts. Specifically, the examination uses Commission forecasts to assess mediumterm prospects for inflation and includes a statement on whether the candidate country is likely to meet the reference value in the months after the examination. In the meantime, all interlocutors considered it key that the NMS seeking euro adoption strengthen their policies further to ensure a successful operation in the monetary union. In this regard, EC and ECB officials underscored the useful disciplining effect of the Maastricht criteria. They also emphasized that the process was an open one, and countries meeting the criteria welcome, as was clear from the recent admission of Cyprus and Malta.

\section{Europe's part in addressing global imbalances}

\section{Staff welcomed the broad-based structural reform efforts underway, as these} would help strengthen prospects for an orderly resolution of global current account imbalances. Structural reforms are of course necessary primarily for domestic reasons but they can help the adjustment process essentially by helping sustain world growth in the face of a U.S. current account adjustment. The authorities' multilateral consultation commitments are all in the structural and financial sector area (Table 3) and are a subset of the initiatives discussed above. They stressed that the implementation of these reforms is continuing. 
32. Staff calculations suggest that the euro's real effective exchange rate remains broadly in line with medium-term fundamentals. EC and ECB officials presented broadly similar calculations but suggested that the exchange rate might be somewhat more appreciated than suggested by the staff, although still broadly in line with medium-term fundamentals. Over the past 6 months, the euro, which floats freely and independently, appreciated slightly in real effective terms, reflecting partly stronger portfolio inflows. According to staff calculations, the euro continues to be close to equilibrium, as are the area's balance of payments and net international investment positions (Figure 18, Tables 4$5)$. Furthermore, exports are growing at a healthy pace. Staff downplayed concerns about the latest exchange rate movements for the recovery.

\section{Europe's role in promoting world trade}

\section{With trade having consistently been a boon to Europe's productivity} performance, an ambitious conclusion to the Doha Round is very much in the EU's interest. There are pressures from some political quarters for the Commission to take a tough stance in the Doha negotiations because of social considerations. However, the evidence for trade liberalization driving income inequality in Europe is weak (Box 3). Also, in the staff's view trade policy is a poor instrument to manage income inequality. The Commission noted that the successful conclusion of the Doha round remains the foremost EU trade policy priority, but that it had already shown sufficient flexibility on agriculture in private discussions in July 2006. They took the view that other key participants need to make additional concessions, including the United States on agricultural subsidies and Brazil, India, and other emerging economies on industrial goods and services. Staff emphasized that a willingness to agree to additional liberalization by the EU, in particular on agriculture tariffs, is needed for an ambitious outcome to the Round. Additional liberalization in agriculture would also provide a greater incentive for the EU's key trade partners to agree to greater liberalization in areas of particular interest to the EU, including industrial tariffs and trade in services.

\section{Staff stressed that free trade agreements (FTAs) were no substitutes for} multilateral trade liberalization in the Doha Round and should not be allowed to distract political energy and attention from the Doha Round negotiations. Earlier this year, the EU has embarked on a new series of FTA discussions with Asian countries, including the ASEAN countries, India, and Korea, as part of its Global Europe initiative. These discussions come on top of a wide array of ongoing FTA discussions, including those with the Andean countries, Central America, Mercosur, and the 79 African, Caribbean, and Pacific (ACP) countries (the latter in the context of Economic Partnership Agreement (EPA) discussions). The Commission stated that the EU's bilateral agenda is a complement to, and not a substitute for, multilateral negotiations. Staff agreed that bilateral agreements may provide benefits to their participants and may be able to secure liberalization in "new" areas that fall outside the scope of Doha Round negotiations. However, they are inferior to 


\section{Box 3. Income Inequality and Globalization}

There is growing concern in Europe over the impact of globalization on high and evenly shared living standards but this is difficult to substantiate in the data. To a large extent, these concerns have surfaced in response to slowing wage growth and falling labor income share in aggregate national income data. However, these data may tell little about the underlying distribution of incomes, as measured by Gini coefficients on household disposable incomes. While Gini data also suggest that inequality has increased in most industrialized countries, this development was much less pronounced in euro-area countries, unlike what labor income shares data suggest.

Change in Income Gini Coefficient and Labor Shares (Late 1970s/Early 1980s - Late 1990s/Early 2000s )

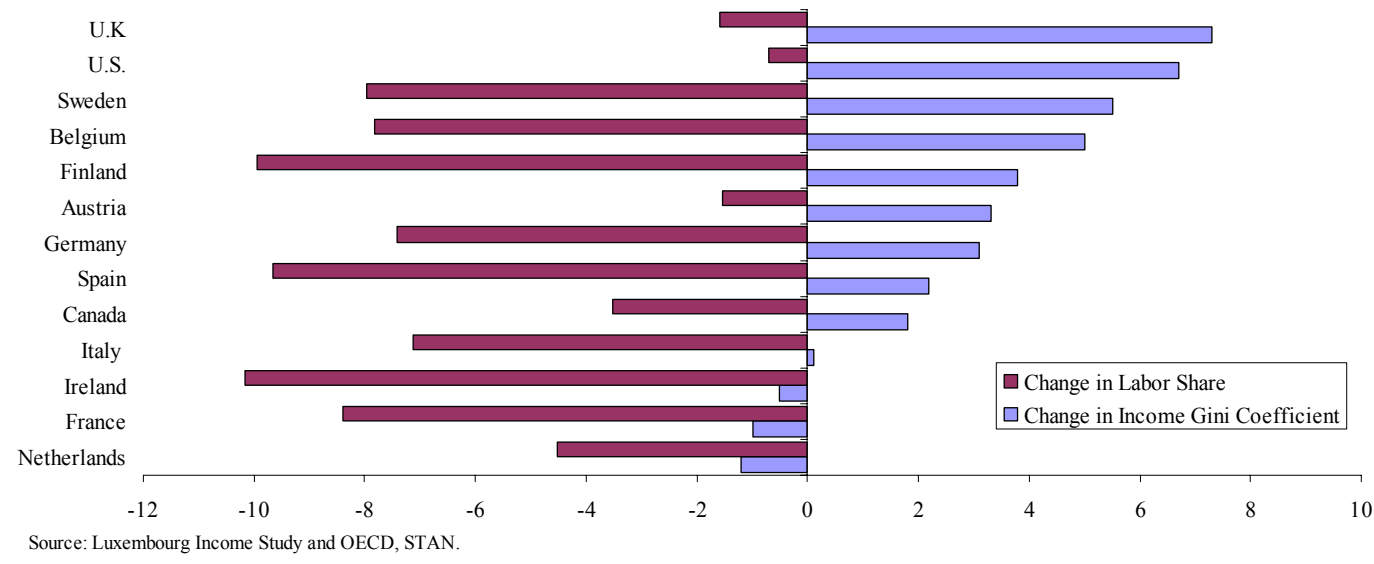

Data on the distribution of wages of prime age males suggest that advanced countries have fared very differently and that, therefore, broad phenomena such as trade liberalization and technological change may not be major drivers of inequality. Inequality of pre-redistribution incomes among prime age males has not changed much in France, Italy, and the Netherlands. In Germany, some limited hollowing out of the distribution it visible, but only at the low end. Polarization has taken place in the US and UK but not during the past "globalization decade." Instead, it took place during the 1980s, when domestic policies on minimum wages and trade union representation changed appreciably.
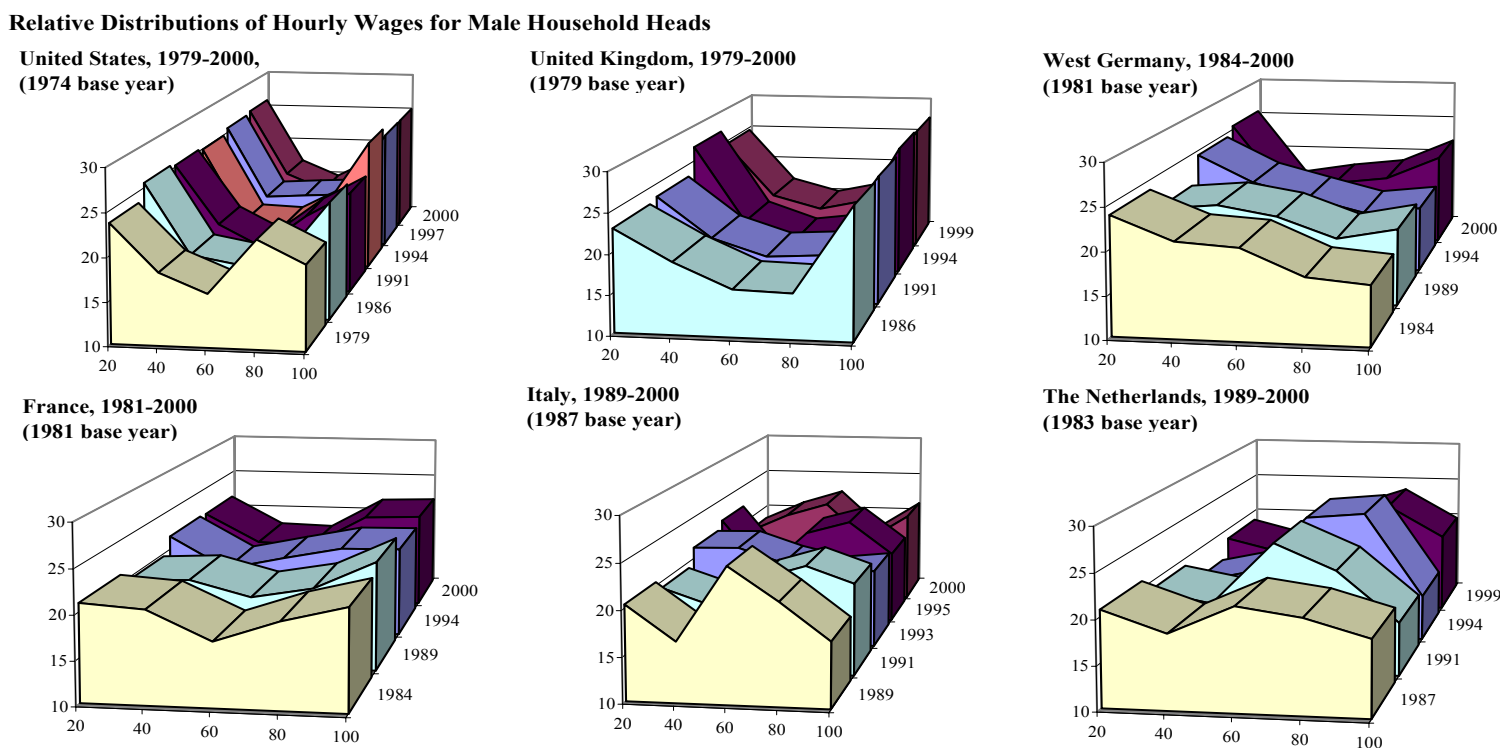

The Netherlands, 1989-2000 (1983 base year)

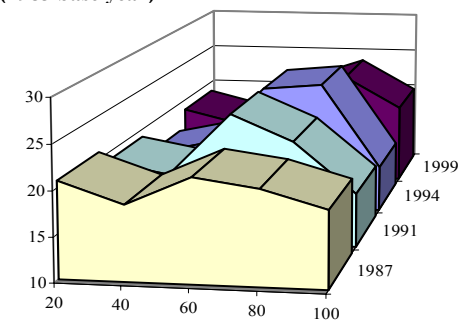

Source: Luxembourg Income Study. Wages are deflated with median wages and the cutoff points for the percentiles are determined by a base year and kept constant.

${ }^{1 /}$ See “Globalization and Income Inequality: A European Perspective,” forthcoming IMF Working Paper. 
multilateral liberalization for both members and non-members; and their pursuit may divert political energy and negotiating capacity away from securing an ambitious Doha Round outcome, both in the EU and the FTA partner countries. The Commission responded that the Asian FTAs will only begin serious negotiations in 2008, after the target for conclusion of the Doha Round.

\section{Staff argued that the ongoing review of the EU's trade defense (e.g.,} antidumping) policy should not increase opportunities for protectionist outcomes. The Commission indicated that it is too early to predict the conclusions of the review, but emphasized that the initiative makes clear that the EU rejects the temptations of protectionism. EC officials also noted that the use of these instruments is consistent with the EU's WTO obligations. Staff agreed, but took the view that the EU should also take more account of the benefits consumers have from trade, and exercise restraint in the use of such trade defense measures.

\section{Staff Appraisal}

36. The euro-area economy is doing well on the heels of a supportive external environment and generally sound policies. Fifty years after the signing of the Treaty of Rome, the envisioned Single Market still holds the key to growing prosperity. The achievements are major and justify optimism. So too does the progress that has been made in preparing for population aging, the key challenge facing welfare systems.

\section{But policymakers now need to make good on their intentions to overcome} tendencies toward good-times complacency. Much of the progress thus far has been accomplished during bad economic times, with policies during good times often falling short of requirements, leaving urgent work undone. The intentions have so far been different this time around. This is welcome but they must be translated into continued action. The euro area's economic governance framework (e.g., the Stability Pact and the Lisbon Agenda) can and should be used to resist good-times complacency.

38. The euro-area economy has moved from recovery to upswing. A benign external environment, favorable financing conditions and generally sound policies have set the stage for a sustained economic expansion, supported by strong domestic investment expenditure and strengthening consumption demand. The external position remains roughly balanced and the real effective exchange rate of the euro continues to trade within range of medium-term equilibrium. Growth is expected to be above potential in 2007 and 2008 and to be accompanied by healthy employment gains thanks to reforms to labor markets and welfare systems, and immigration. The risks to this outlook are relatively small and to the upside in the short run but widen and move to the downside over the medium run, mainly on account of external risks relating to oil prices, global current account imbalances, potential investor flight from risk, and US growth. 
39. With rising resource utilization, inflationary pressures can be expected to build gradually, and some further monetary policy tightening may be required. The policy rate has come within range of neutral and inflation is widely forecast around 2 percent. Wage demands remain quite moderate, but may firm as unemployment recedes. As the upswing unfolds, the necessary magnitude of further monetary tightening depends in part on wages and the extent to which reforms and demographics have improved labor supply as well as on the pricing behavior of firms and productivity growth. It also hinges on the evolution of risks to activity further out, including those related to global imbalances and the exchange rate, which are presently seen on the downside.

40. The key challenge facing fiscal policy is to ensure that countries that have not yet reached their MTO adjust by at least $1 / 2$ percent of GDP per year. Fiscal policy performances in 2006 were generally strong, and the announced intentions to reach MTOs by 2010 at the latest are to the point. Meeting these objectives is necessary to limit risks of procyclical policies in future downturns and to prepare for the build-up in population agingrelated public expenditure that is in the offing. The pressures to slow adjustment and to spend revenue windfalls will increase as the upswing unfolds, however. These pressures must be resisted and the standards of the preventive arm of the Stability and Growth Pact be met. In doing so, consolidation measures ought to be cast in a medium-term budgetary framework aimed at improving incentives to work and invest. In this regard, the trend toward strengthening fiscal policy rules and governance mechanisms is welcome. This should help bring forward the credibility gains from adopting complementary fiscal and structural policies.

41. On the structural side, the fundamental challenge is to effect a joint acceleration of productivity and employment. Reforms to and adjustment in labor markets have led to a significant strengthening of employment performance, consistent with the area commitments under the Multilateral Consultations. But the area's productivity performance has been weak, in particular in the nontradable services sectors, suggesting that the contestability of national services markets needs to be raised. The Services Directive is a significant step in this direction and to hasten its effect, its implementation should be monitored in a framework featuring interim progress reports. Concurrently, labor market reforms need to remain oriented toward strengthening participation and incentives to work.

42. The revamped Lisbon Strategy is picking up steam, but still has some way to go in fostering ownership, harnessing the national and area-wide synergies among reforms, and becoming more transparent. The National Reform Programs (NRP) are useful vehicles to foster greater internal coordination of nationally-driven reform programs as well as coordination of the latter with Community-led initiatives. And the return to issuing country-specific policy recommendations testifies to the renewal of the Lisbon Agenda, which is welcome. These recommendations should, however, increasingly consider NRP transparency and governance issues. 
43. The integration of the markets for financial services is one of the most promising avenues for boosting Europe's productivity and growth performance, but it needs to be complemented by steps imparting a stronger area-wide perspective to the financial stability framework. Retail financial services need to become more contestable and Europe's capital markets developed further. This requires a consistent cross-country implementation of the EU FSAP (notably MiFID) and integration of the financial infrastructure (payments systems and securities clearing and settlement systems). On the financial stability framework, progress is being held back by the continuing tension between the impulse toward integration on the one hand and the preference for a decentralized approach, in particular for supervision, on the other. Specifically, under the EU's home-host supervision model, supervisors are accountable only to their national authorities, informational asymmetries between home and host supervisors are large, and actions by one supervisor have potentially large effects on the jurisdiction of another. Especially when applied to large cross-border financial institutions (LCFI), this setting largely precludes progress toward efficient and effective crisis management and resolution, thus fostering moral hazard and unnecessary risks for national taxpayers. It is also hampering progress on prevention issues, e.g., supervisory convergence and information sharing.

\section{A more integration-compatible decentralized financial stability framework will} need to rest on a foundation that places more emphasis on joint responsibility and accountability. In this regard, the proposal to introduce a European orientation to the mandates of national prudential authorities is welcome. For this to be effective, however, the mandate should include responsibility to minimize the collective costs facing EU states from potential LCFI failures. With such mandates, existing initiatives would acquire new life and urgently required new initiatives would become more practicable. In particular, revamped cross-border arrangements for supervisory cooperation and memoranda of understanding should become better able to keep pace with market developments and address the informational and accountability issues, including the need for more (and more standardized) ex ante cooperation and information sharing than is common. Such arrangements at the level of individual LCFI would need to be complemented by a system-wide arrangement that would need to include extensive information sharing with the ECB. A joint accountability framework could also enable progress on other thorny issues, including deposit insurance, work on converging supervisory powers, developing and implementing convergent pre-crisis sanctions and tools, and analyzing and improving the operation of insolvency laws as applied to banks in an area-wide context.

\section{With trade having consistently been a boon to Europe's productivity} performance, an ambitious conclusion to the Doha Round is very much in the EU's interest. A willingness to agree to additional liberalization, in particular in agriculture, is needed on the part of the EU for successful agreement, and the window of opportunity to reach such an agreement may well be closing. Although well-designed free trade agreements can be complementary, the trade policy focus should remain on multilateralism. The EU 
should also take more account of the benefits consumers have from trade and exercise restraint in the use of contingent protection such as antidumping and special textile safeguards, even if these are compatible with WTO obligations.

46. The quality, availability, and timeliness of statistics are adequate for effective areawide surveillance although further improvements are necessary, including with respect to euro area-wide financial soundness indicators.

47. It is proposed that the next consultation on the euro-area policies in the context of Article IV obligations of member countries follow the standard 12-month cycle. 


\section{Table 1. Euro Area: Main Economic Indicators}

(in percent change)

\begin{tabular}{|c|c|c|c|c|c|c|c|}
\hline & 2002 & 2003 & 2004 & 2005 & 2006 & 2007 & 2008 \\
\hline \multicolumn{8}{|l|}{ Demand and Supply } \\
\hline Private consumption & 0.8 & 1.2 & 1.5 & 1.5 & 1.7 & 1.9 & 2.4 \\
\hline Public consumption & 0.8 & 1.2 & 1.6 & 1.6 & 1.7 & 1.7 & 2.3 \\
\hline Gross fixed investment & -1.5 & 1.1 & 2.3 & 2.6 & 4.9 & 6.2 & 4.8 \\
\hline Final domestic demand & 0.6 & 1.3 & 1.6 & 1.6 & 2.6 & 2.7 & 2.7 \\
\hline Stockbuilding $1 /$ & -0.3 & 0.2 & 0.3 & 0.0 & 0.1 & -0.1 & 0.0 \\
\hline Domestic Demand & 0.4 & 1.5 & 2.0 & 1.8 & 2.5 & 2.6 & 2.7 \\
\hline Foreign balance $1 /$ & 0.5 & -0.7 & 0.1 & -0.3 & 0.2 & 0.0 & -0.2 \\
\hline Exports 2/ & 1.7 & 1.1 & 6.9 & 4.2 & 8.3 & 6.0 & 5.6 \\
\hline Imports 2/ & 0.3 & 3.1 & 6.8 & 5.0 & 7.9 & 6.2 & 6.2 \\
\hline Real GDP & 0.9 & 0.8 & 2.0 & 1.5 & 2.7 & 2.6 & 2.5 \\
\hline \multicolumn{8}{|l|}{ Resource Utilization } \\
\hline Potential GDP & 2.1 & 1.9 & 1.9 & 1.9 & 2.0 & 2.1 & 2.1 \\
\hline Output gap & 0.1 & -1.1 & -1.0 & -1.4 & -0.7 & -0.2 & 0.2 \\
\hline Employment & 0.9 & 0.7 & 0.7 & 0.8 & 1.4 & 1.2 & 0.9 \\
\hline Unemployment rate $3 /$ & 8.2 & 8.7 & 8.8 & 8.6 & 7.8 & 7.0 & 6.9 \\
\hline \multicolumn{8}{|l|}{ Prices } \\
\hline GDP deflator & 2.6 & 2.1 & 1.9 & 1.9 & 1.8 & 2.0 & 1.9 \\
\hline Consumer prices & 2.3 & 2.1 & 2.1 & 2.2 & 2.2 & 2.0 & 2.0 \\
\hline \multicolumn{8}{|l|}{ Public Finance 4/ } \\
\hline General government balance & -2.6 & -3.1 & -2.8 & -2.5 & -1.7 & -1.0 & -1.0 \\
\hline General government structural balance & -2.5 & -2.5 & -2.3 & -1.8 & -1.2 & -0.7 & -0.8 \\
\hline General government gross debt & 68.2 & 69.3 & 69.8 & 70.5 & 69.0 & 67.2 & 65.7 \\
\hline \multicolumn{8}{|l|}{ Interest Rates } \\
\hline Short-term deposit rate & 3.3 & 2.3 & 2.1 & 2.3 & 3.1 & $\ldots$ & $\ldots$ \\
\hline Long-term government bond yields & 4.9 & 3.9 & 3.8 & 3.3 & 4.0 & $\ldots$ & $\ldots$ \\
\hline \multicolumn{8}{|l|}{ Exchange Rates } \\
\hline U.S. dollar per euro & 0.94 & 1.13 & 1.24 & 1.25 & 1.26 & $\ldots$ & $\ldots$ \\
\hline Nominal effective rate $(2000=100)$ & 105.1 & 117.6 & 122.0 & 121.7 & 122.6 & $\ldots$ & $\ldots$ \\
\hline Real effective rate $(2000=100) 5 /$ & 107.1 & 122.3 & 127.8 & 128.0 & 128.0 & $\ldots$ & $\ldots$ \\
\hline \multicolumn{8}{|l|}{ External Sector 4/ 6/ } \\
\hline Current account balance & 0.8 & 0.4 & 0.8 & 0.0 & -0.2 & -0.1 & -0.4 \\
\hline Trade balance $7 /$ & 1.8 & 1.4 & 1.3 & 0.6 & 0.3 & $\ldots$ & $\ldots$ \\
\hline \multicolumn{8}{|l|}{ Memorandum items 4/ 8/ } \\
\hline Current account balance & 0.7 & 0.5 & 1.1 & 0.2 & 0.0 & -0.2 & -0.4 \\
\hline Trade balance $7 /$ & 2.1 & 1.8 & 1.6 & 0.9 & 0.7 & 0.6 & 0.3 \\
\hline
\end{tabular}

Sources: IMF, World Economic Outlook; Eurostat, ECB Monthly Bulletin.

1/ Contribution to growth, in percentage points.

2/ Includes intra-euro area trade.

3/ In percent.

4/ In percent of GDP.

5/ Based on normalized unit labor costs.

6/ Based on ECB data, which exclude intra-euro area flows.

7/ Data for goods.

8/ Calculated as the sum of individual countries' balances. 
Table 2. Financial Conditions of Large and Complex Banking Groups in the Euro Area (2004 - H1 2006)

\begin{tabular}{|c|c|c|c|c|c|c|c|}
\hline & $\min$. & $\begin{array}{c}\text { 1st } \\
\text { quartile }\end{array}$ & median & average & $\begin{array}{c}\text { weighted } \\
\text { average }\end{array}$ & $\begin{array}{c}\text { 3rd } \\
\text { quartile }\end{array}$ & $\max$. \\
\hline \multicolumn{8}{|c|}{ Return on equity (\%) } \\
\hline 2004 & 4.30 & 10.27 & 17 & 17.17 & 17.32 & 20.85 & 33.2 \\
\hline 2005 & 9 & 16.22 & 17.6 & 19.56 & 19.87 & 23.25 & 37 \\
\hline H1 2006 & 9.1 & 18.07 & 22.2 & 20.78 & 20.77 & 23.75 & 35.8 \\
\hline \multicolumn{8}{|c|}{ Return on risk-weighted assets (\%) } \\
\hline 2004 & 0.2 & 1.11 & 1.14 & 1.14 & 1.17 & 1.5 & 2.26 \\
\hline 2005 & 0.81 & 1.11 & 1.51 & 1.44 & 1.46 & 1.75 & 2.26 \\
\hline H1 2006 & 0.72 & 1.15 & 1.44 & 1.51 & 1.43 & 1.85 & 2.78 \\
\hline \multicolumn{8}{|c|}{ Net interest income (\% total assets) } \\
\hline 2004 & 0.43 & 0.68 & 0.9 & 1.04 & 0.93 & 1.31 & 1.87 \\
\hline 2005 & 0.48 & 0.6 & 0.72 & 0.94 & 0.87 & 1.3 & 1.84 \\
\hline H1 2006 & 0.49 & 0.69 & 0.8 & 0.97 & 0.91 & 1.12 & 2.08 \\
\hline \multicolumn{8}{|c|}{ Net interest income (\% total income) } \\
\hline 2004 & 24.07 & 38.89 & 52.32 & 47.85 & 47.85 & 56.51 & 69.54 \\
\hline 2005 & 23.53 & 35.22 & 50.36 & 48.12 & 46.04 & 59.88 & 68.7 \\
\hline H1 2006 & 25.5 & 39.58 & 49.12 & 47.41 & 46.99 & 53.68 & 72.57 \\
\hline \multicolumn{8}{|c|}{ Trading income (\% total income) } \\
\hline 2004 & 2.69 & 7.37 & 9.59 & 11.98 & 12.98 & 15.68 & 28.73 \\
\hline 2005 & 2.58 & 6.86 & 9.66 & 12.73 & 14.16 & 15.35 & 37.14 \\
\hline H1 2006 & 0 & 7.39 & 13.47 & 14.26 & 15.84 & 18.39 & 32.87 \\
\hline \multicolumn{8}{|c|}{ Fees and commissions ( $\%$ total income) } \\
\hline 2004 & 15.9 & 20.67 & 29.34 & 29.27 & 28.96 & 36.84 & 44.15 \\
\hline 2005 & 17.12 & 21.69 & 30 & 28.4 & 27.92 & 34.8 & 40.02 \\
\hline H1 2006 & 12.85 & 17.91 & 27.02 & 26.51 & 26.42 & 34.14 & 39.84 \\
\hline \multicolumn{8}{|c|}{ Other income ( $\%$ total income) } \\
\hline 2004 & -3.07 & 2.51 & 4.25 & 5.81 & 5.95 & 6.88 & 26.7 \\
\hline 2005 & -0.76 & 2.74 & 4.71 & 5.75 & 6.35 & 2.74 & 16.73 \\
\hline H1 2006 & -0.7 & 2.69 & 4.61 & 9.09 & 8.43 & 2.69 & 16.73 \\
\hline \multicolumn{8}{|c|}{ Net loan impairment charges ( $\%$ total assets) } \\
\hline 2004 & 0.03 & 0.06 & 0.07 & 0.11 & 0.09 & 0.09 & 0.4 \\
\hline 2005 & -0.02 & 0.02 & 0.05 & 0.08 & 0.08 & 0.11 & 0.29 \\
\hline H1 2006 & -0.01 & 0.02 & 0.05 & 0.09 & 0.08 & 0.13 & 0.34 \\
\hline \multicolumn{8}{|c|}{ Cost-income ratio (\%) } \\
\hline 2004 & 48.60 & 60.00 & 67.50 & 66.50 & 68.48 & 70.9 & 85.30 \\
\hline 2005 & 46.70 & 57.40 & 63.40 & 63.40 & 63.84 & 67.00 & 89.40 \\
\hline H1 2006 & 38.50 & 52.85 & 61.60 & 59.10 & 60.52 & 64.00 & 77.70 \\
\hline \multicolumn{8}{|c|}{ Tier 1 ratio (\%) } \\
\hline 2004 & 6.32 & 7.04 & 7.70 & 8.03 & 7.87 & 8.45 & 10.90 \\
\hline 2005 & 5.53 & 7.55 & 8.10 & 8.38 & 8.14 & 9.10 & 11.60 \\
\hline H1 2006 & 5.94 & 7.31 & 7.60 & 8.18 & 8.00 & 9.00 & 11.40 \\
\hline \multicolumn{8}{|c|}{ Overall solvency ratios (\%) } \\
\hline 2004 & 8.46 & 10.4 & 11.10 & 11.34 & 11.02 & 12.77 & 13.30 \\
\hline 2005 & 8.50 & 10.74 & 11.30 & 11.70 & 11.39 & 12.48 & 16.30 \\
\hline H1 2006 & 9.50 & 10.50 & 10.92 & 11.31 & 11.19 & 11.45 & 15.70 \\
\hline
\end{tabular}

Sources: Individual institutions' financial reports and ECB calculations. 
Table 3. Euro Area: Policy Progress and Plans Relevant to the IMFC Strategy ${ }^{1}$

Over the past year, policies related to the IMFC strategy included structural reforms in three main areas:

- $\quad$ Strengthening competition in product markets. Liberalization of network industries; more effective competition policy; enhanced efficiency of public interventions; adoption of the revised Services Directive.

- Implementing new measures in the labor market. A series of measures, implementation of which is ongoing, have increased labor force participation to 64.5 percent in 2006 (6.6 percentage points since 1995). Many euro-area countries have reformed their public pension systems since 2001 and have tightened early-retirement schemes.

- Integrating financial markets across the EU. Multiple initiatives are underway, notably in context of the Financial Services Action Plan (FSAP) and Lamfalussy framework. ${ }^{2}$

\section{Looking forward, the euro area authorities' policy plans include the following:}

- $\quad$ Further reform in product markets. Priorities include further reducing market regulation and improving the business environment; transposition of the Services Directive in all Member States by December 2009 at the latest; developing an internal market for network industries like gas and electricity and removing barriers in regulated trades and professions.

- $\quad$ Further reform in labor markets. Priorities under the Lisbon-led National Action Plans include further reform to foster labor utilization and productivity by increasing fiscal incentives to work and further adjusting benefit systems; fostering flexibility and security in the labor market, including by modernizing employment protection legislation; better aligning wage and productivity developments; and enacting measures to promote labor mobility across borders and between occupations. ${ }^{3}$

- $\quad$ Further reform in financial markets. Implementation of the Markets in Financial Instruments Directive (MiFID)—expected to come into effect on November 1, 2007; integration of market for clearing and settlement services (TARGET2-Securities, Code of Conduct) and payments systems (SEPA); implementation of the Solvency II Directive for insurance companies; and work to create a more integrated retail and wholesale financial markets. ${ }^{4}$

\footnotetext{
${ }^{1}$ For detailed description of the policy progress and plans see the IMFC report at: http://www.imf.org/external/np/sec/pr/2007/pr0772.htm.

${ }^{2}$ For details, see http://ec.europa.eu/internal market/finances/actionplan/index en.htm and http://ec.europa.eu/internal market/securities/lamfalussy/index en.htm.

${ }^{3}$ For details, see http://ec.europa.eu/growthandjobs/annual-report-1206 en.htm and http://ec.europa.eu/internal market/finances/docs/white paper/white paper en.pdf

${ }^{4}$ For details, see White Paper on Financial Services Policy 2005-2010, available at: http://ec.europa.eu/internal market/finances/docs/white paper/white paper en.pdf
} 
Table 4. Euro Area: Balance of Payments

\begin{tabular}{|c|c|c|c|c|c|c|c|c|}
\hline & 2000 & 2001 & 2002 & 2003 & 2004 & 2005 & 2006 & 2006Q4 \\
\hline & \multicolumn{8}{|c|}{ (in billions euro) } \\
\hline Current account & -99.2 & -22.0 & 56.9 & 32.6 & 55.5 & -8.3 & -16.9 & 11.1 \\
\hline Goods & 7.7 & 73.3 & 127.8 & 105.0 & 103.6 & 48.2 & 28.5 & 16.9 \\
\hline Services & -10.4 & -3.4 & 17.2 & 22.0 & 30.9 & 36.0 & 36.3 & 8.9 \\
\hline Income & -46.0 & -40.3 & -39.3 & -38.3 & -19.8 & -22.0 & -7.5 & 4.5 \\
\hline Current transfers & -50.4 & -51.5 & -48.5 & -56.3 & -59.0 & -70.2 & -73.8 & -19.1 \\
\hline Capital account & 11.3 & 6.2 & 10.3 & 12.3 & 16.7 & 11.9 & 10.7 & 5.6 \\
\hline Financial account & 73.6 & -29.1 & -15.6 & -0.3 & -21.1 & 37.4 & 109.0 & -57.3 \\
\hline Direct investment & -14.4 & -110.2 & 20.9 & -11.5 & -64.0 & -202.3 & -145.8 & -56.6 \\
\hline Portfolio investment & -102.5 & 73.3 & 139.5 & 73.5 & 68.3 & 156.8 & 255.1 & 107.6 \\
\hline Equity & -234.1 & 131.3 & 46.4 & 30.7 & 17.1 & 148.0 & 175.9 & 60.2 \\
\hline Debt instruments & 134.4 & -59.4 & 93.7 & 43.3 & 50.8 & 9.1 & 79.3 & 47.5 \\
\hline Financial derivatives & -10.0 & -0.7 & -12.2 & -14.3 & -6.7 & -10.7 & -5.7 & -2 \\
\hline Other investment & 186.4 & -9.3 & -161.2 & -76.0 & -30.8 & 75.7 & 9.3 & -101.1 \\
\hline Reserve assets & 14.7 & 18.0 & -2.5 & 28.0 & 12.5 & 18.0 & -3.6 & -5.2 \\
\hline \multirow[t]{2}{*}{ Errors and omissions } & 14.2 & 44.7 & -51.7 & -44.3 & -51.0 & -41.3 & -103.0 & 40.7 \\
\hline & \multicolumn{8}{|c|}{ (in percent of GDP) } \\
\hline Current account & -1.5 & -0.3 & 0.8 & 0.4 & 0.7 & -0.1 & -0.2 & 0.6 \\
\hline Goods & 0.1 & 1.0 & 1.8 & 1.4 & 1.3 & 0.6 & 0.3 & 0.8 \\
\hline Services & -0.2 & 0.0 & 0.2 & 0.3 & 0.4 & 0.4 & 0.4 & 0.4 \\
\hline Income & -0.7 & -0.6 & -0.5 & -0.5 & -0.3 & -0.3 & -0.1 & 0.2 \\
\hline Current transfers & -0.8 & -0.7 & -0.7 & -0.8 & -0.8 & -0.9 & -0.9 & -0.9 \\
\hline Capital account & 0.2 & 0.1 & 0.1 & 0.2 & 0.2 & 0.1 & 0.1 & 0.3 \\
\hline Financial account & 1.1 & -0.4 & -0.2 & 0.0 & -0.3 & 0.5 & 1.3 & -2.8 \\
\hline Direct investment & -0.2 & -1.6 & 0.3 & -0.2 & -0.8 & -2.5 & -1.7 & -2.8 \\
\hline Portfolio investment & -1.5 & 1.0 & 1.9 & 1.0 & 0.9 & 2.0 & 3.0 & 5.3 \\
\hline Equity & -3.5 & 1.9 & 0.6 & 0.4 & 0.2 & 1.8 & 2.1 & 3.0 \\
\hline Debt instruments & 2.0 & -0.8 & 1.3 & 0.6 & 0.7 & 0.1 & 0.9 & 2.4 \\
\hline Financial derivatives & -0.1 & 0.0 & -0.2 & -0.2 & -0.1 & -0.1 & -0.1 & -0.1 \\
\hline Other investment & 2.8 & -0.1 & -2.2 & -1.0 & -0.4 & 0.9 & 0.1 & -5.0 \\
\hline Reserve assets & 0.2 & 0.3 & 0.0 & 0.4 & 0.2 & 0.2 & 0.0 & -0.3 \\
\hline Errors and omissions & 0.2 & 0.6 & -0.7 & -0.6 & -0.7 & -0.5 & -1.2 & 2.0 \\
\hline \multirow{4}{*}{$\begin{array}{l}\text { Memorandum items: } \\
\text { GDP (in billions of euros) } \\
\text { Reserves of the eurosystem 1/ } \\
\text { (in billions of euros) }\end{array}$} & & & & & & & & \\
\hline & $6,712.3$ & $7,003.8$ & $7,246.8$ & $7,456.7$ & $7,752.8$ & $8,014.5$ & $8,378.1$ & $2,015.8$ \\
\hline & & & & & & & & \\
\hline & 391.2 & 392.7 & 366.1 & 306.7 & 281 & 320.1 & $\cdots$ & $\ldots$ \\
\hline
\end{tabular}

Sources: ECB; Datastream.

1 / End of period stocks. 
Table 5. Euro Area: Net Investment Position 1/ (in percent of GDP)

\begin{tabular}{|c|c|c|c|c|c|c|c|}
\hline & 2000 & 2001 & 2002 & 2003 & 2004 & 2005 & 2006Q4 \\
\hline Assets & 102.9 & 110.7 & 102.4 & 106.8 & 113.1 & 134.8 & 147.8 \\
\hline Direct investment abroad & 26.0 & 29.8 & 27.7 & 29.1 & 30.1 & 33.8 & 36.0 \\
\hline Portfolio investment abroad & 35.3 & 35.8 & 31.6 & 35.6 & 39.2 & 48.3 & 52.7 \\
\hline Financial derivatives & 1.6 & 1.9 & 1.8 & 2.2 & 2.2 & 2.9 & 3.5 \\
\hline Other investment abroad & 34.4 & 37.6 & 36.2 & 35.8 & 37.9 & 45.7 & 51.7 \\
\hline Reserve assets & 5.8 & 5.6 & 5.1 & 4.1 & 3.6 & 4.0 & 3.9 \\
\hline Liabilities & 110.5 & 116.3 & 112.2 & 117.3 & 123.8 & 145.0 & 159.4 \\
\hline Direct investment in the EU & 20.7 & 23.7 & 25.2 & 27.9 & 28.8 & 29.8 & 30.4 \\
\hline Portfolio investment in the EU & 47.7 & 47.8 & 44.6 & 47.9 & 52.0 & 62.6 & 70.4 \\
\hline Financial Derivatives & 1.5 & 1.8 & 2.0 & 2.3 & 2.4 & 3.1 & 3.6 \\
\hline Other investment in the EU & 40.5 & 43.0 & 40.4 & 39.2 & 40.6 & 49.5 & 55.0 \\
\hline Net investment position & -7.6 & -5.7 & -9.9 & -10.5 & -10.7 & -10.2 & -11.6 \\
\hline Direct investment & 5.3 & 6.0 & 2.5 & 1.2 & 1.4 & 4.0 & 5.7 \\
\hline Portfolio investment & -12.4 & -11.9 & -13.0 & -12.3 & -12.9 & -14.3 & -17.7 \\
\hline Financial Derivatives & 0.0 & 0.0 & -0.2 & -0.1 & -0.2 & -0.2 & -0.2 \\
\hline Other investment & -6.1 & -5.4 & -4.2 & -3.4 & -2.7 & -3.8 & -3.4 \\
\hline Reserve assets & 5.6 & 5.6 & 5.1 & 4.1 & 3.6 & 4.0 & 3.9 \\
\hline
\end{tabular}

Source: European Central Bank.

1/ Data correspond to the end of the indicated period. They are expressed as a percent of the cumulated GDP of the four quarters ending on that date. 
Figure 1. Euro Area: Cyclical Developments (Annualized quarter-on-quarter percent change, unless otherwise specified)

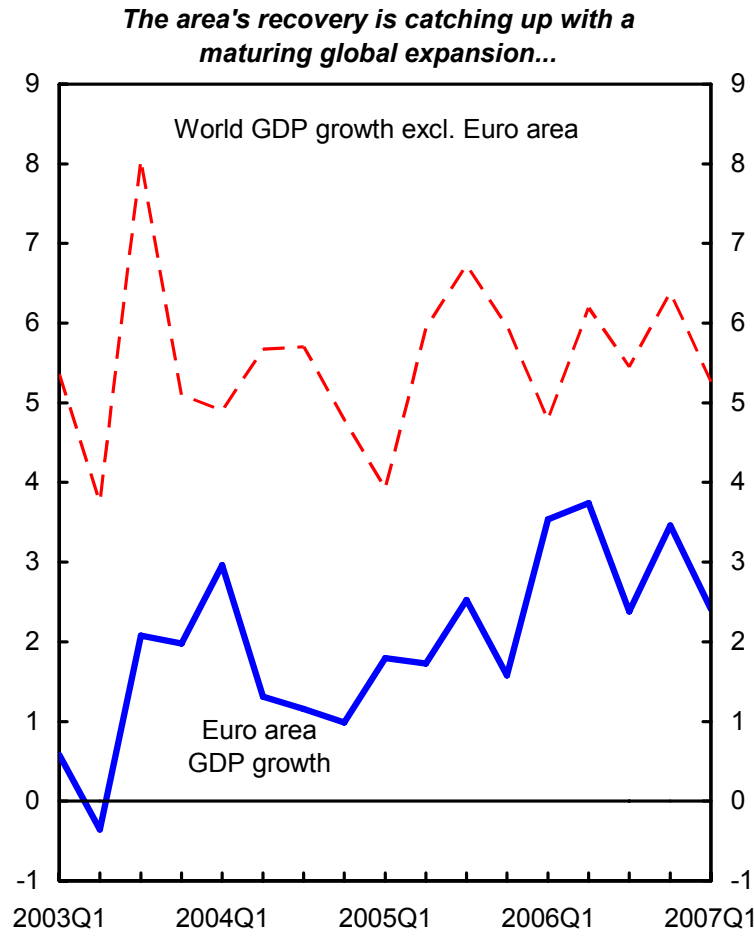

...after having lagged for several years, including
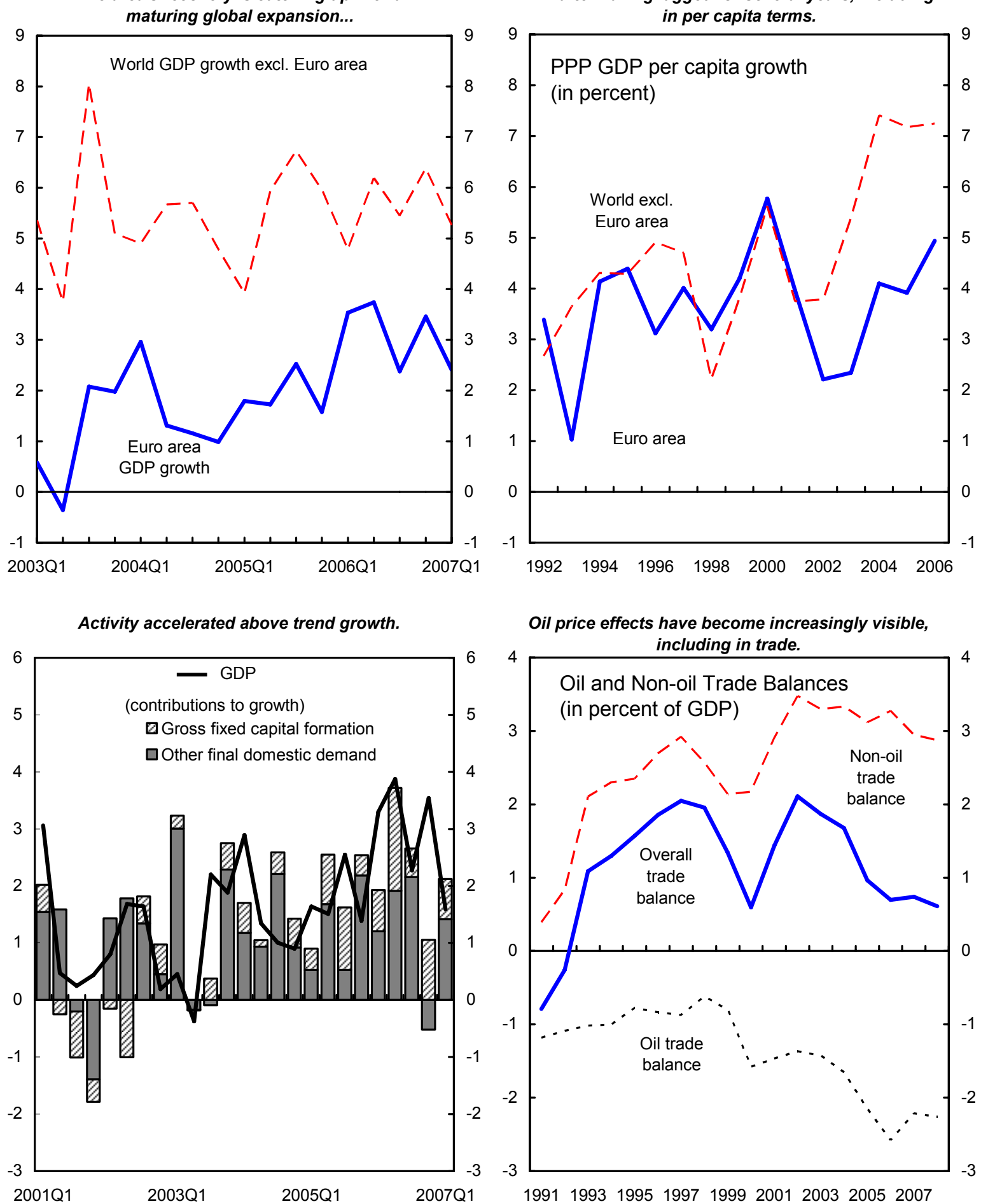

Oil price effects have become increasingly visible,

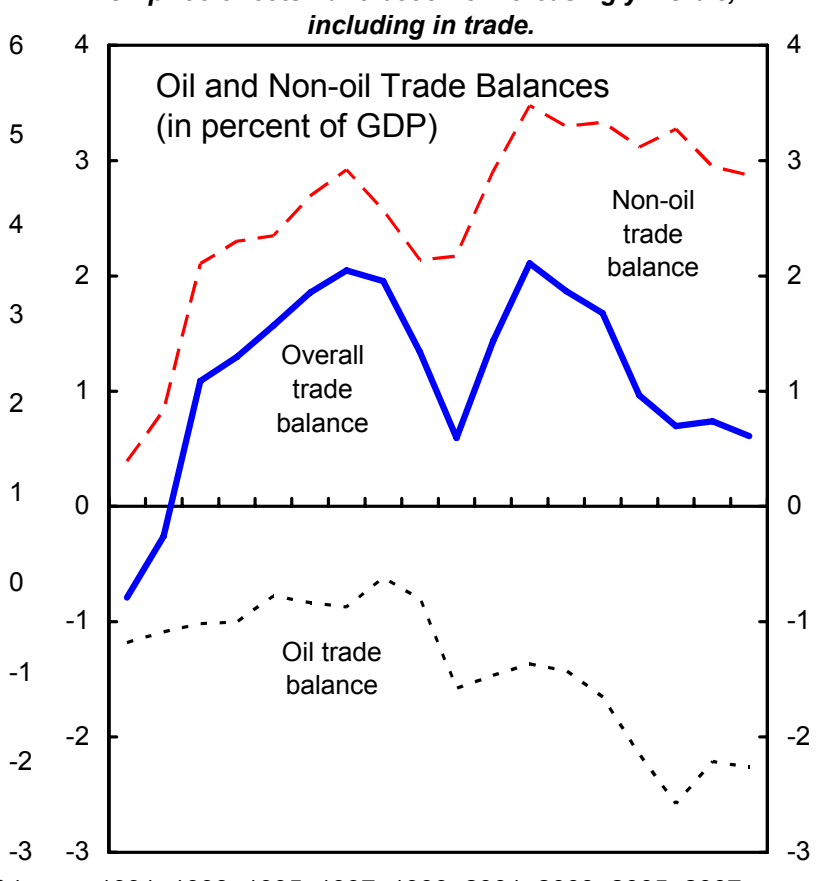

Sources: Eurostat; Datastream; and IMF, World Economic Outlook. 
Figure 2. Euro Area: Investment, 1996-2006 (in percent, unless otherwise specified)
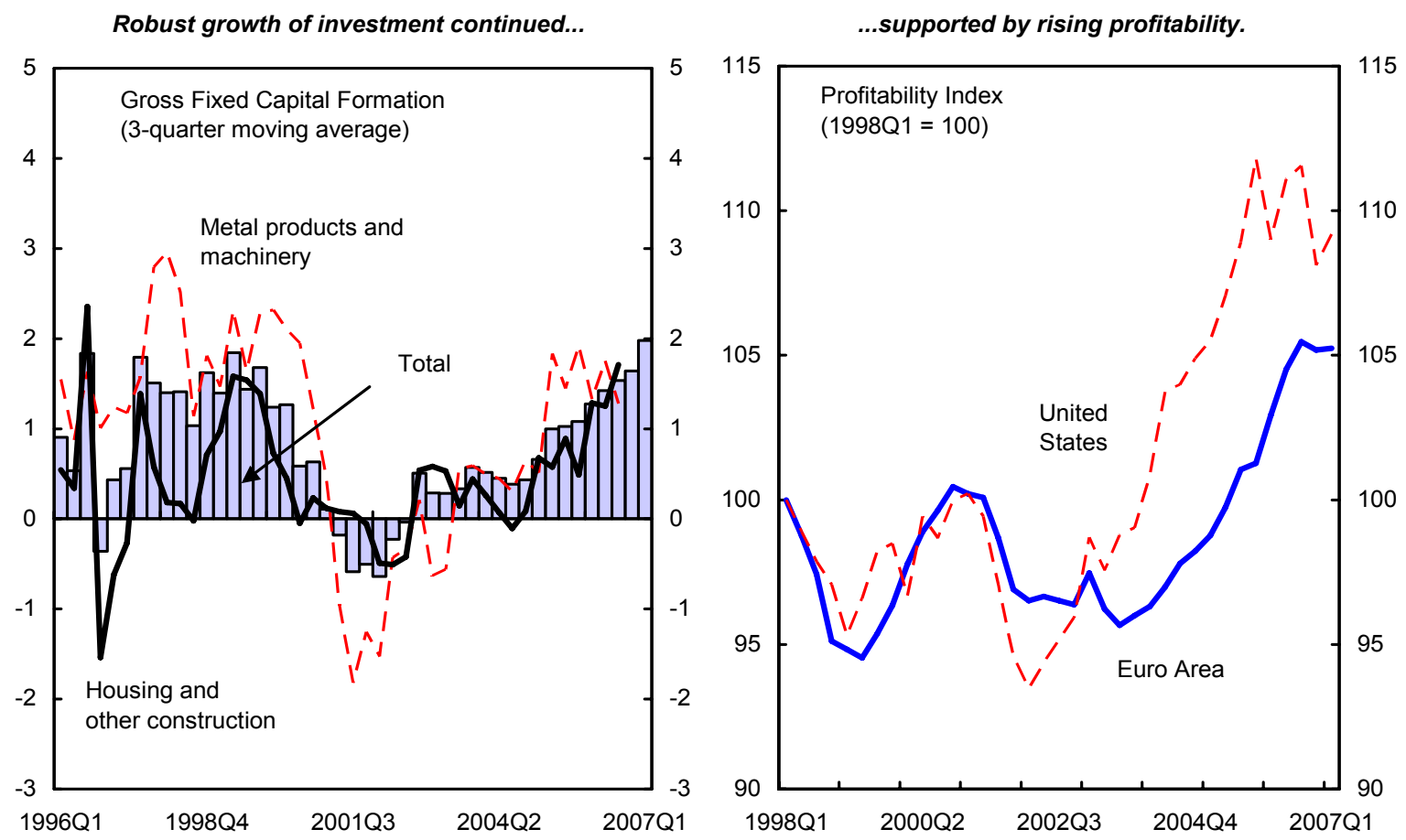

Bank-based financing is growing at a brisk pace...

...but market financing is recovering only slowly.
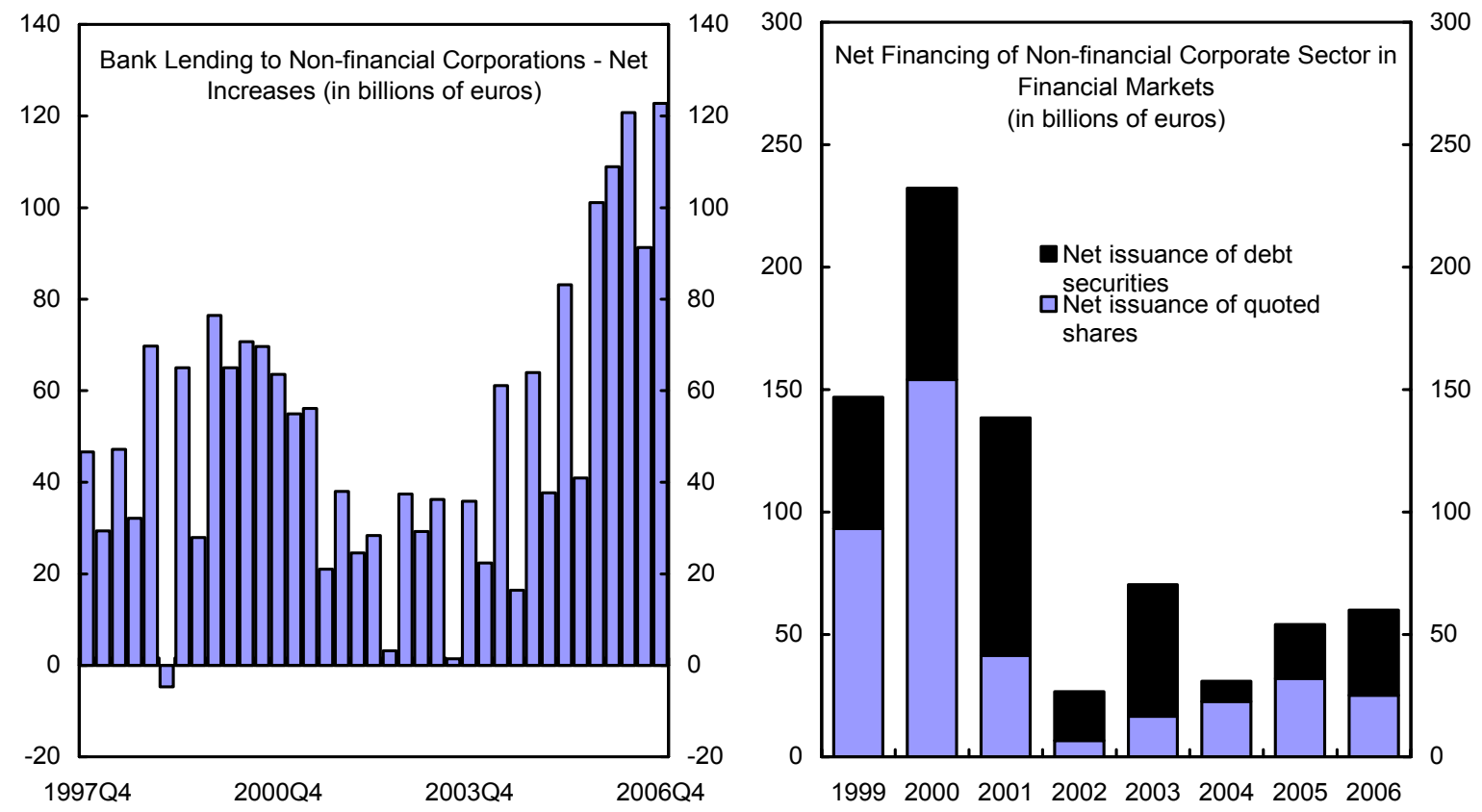

Sources: Eurostat; ECB; Haver Analytics; and IMF staff calculations. 
Figure 3. Euro Area: Evolution of the Cycle since the 1970s 1/ (With respect to trough values)

Consumption has caught up with the past cycle...

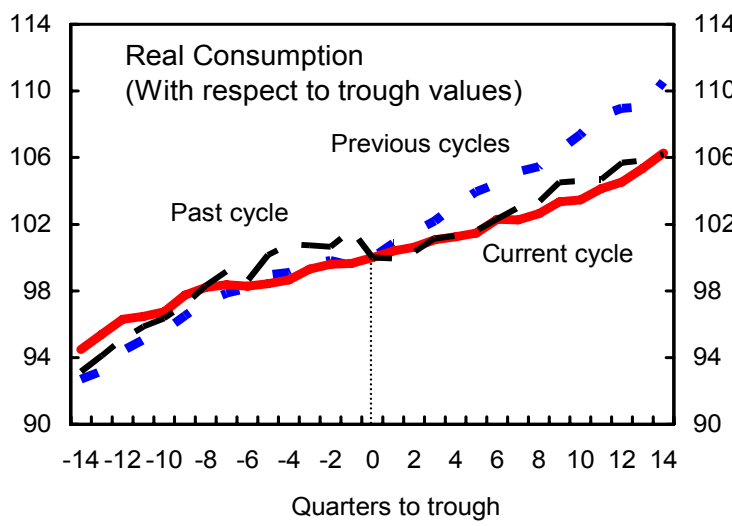

...driven by buoyant investment...
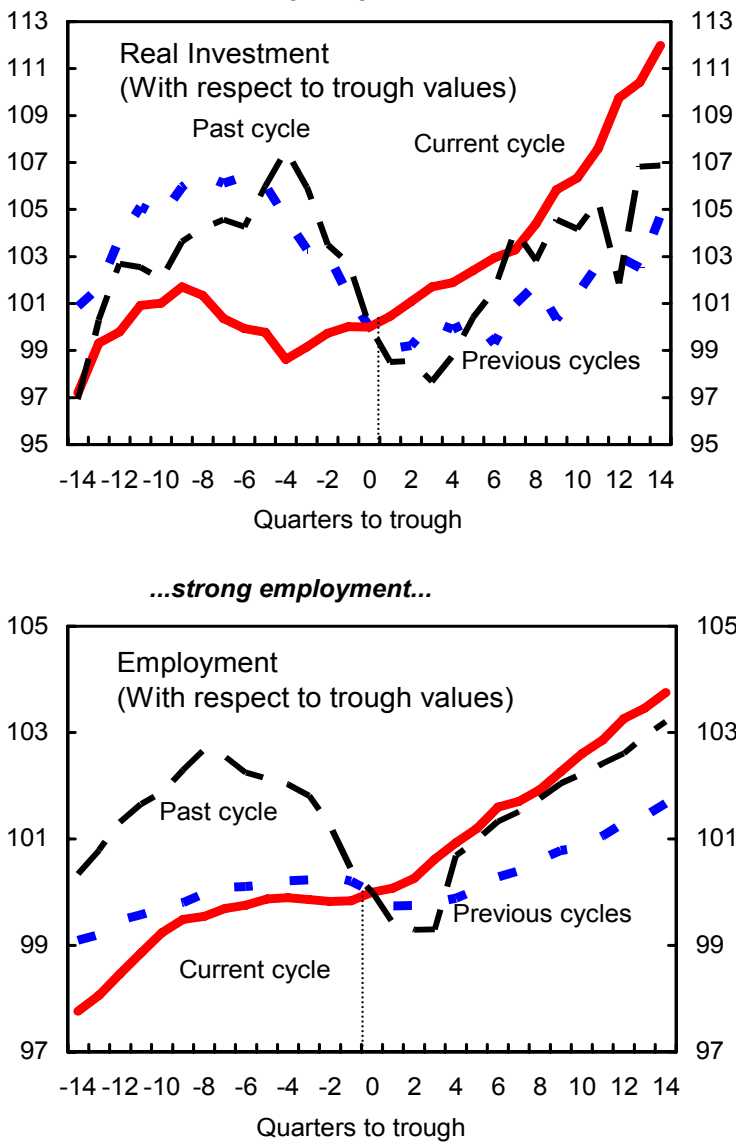

...and so has real GDP growth..

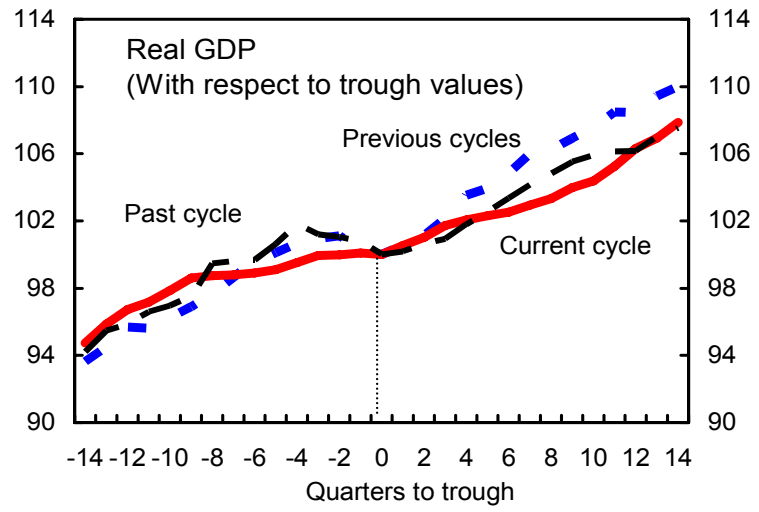

...solid export growth...
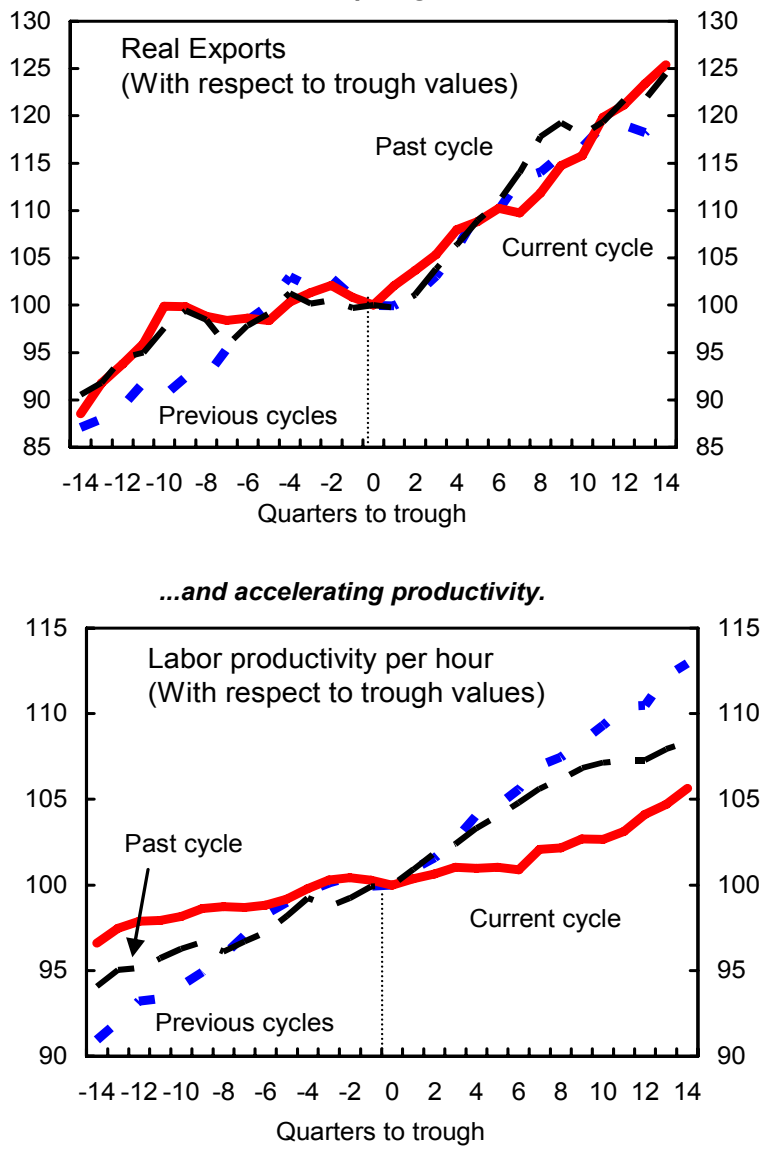

Sources: ECB; IMF, World Economic Outlook; and Fund staff estimates.

1/ Cycle troughs: current-2003Q2; past-1993Q1; previous cycles—an average of two cycles with troughs in 1975Q1 and 1981Q1; trough definitions are in line with EC; Sample: 1971Q1-2006Q3. 
Figure 4. Euro Area: Households and Consumption (in percent, unless otherwise specified)

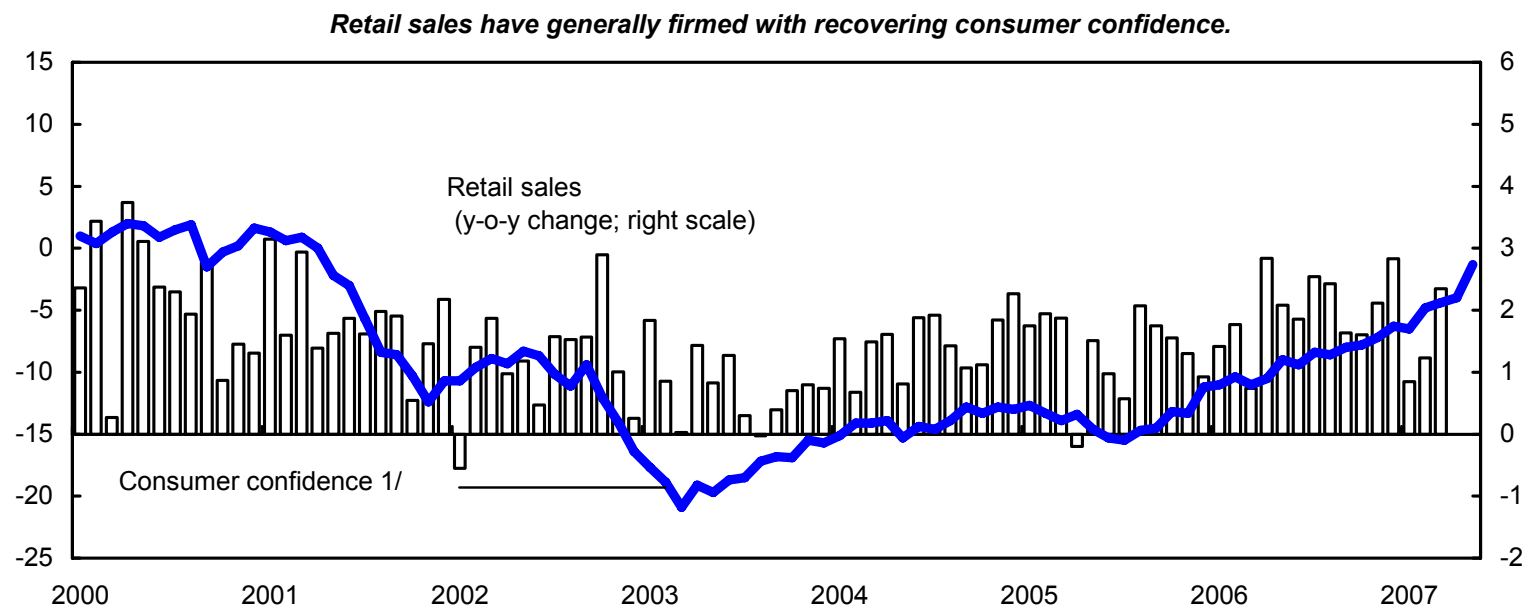

Housing affordability is starting to come down...
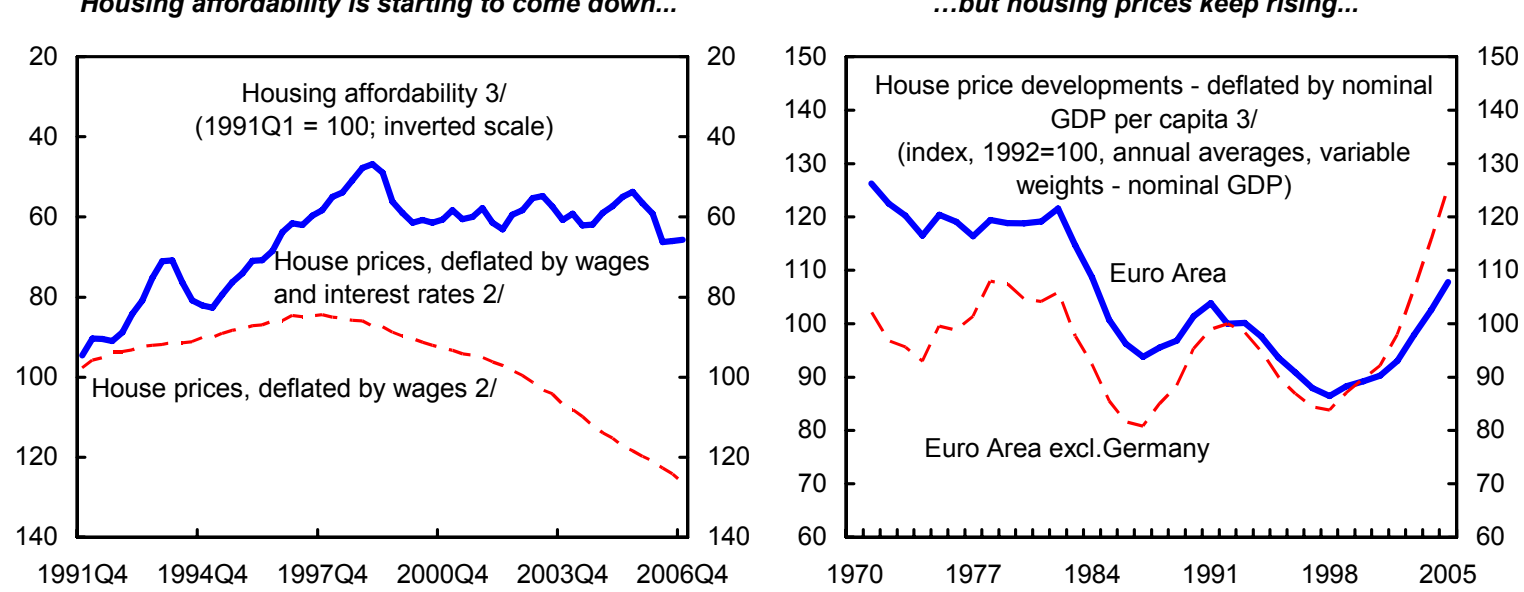

...and so is mortgage borrowing.

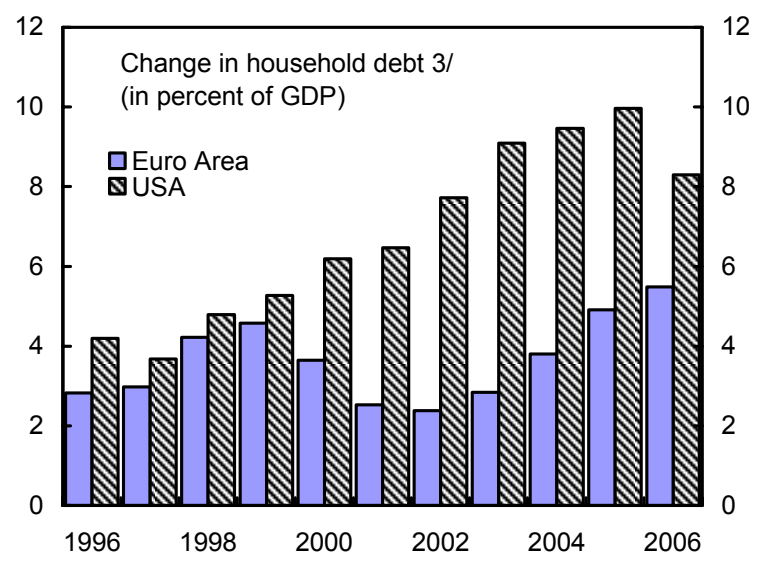

Household indebtedness, although rising, is lower

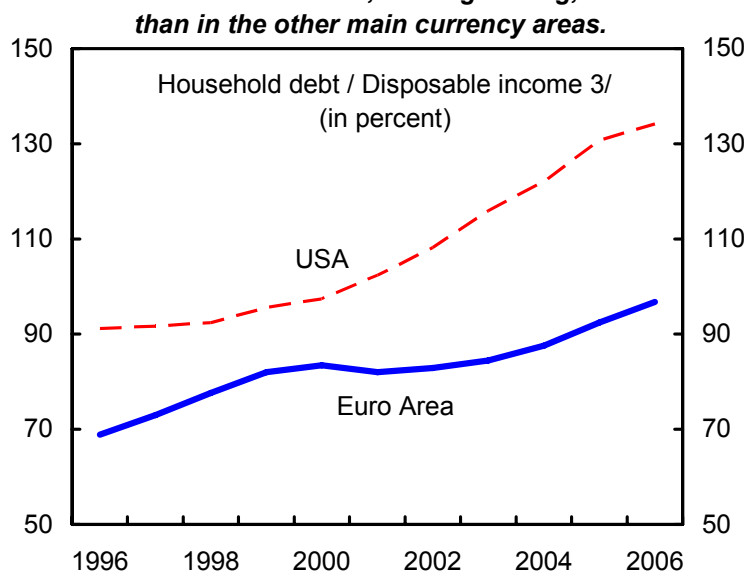

Sources: OECD and Haver Analytics.

$1 /$ Balance of opinion on financial and general economic situation.

2/ Based on nominal compensation per employee and changes in the debt service of a 20 -year fixedrate mortgage.

3/ 2006 figures are in part staff projections. 
Figure 5. Euro Area: Indicators of Capacity and Labor Constraints (in percent, unless otherwise specified)

\section{Capacity constraints in most euro-area members are less binding than at the peak of the last cycle.}

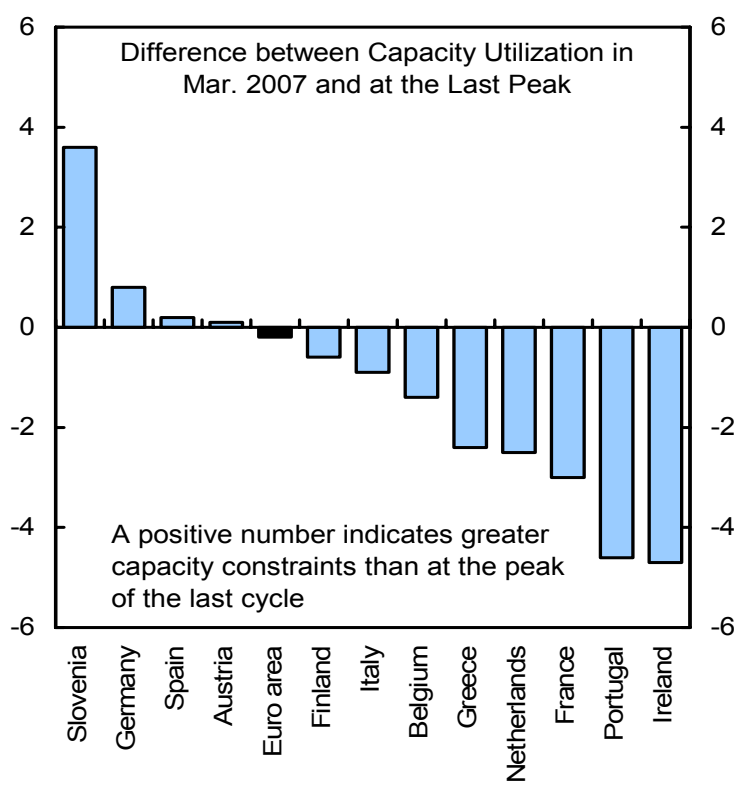

Unemployment rates are falling below the troughs of the last cycle.

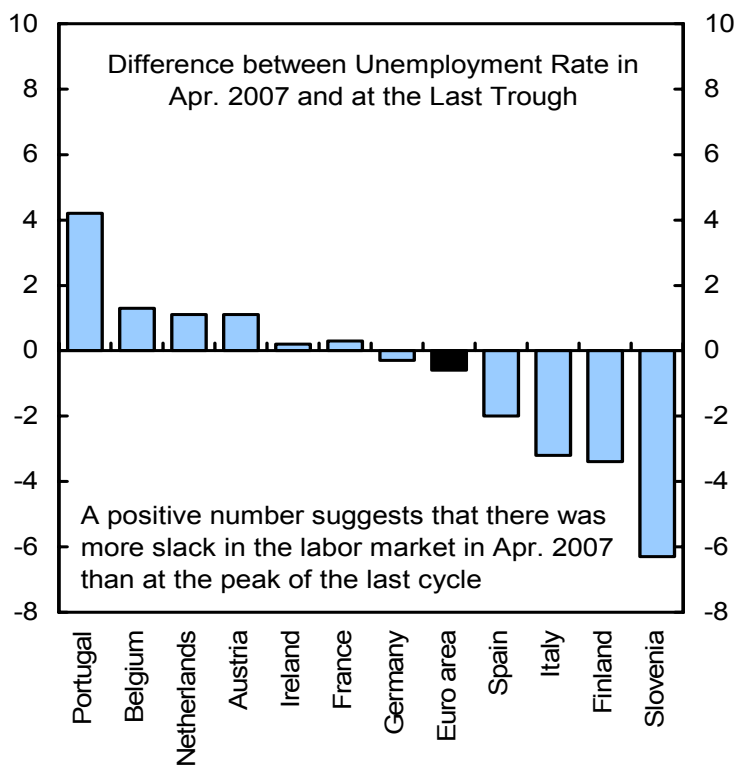

Where constraints are binding, it is mainly on account of equipment.

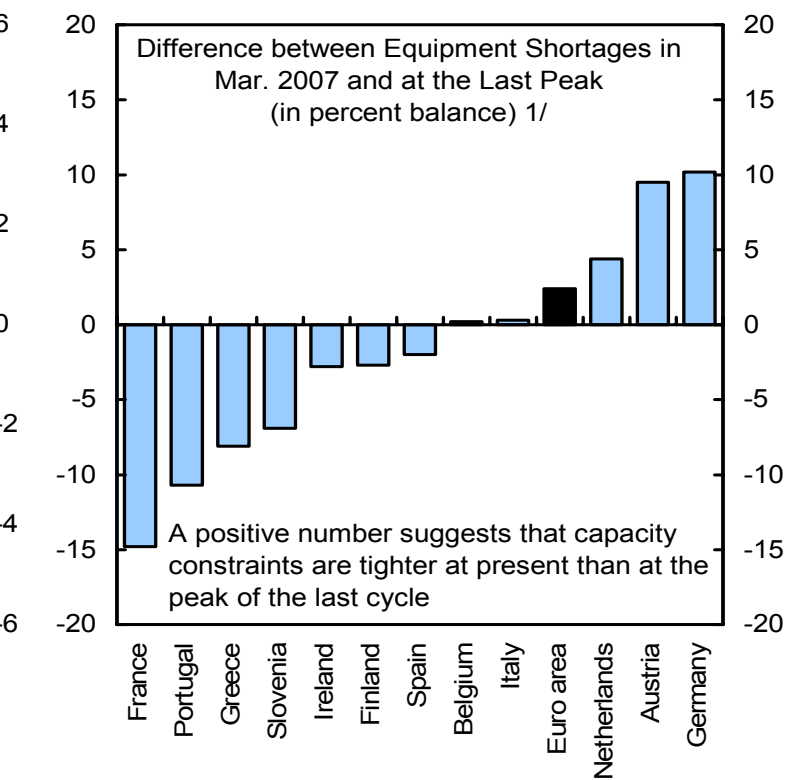

Yet firms in most countries see labor shortages as less of a constraint on production.

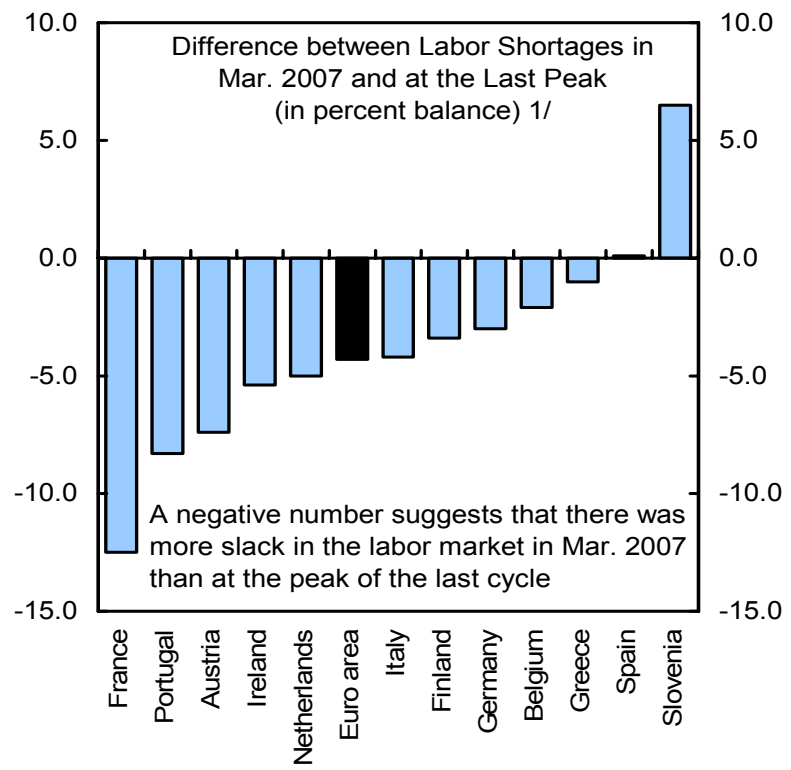

Sources: European Commission; European Committee; Haver; and IMF staff estimates. $1 /$ Percent balance equals percent of respondents reporting an increase minus the percent of respondents reporting a decrease. 
Figure 6. Euro Area: Labor Market Indicators, 1997-2006

Unemployment continues to decline...

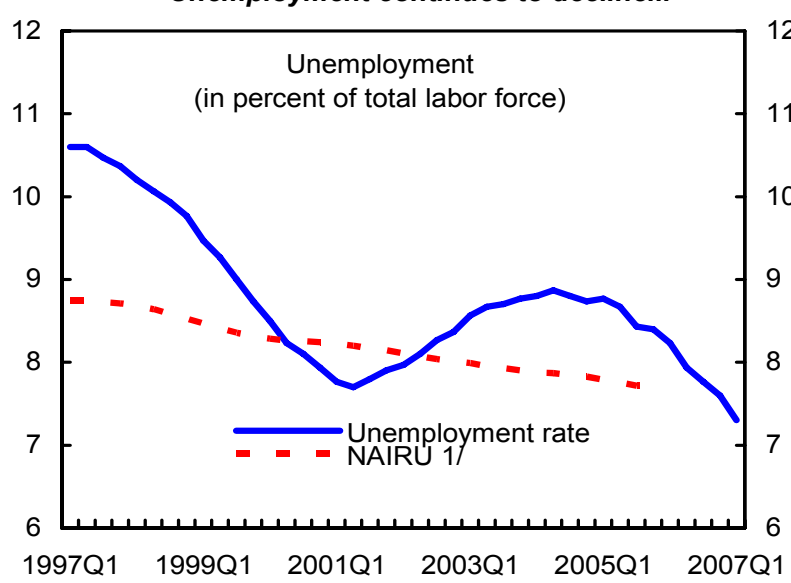

...even for full-time positions.

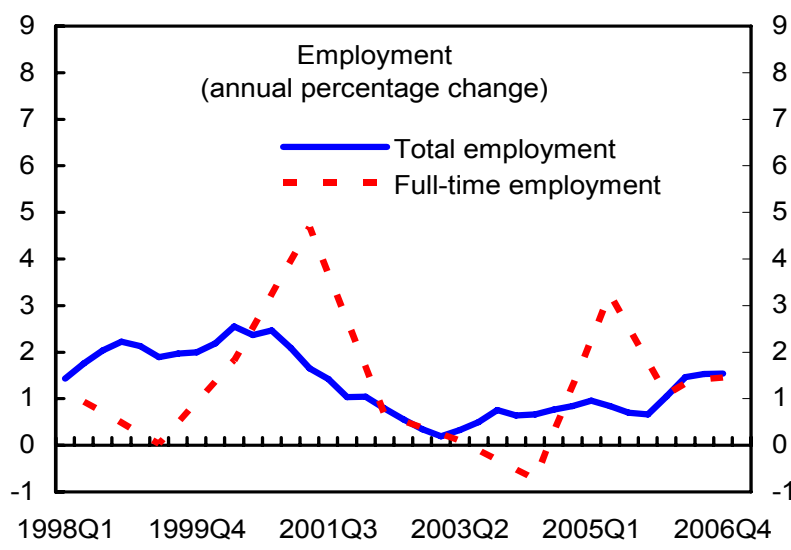

Some indicators suggest slack diminished...

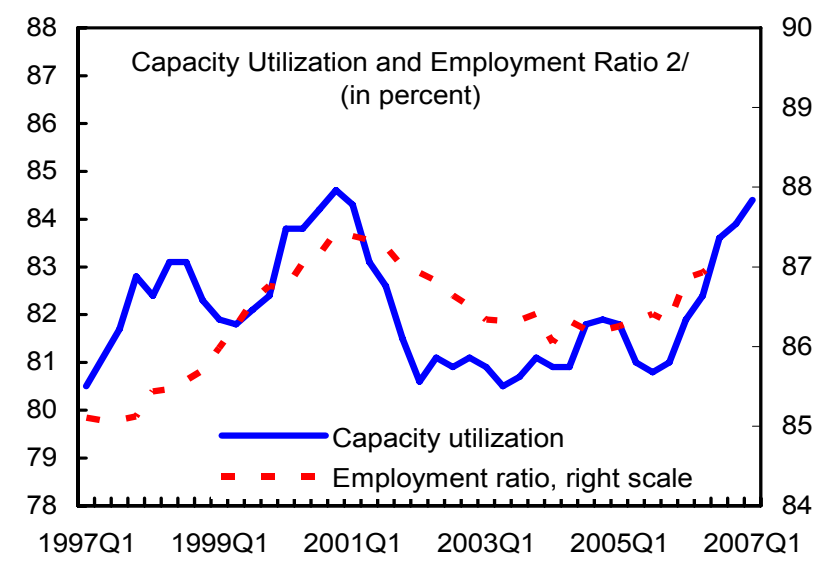

...and employment is rising...

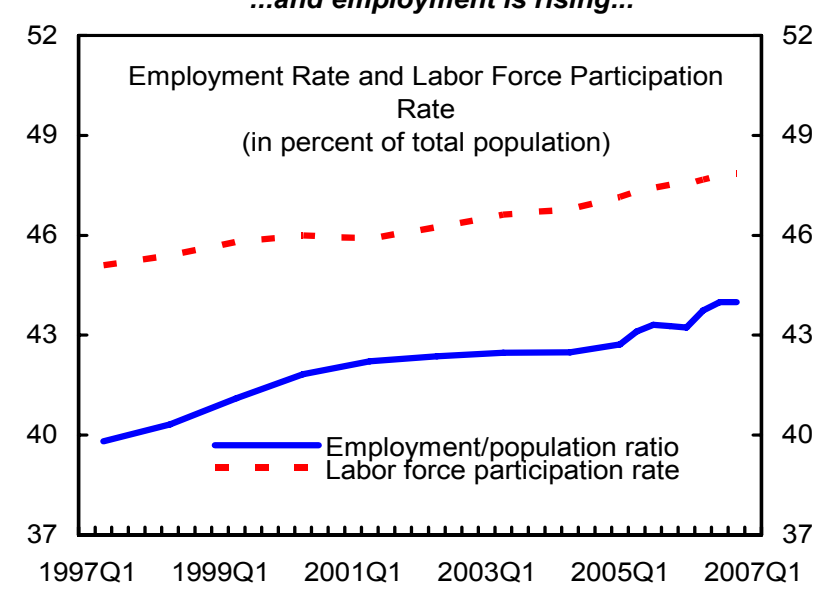

The composition of employment has nonetheless shifted toward part-time and temporary work.

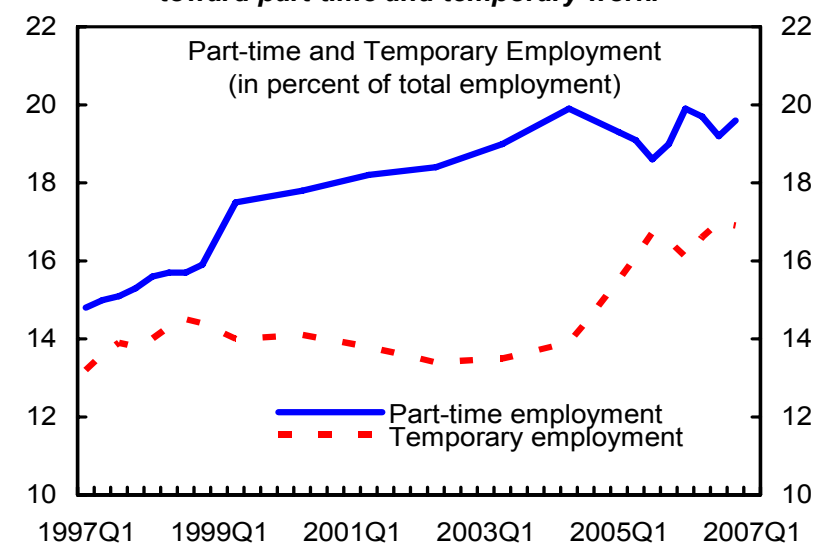

...but less so on account of general labor market development.

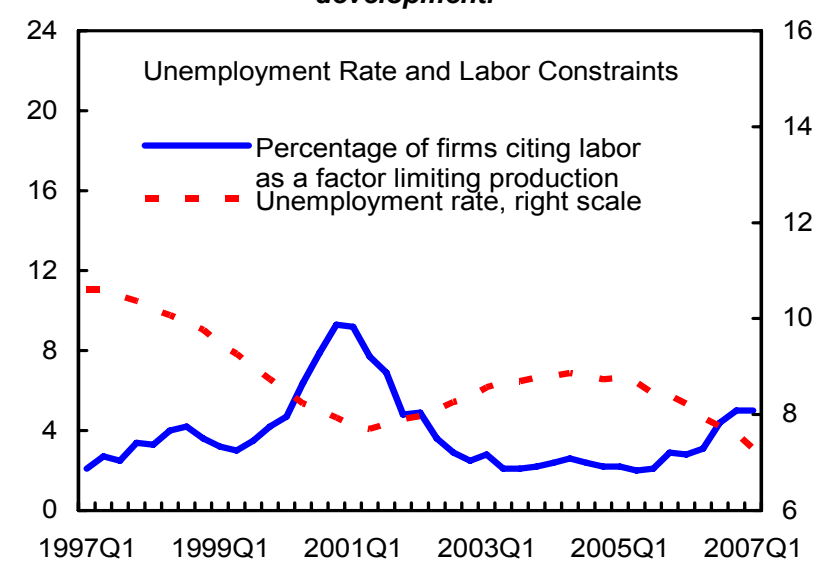

Sources: Eurostat; OECD; EC Quarterly Business and Consumer Survey; and IMF staff estimates. 1/ Excluding Greece, Luxembourg, and Slovenia.

2/ Males, 25-54 years old. 
Figure 7. Euro Area: Leading Indicators

PMI Manufacturing and Industrial Production

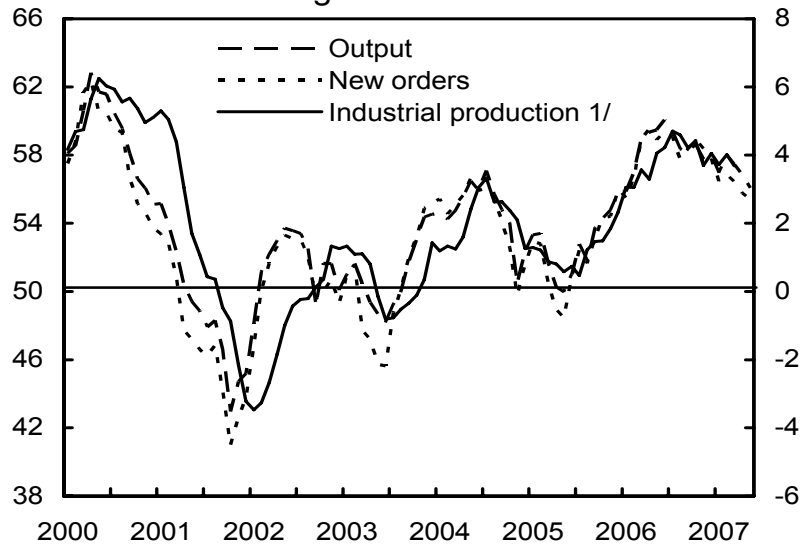

PMI and Output
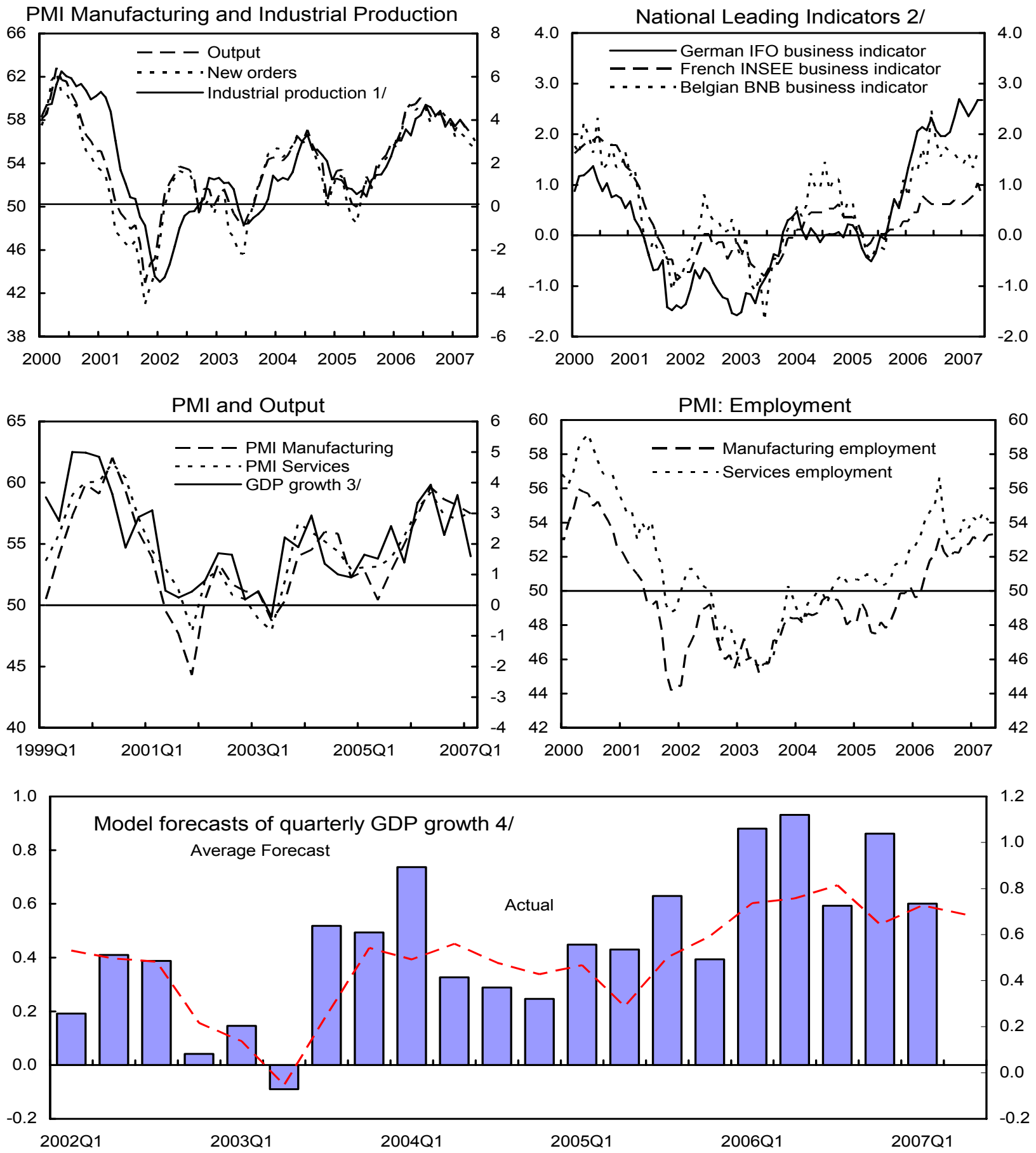

Sources: Eurostat, Reuters, IFO, INSEE, National of Belgium, and staff calculations.

$1 /$ Year-on-year percent change, three-month moving average, right scale.

2/ Standardized over 1991-2004 period.

3/ Year-on-year growth, right scale.

4/ Quarter-on-quarter growth, right scale.

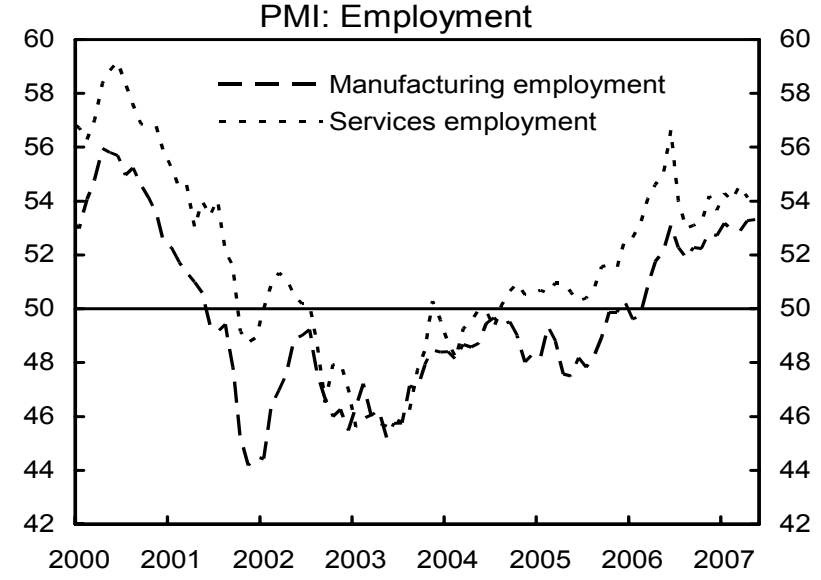

.2

0.8

0.2 
Figure 8. Euro Area: Price, Income, and Cost Dispersions
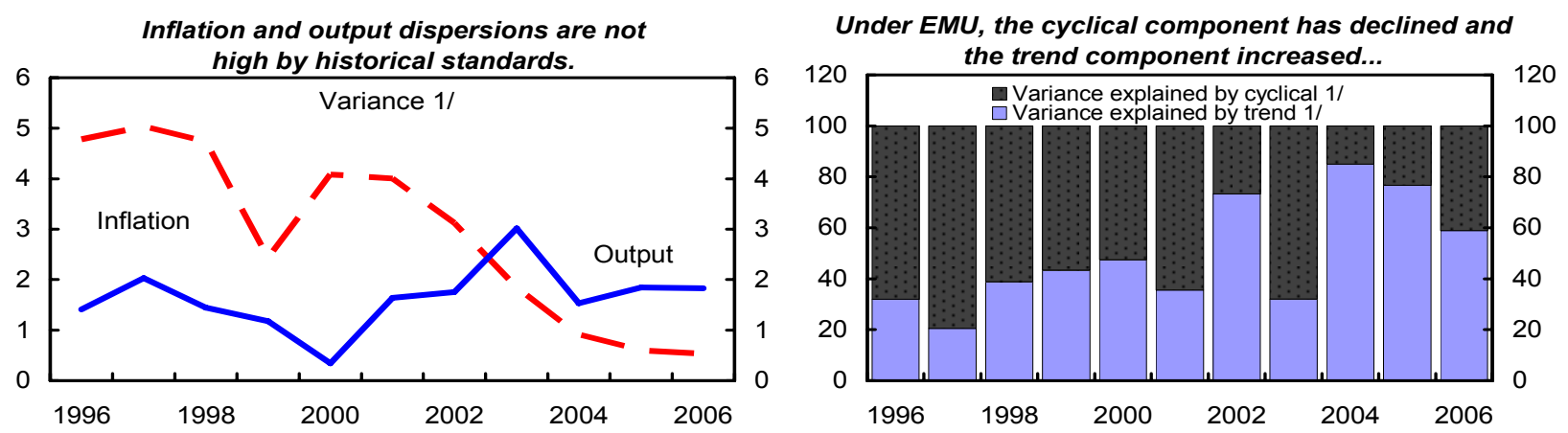

... and dispersions remained persistent...
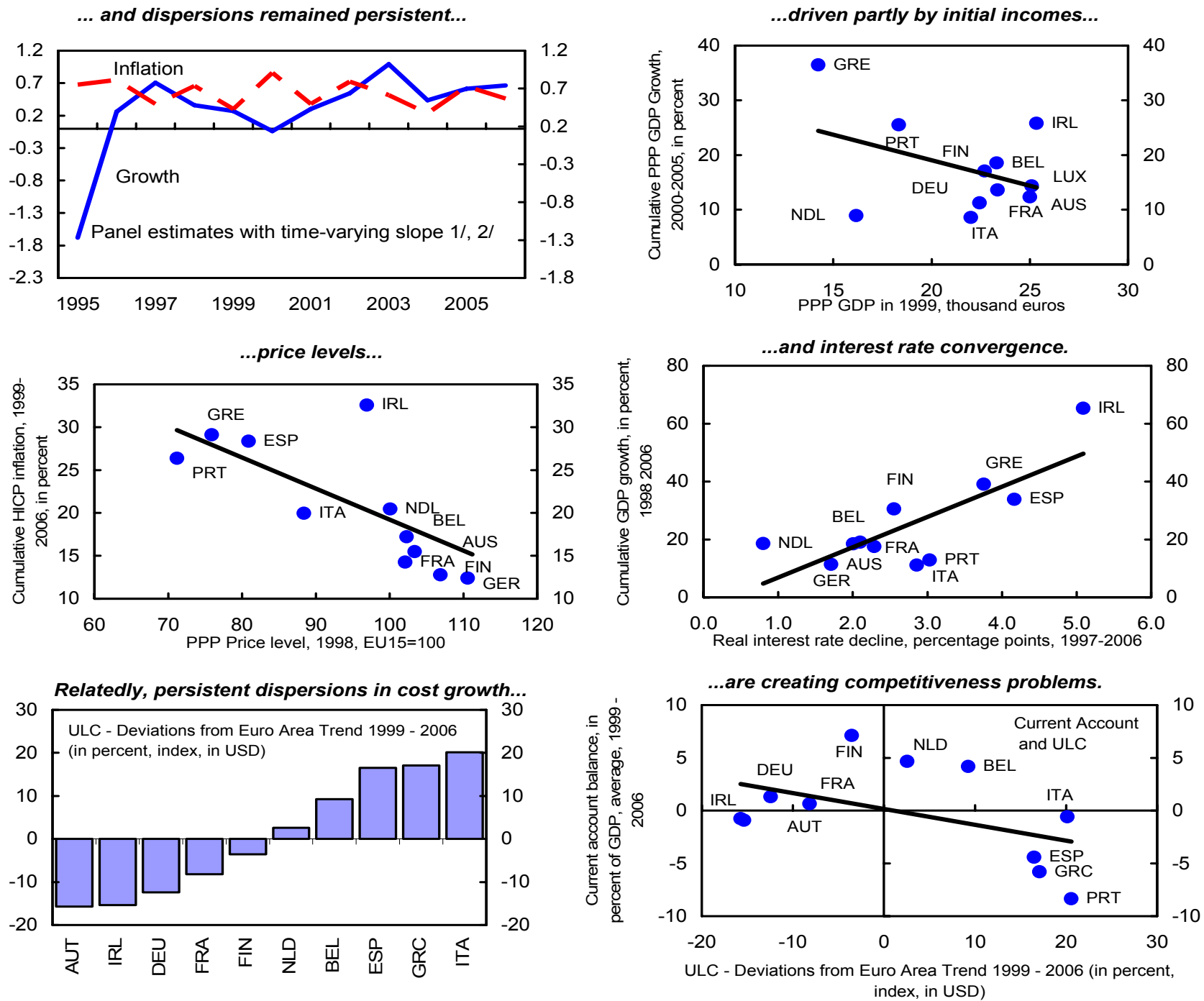

Source: IMF, World Economic Outlook.

$1 /$ Excluding Ireland and Luxemburg.

2/ Estimated equation: $x_{t, i}-\bar{x}_{t}=\alpha_{i}+\beta_{t}\left(x_{t-1, i}-\bar{x}_{t-1}\right)+\varepsilon_{t, i}$ where $x_{t, i}$-growth/inflation of each member state; $\bar{x}_{t}$-euro area growth/inflation; $\beta_{t}$-persistence parameter. 
Figure 9. Euro Area: Inflation and Labor Costs, 1999-2007 (in percent, unless otherwise specified)

Headline and core inflation have converged...

...as energy price increases have diminished.
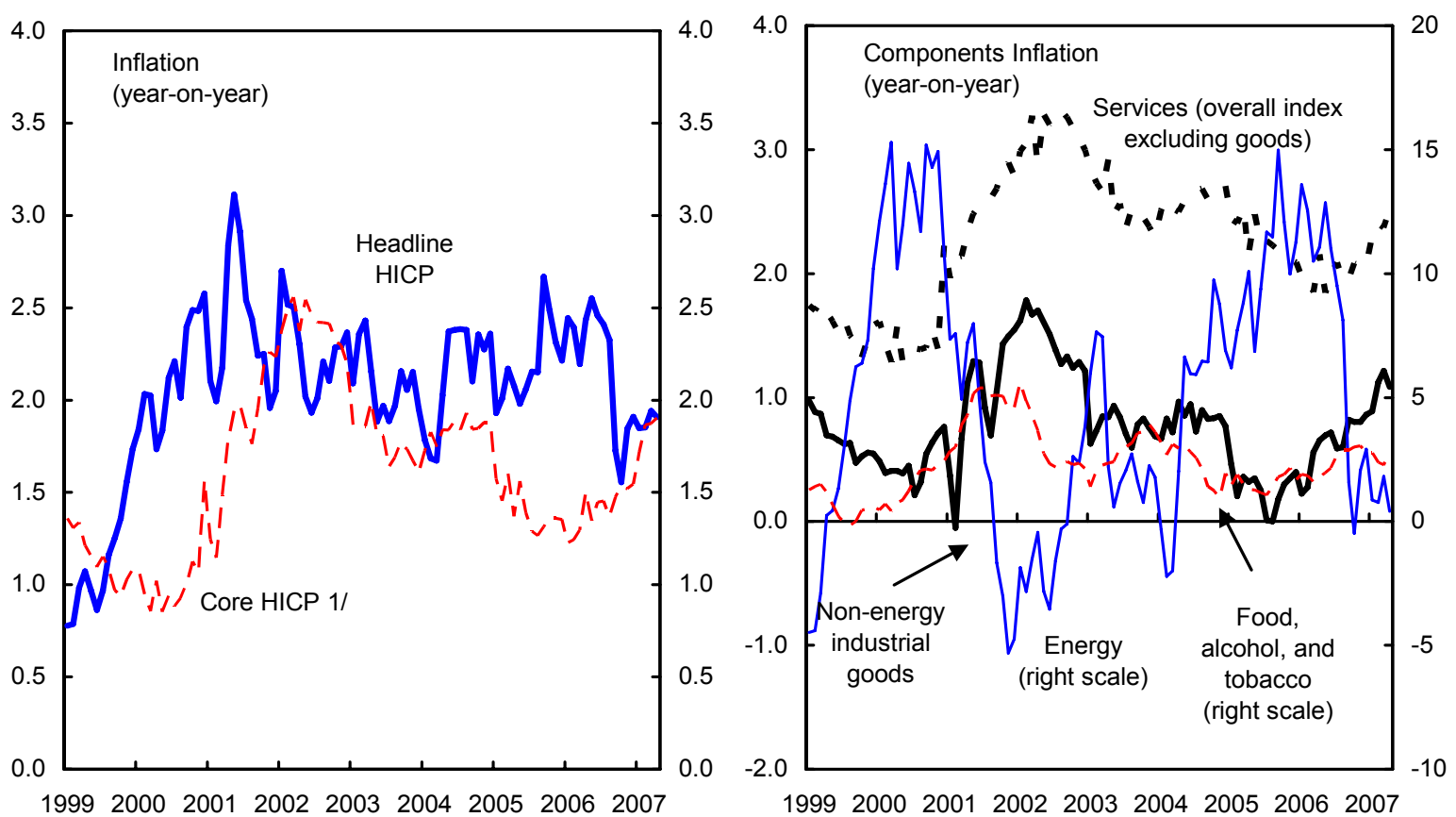

Wage growth is still subdued...

...and underlying inflation has edged up only

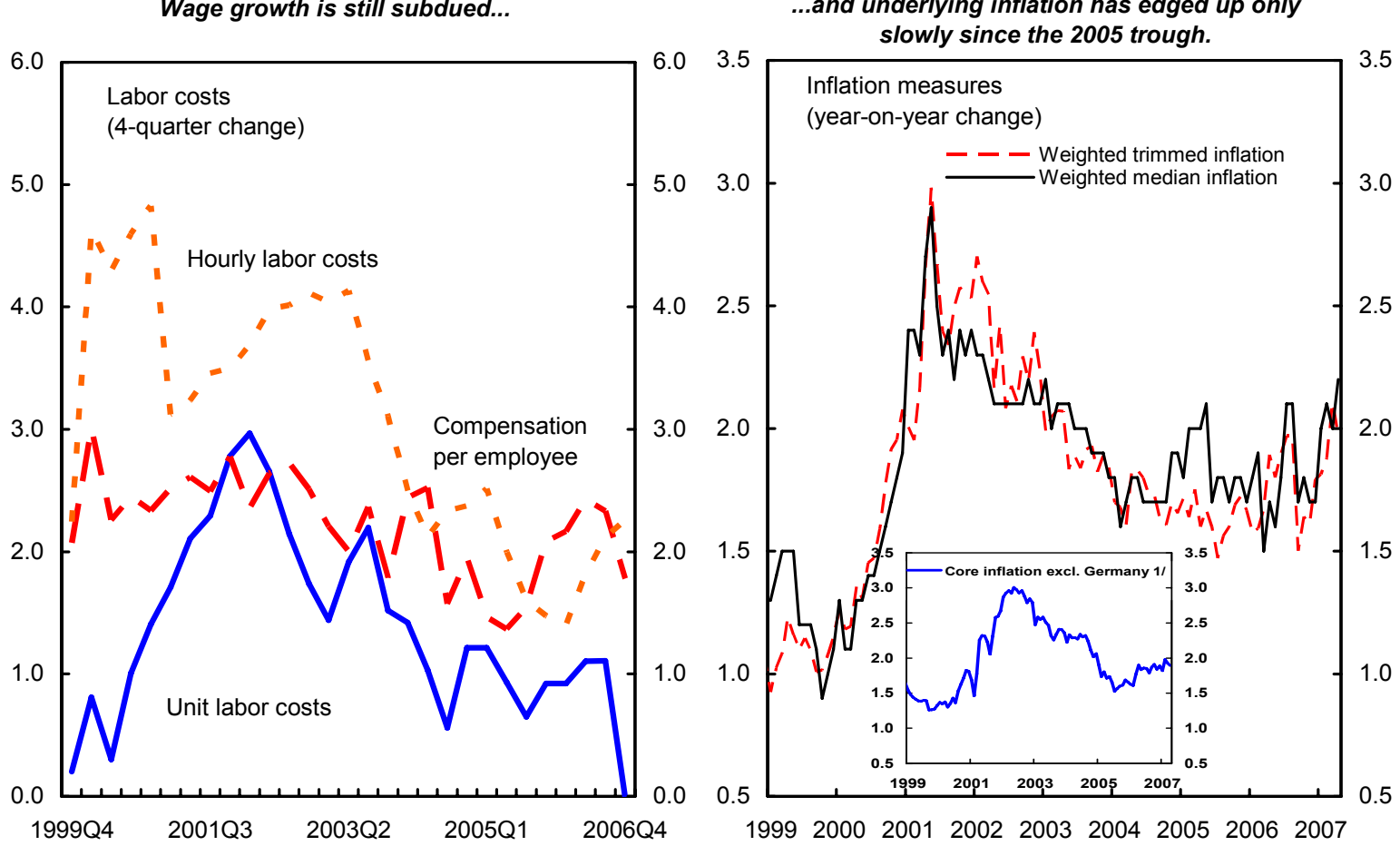

Sources: Eurostat; ECB; and Haver Analytics.

1/ Excludes energy, food, alcohol, and tobacco. 
Figure 10. Euro Area: Labor Costs and Labor Utilization

The wage-unemployment trade off has improved...
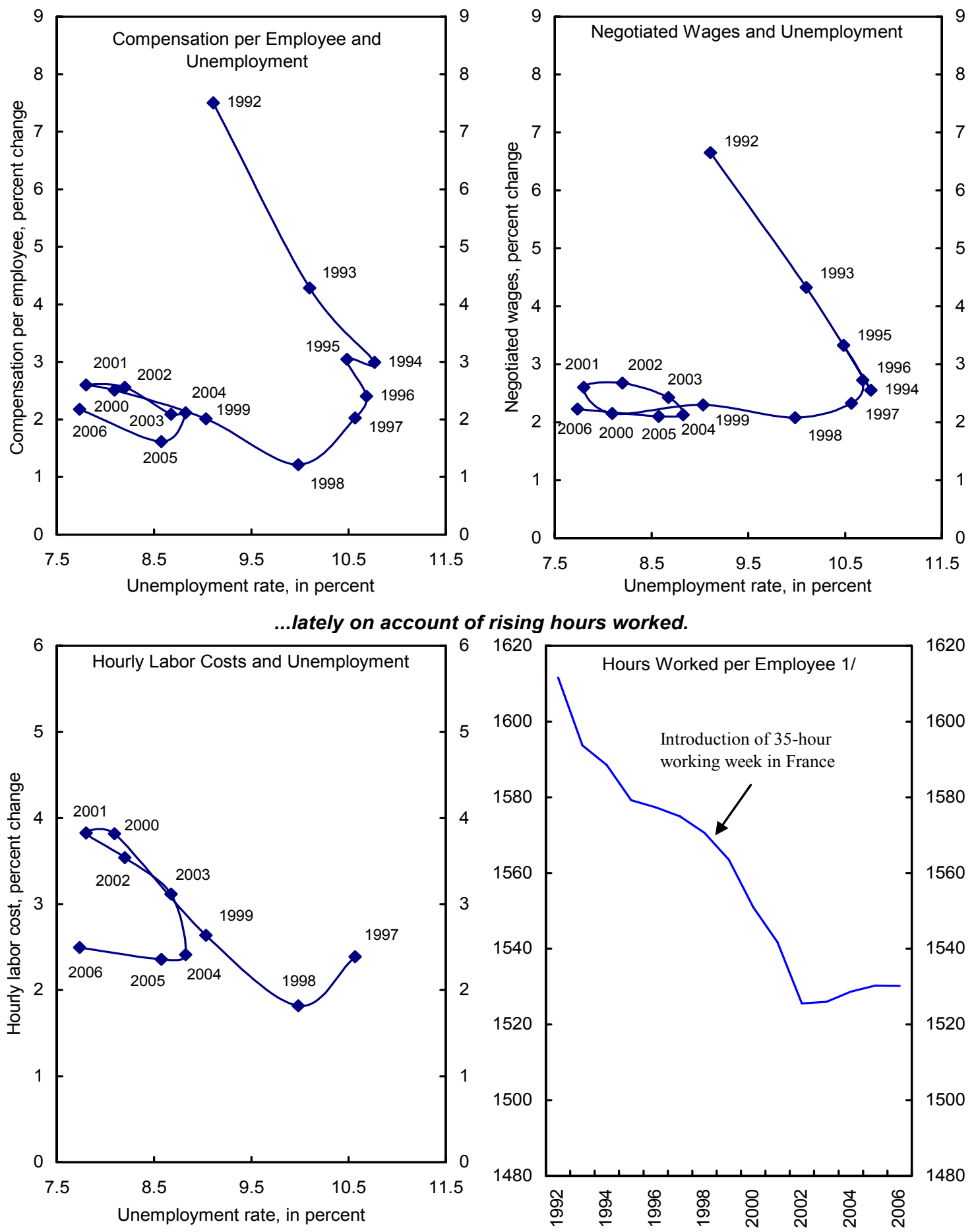

Sources: OECD, ECD, and Fund staff estimates.

1/ Excluding Greece and Portugal; weighted by employment. 
44

Figure 11. Euro Area: Model Forecasts of Inflation (Year-on-year, in percent)
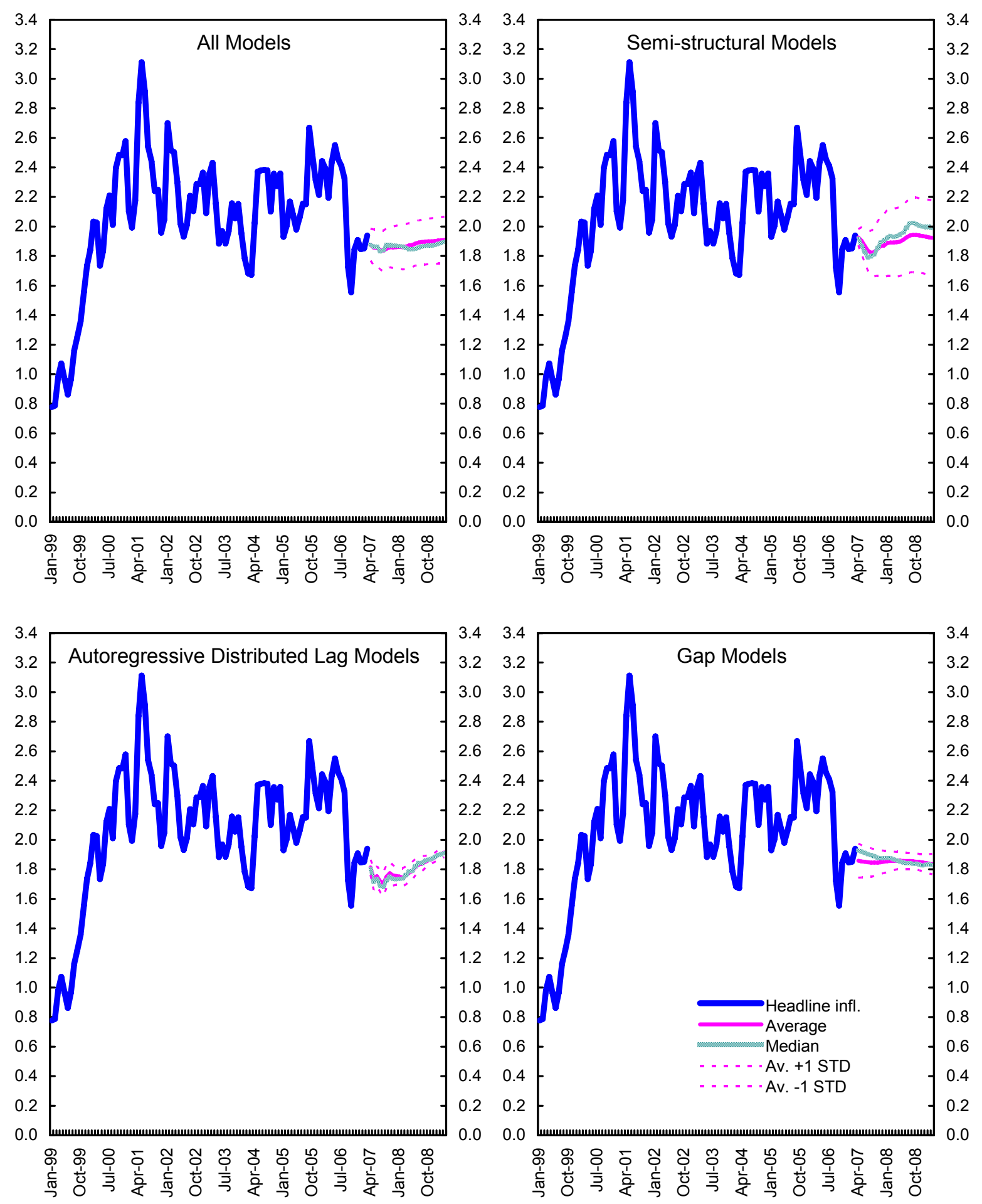

Source: IMF staff calculations, see IMF Working Paper 06/197. 
Figure 12. Euro Area: Monetary Policy and Market Expectations, 1999-2007 (in percent, unless otherwise specified)

After 2 1/2 years at 2 percent, policy rates have been raised eight times since December 2005...

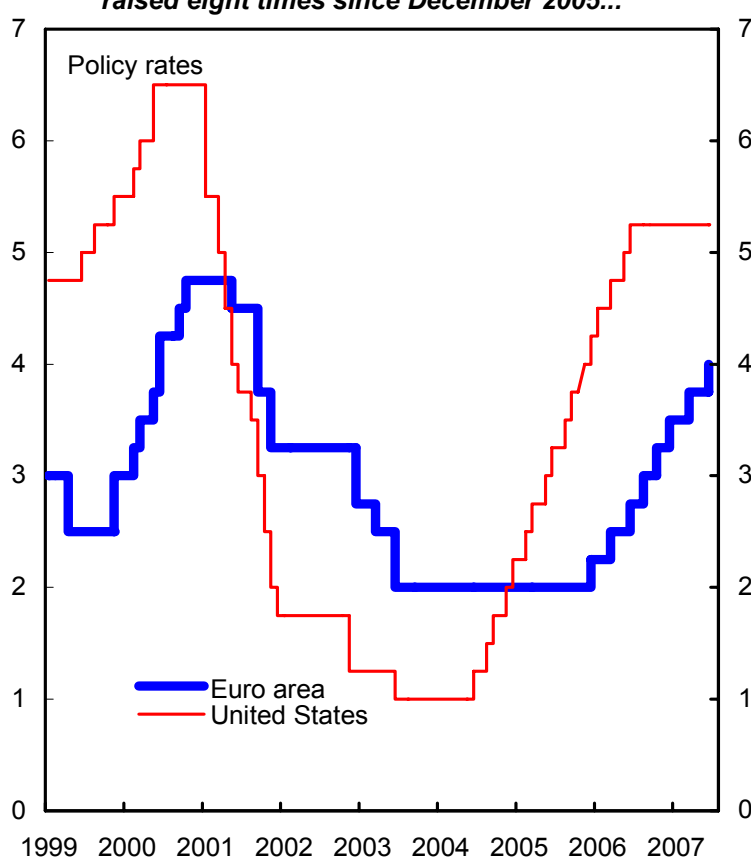

Inflation expectations remain well anchored...

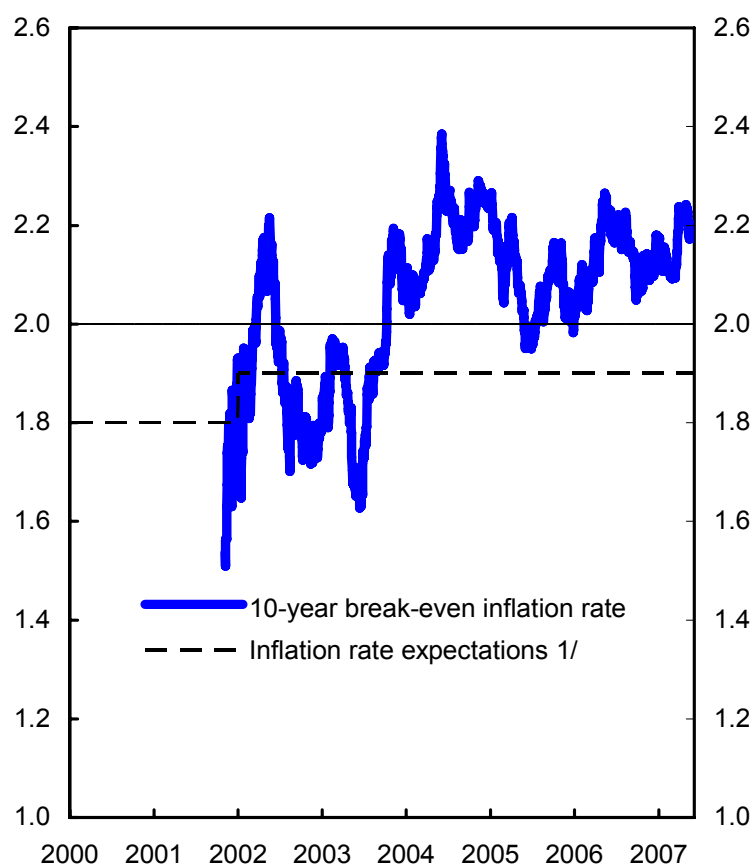

....and markets expect 50bp increase by the end of 2007.

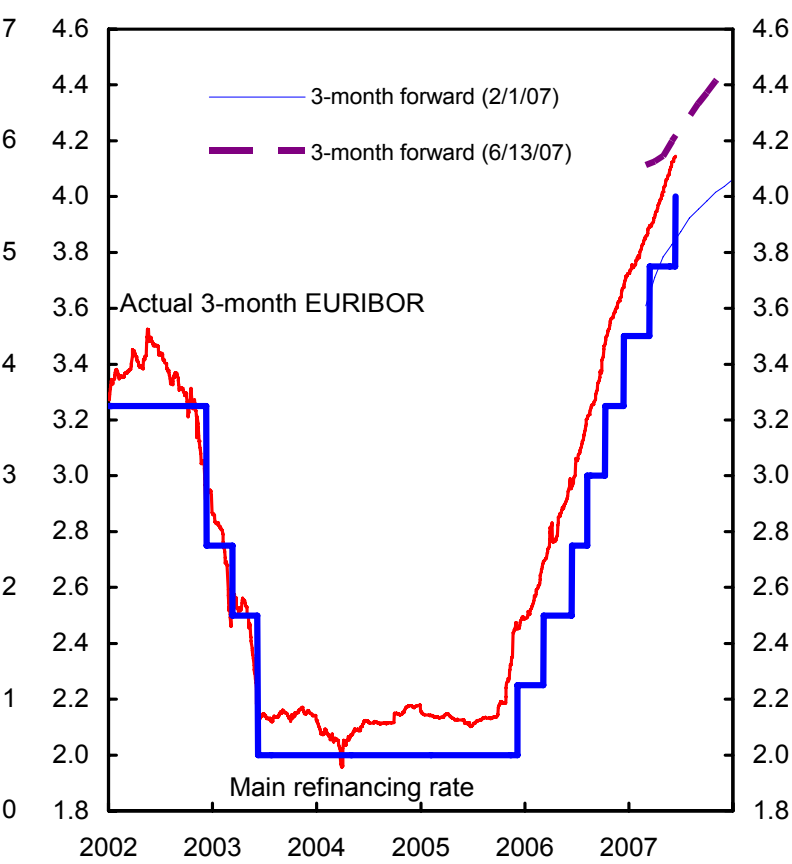

...in line with break-even inflation trends.

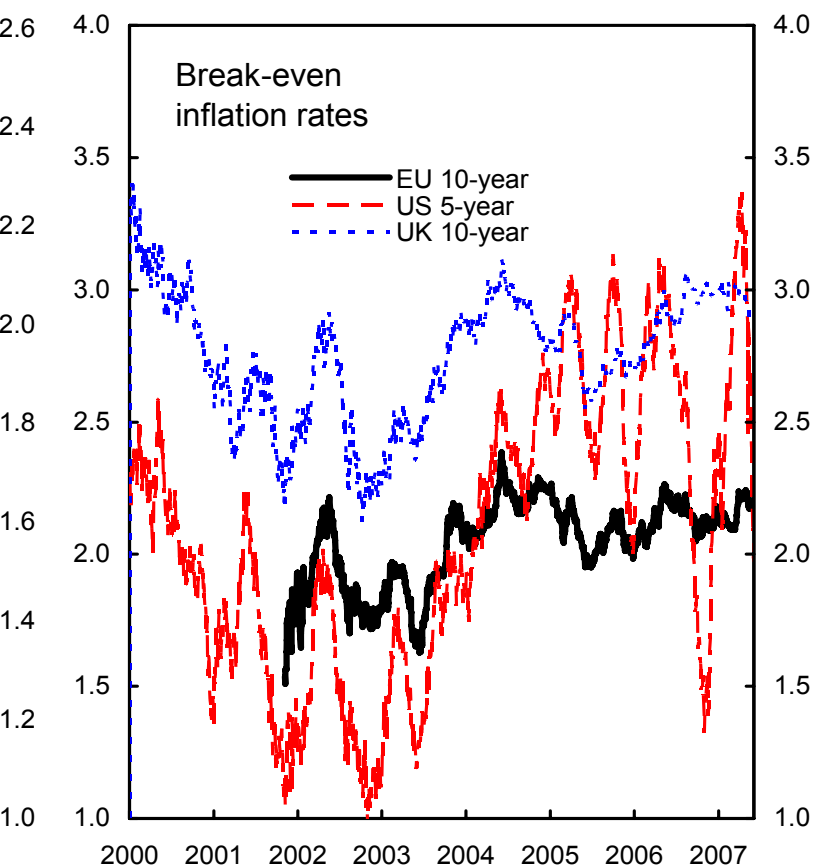

Sources: Datastream; ECB; Eurostat; and staff calculations and forecasts.

1/ Survey of Professional Forecasters. 
Figure 13. Euro Area: Money and Credit, 1980-2007 (in percent, unless otherwise specified)

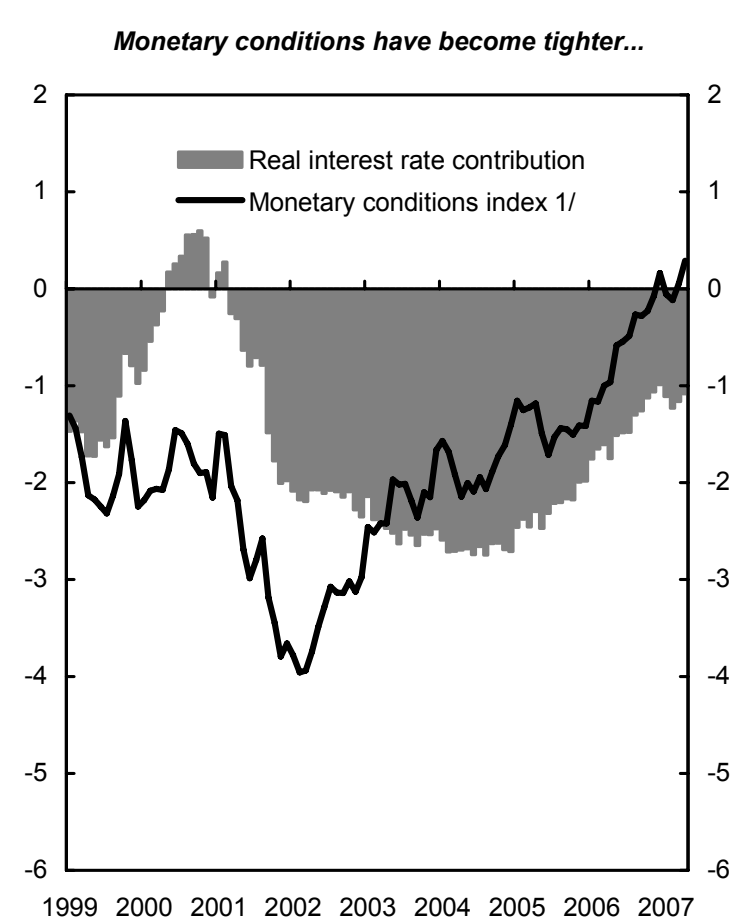

...but the ECB perceives a liquidity "overhang" as a key upside inflation risk as the recovery strengthens.

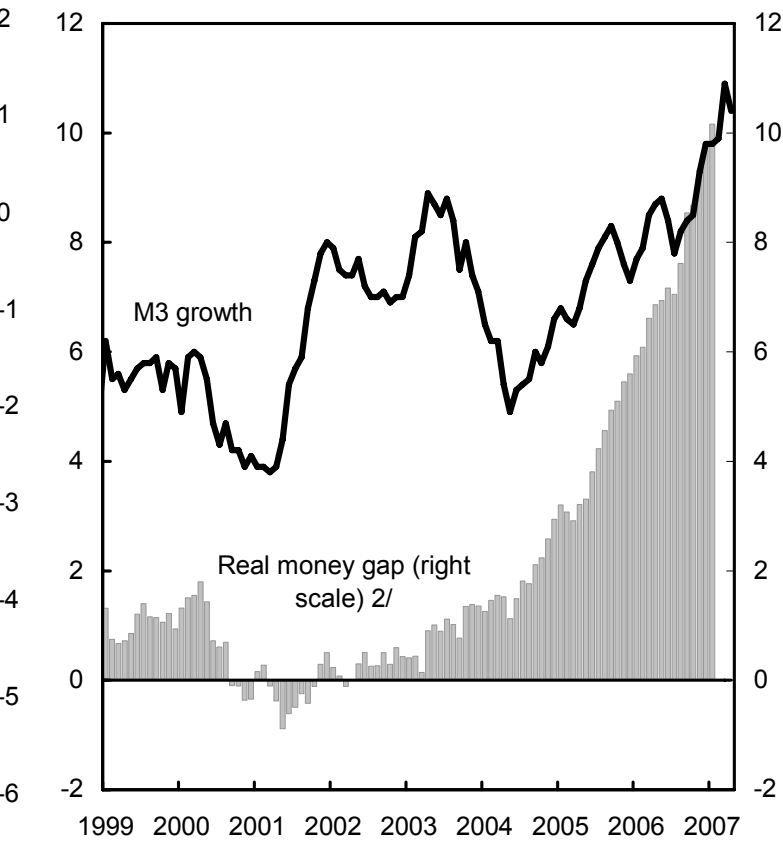

Variable declines in money velocity, however, leave inflation implications less clear.

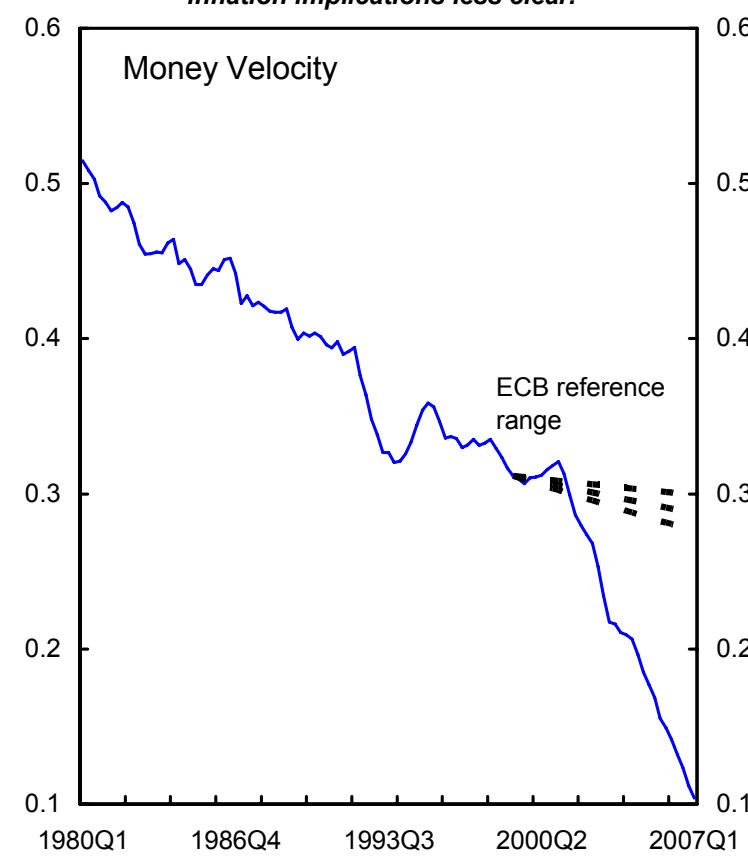

Credit growth remains high across the board.

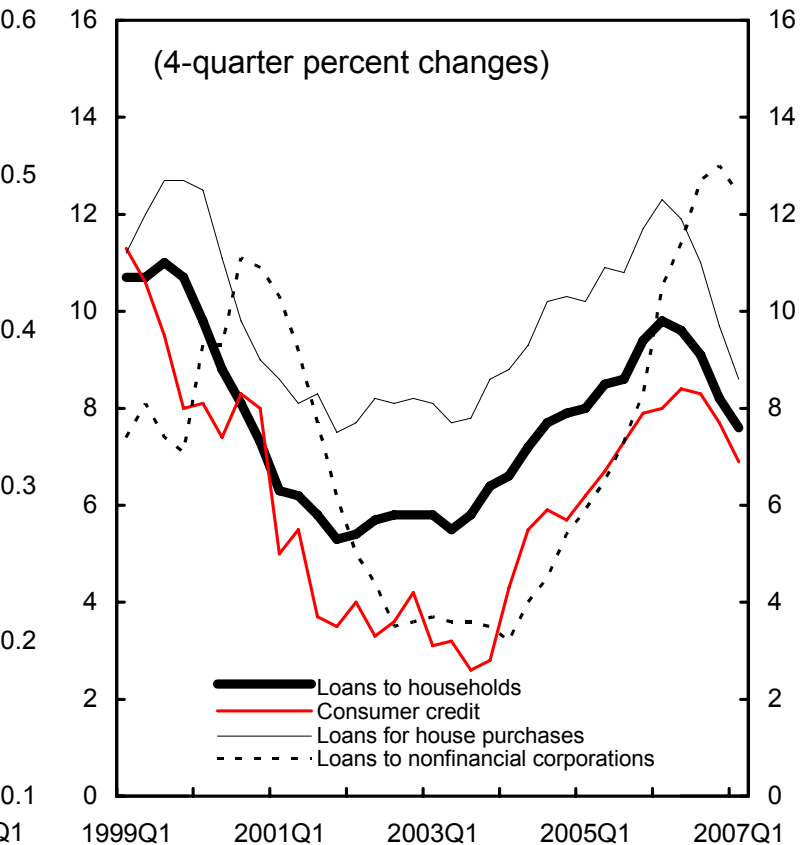

Sources: ECB; Datastream; Bloomberg; and staff calculations.

1/ Deviations from 1990-2004 mean.

2/ Deviation (in percent of the actual real stock of M3 from an estimate of the long-run real stock of M3, consistent with long-run inflation of 1.75 percent a year and assuming that the real money gap was zero in January 1999. 
Figure 14. Euro Area: Fiscal Developments (in percent of GDP, unless otherwise noted)

The area's fiscal deficit has improved...

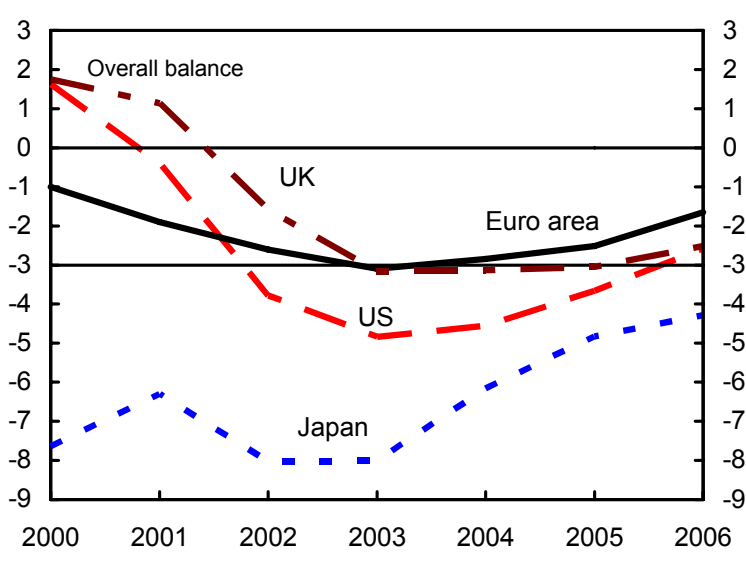

The close-to-balance criterion remains elusive, in particular, for the countries currently under the EDP...

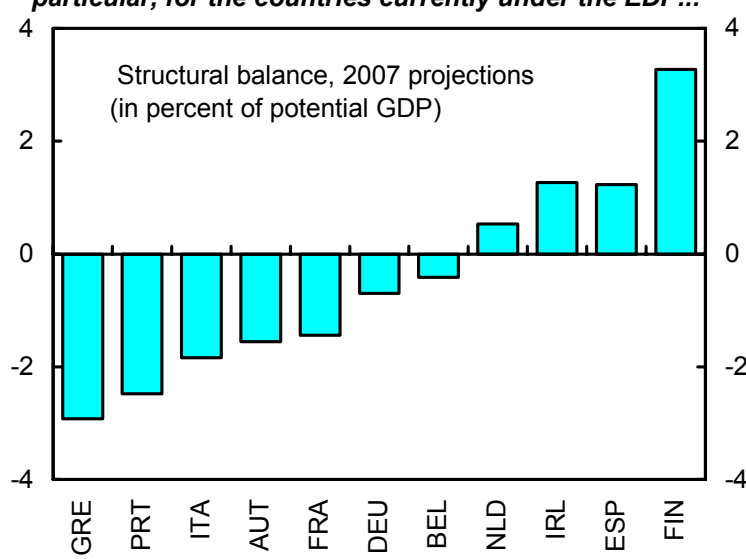

Deficit targets in Stability Programs improved for the first time but...

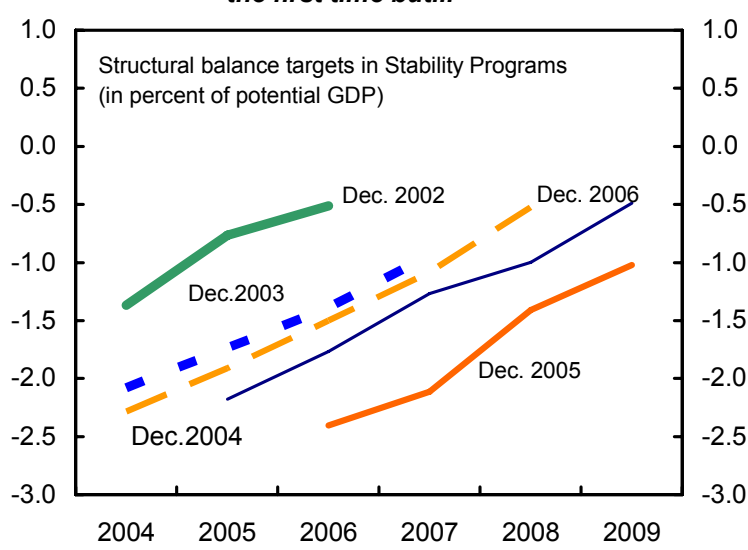

....and fiscal policy has so far been countercyclical during the current upswing.

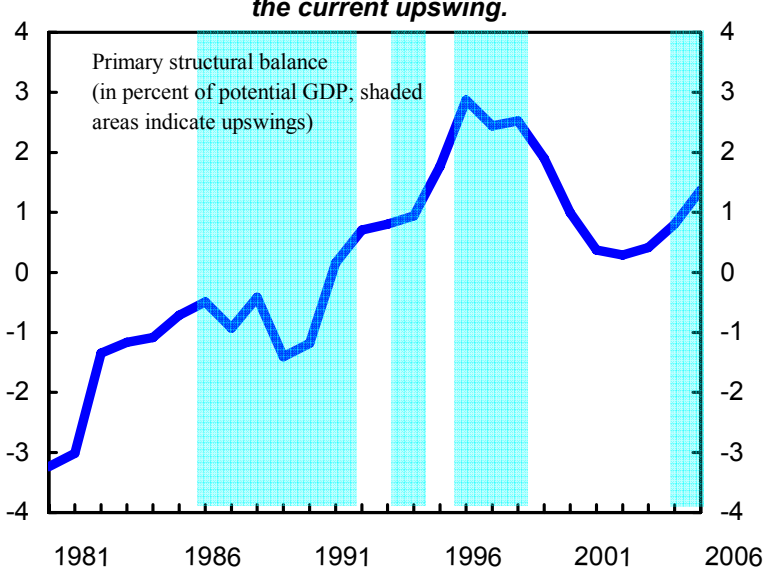

...but the overall public debt-to-GDP ratio is expected to decline further.

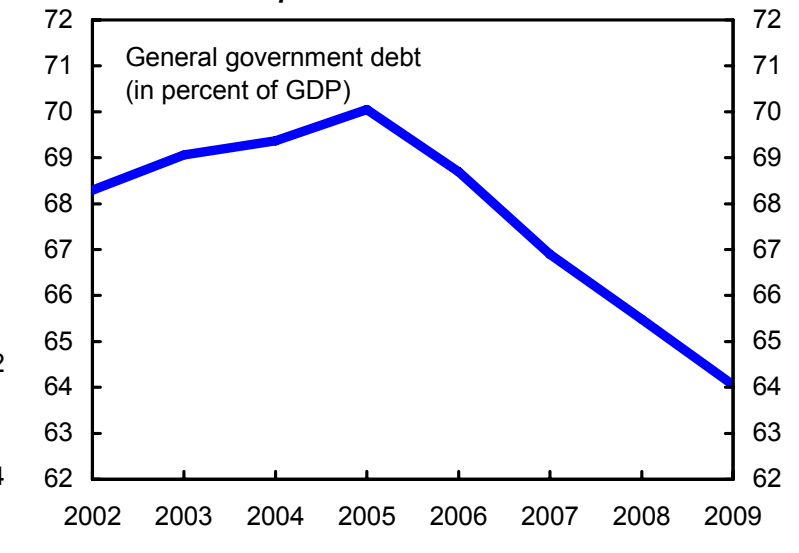

looking ahead, few credible measures back them

up.

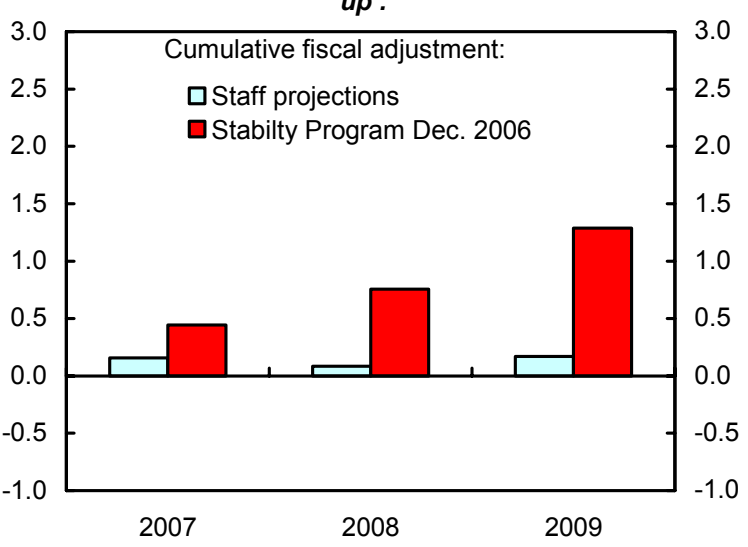

Sources: European Commission; IMF, World Economic Outlook; and IMF staff calculations. 
Figure 15. Euro Area: Economy-wide Regulations

Product market ...

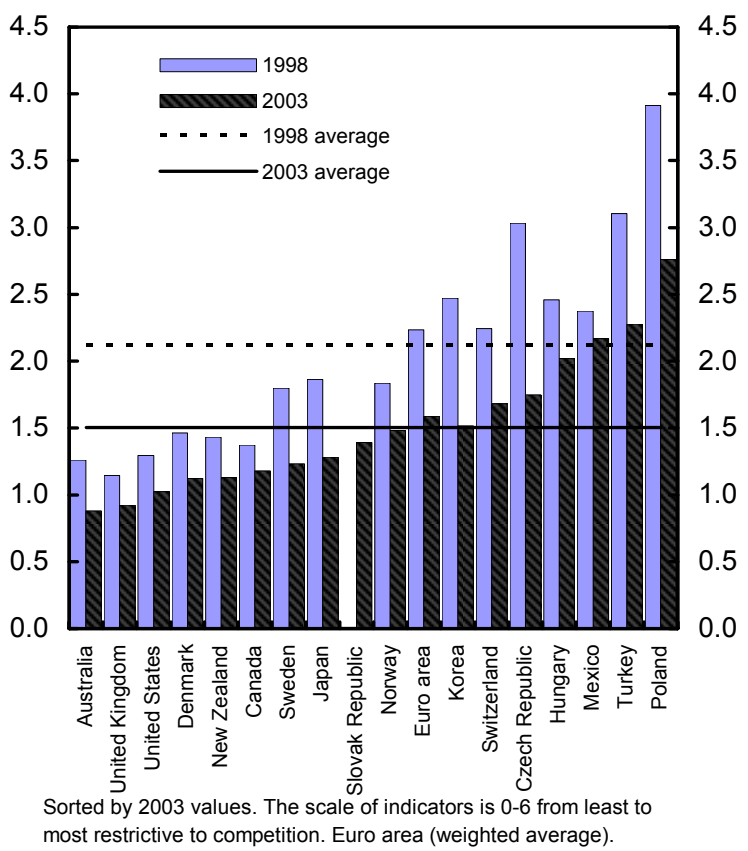

most restrictive to competition. Euro area (weighted average).
... administrative ...

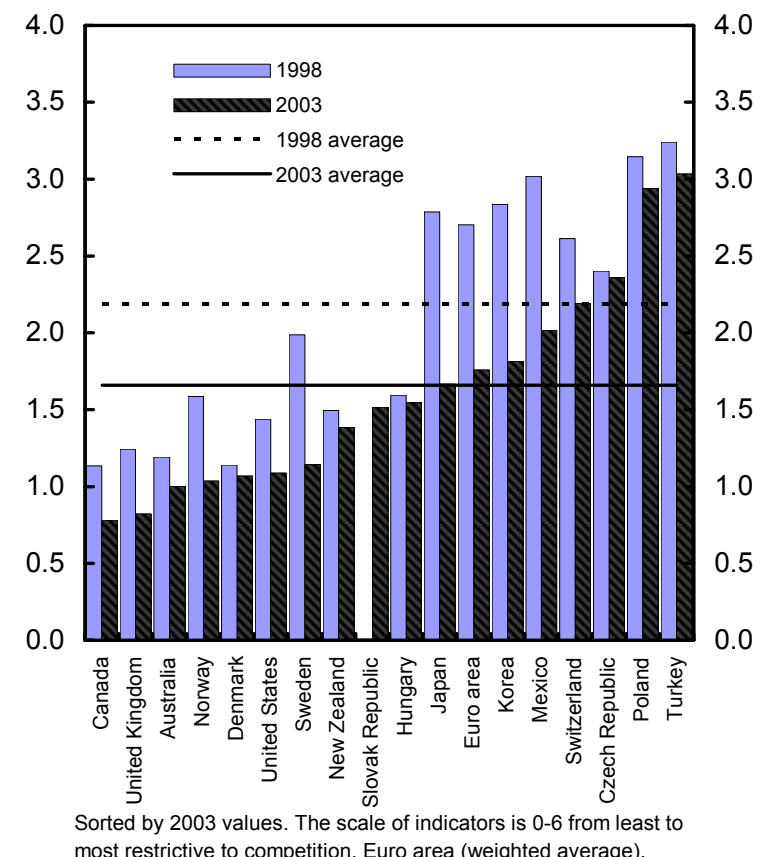

... and labor market regulations remain high.

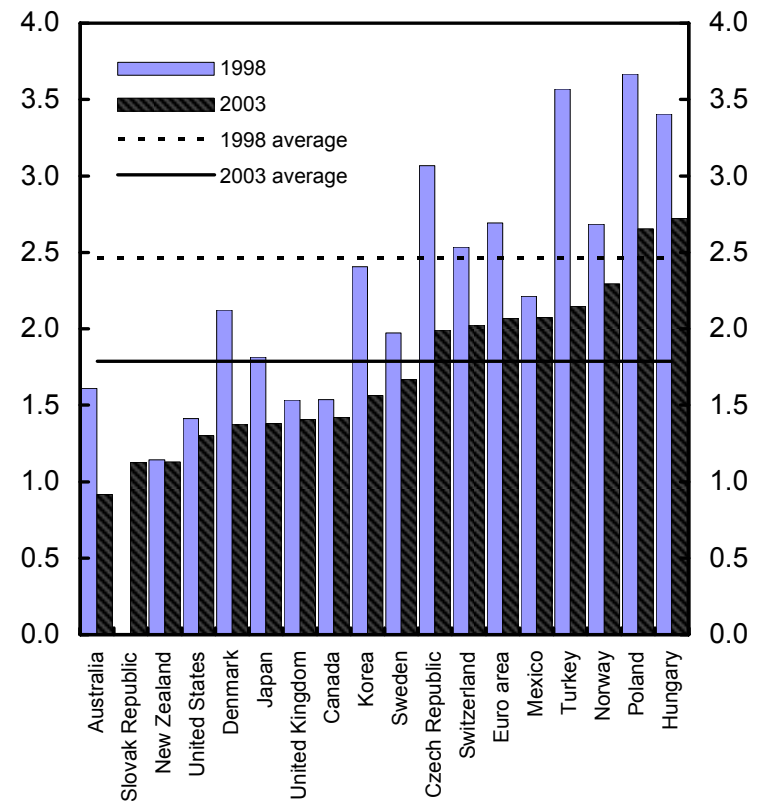

Sorted by 2003 values. The scale of indicators is 0-6 from least to most restrictive to competition. Euro area (weighted average).

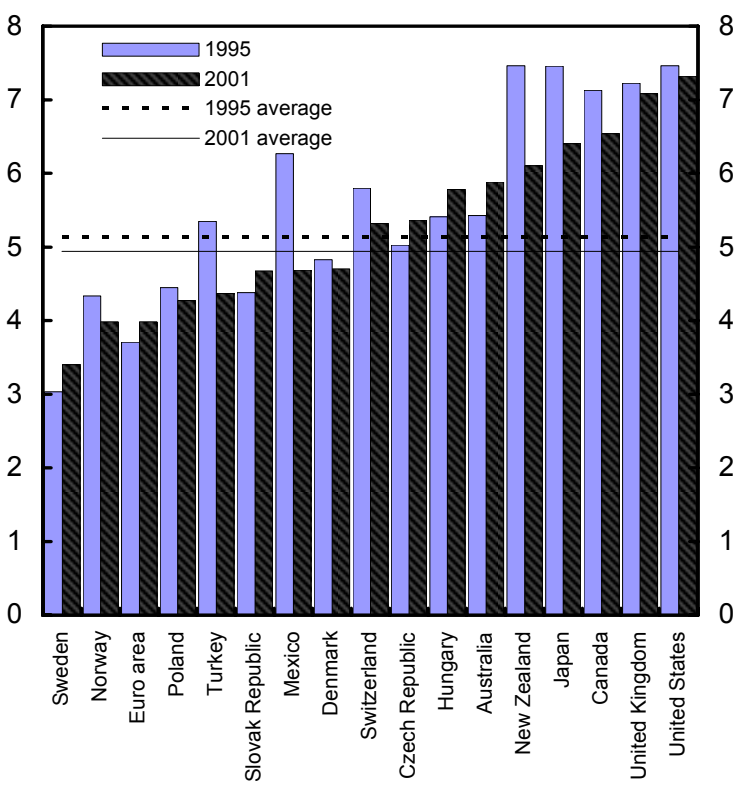

Sorted by 2001 values. The scale of indicators is $1-10$ from most to least regulated; Euro area (weighted average).

Source: OECD, and based on a database compiled for the April 2004 WEO. 
Figure 16. Euro Area: Banking Sector Developments (100 Largest Banks; in percent, unless otherwise noted)
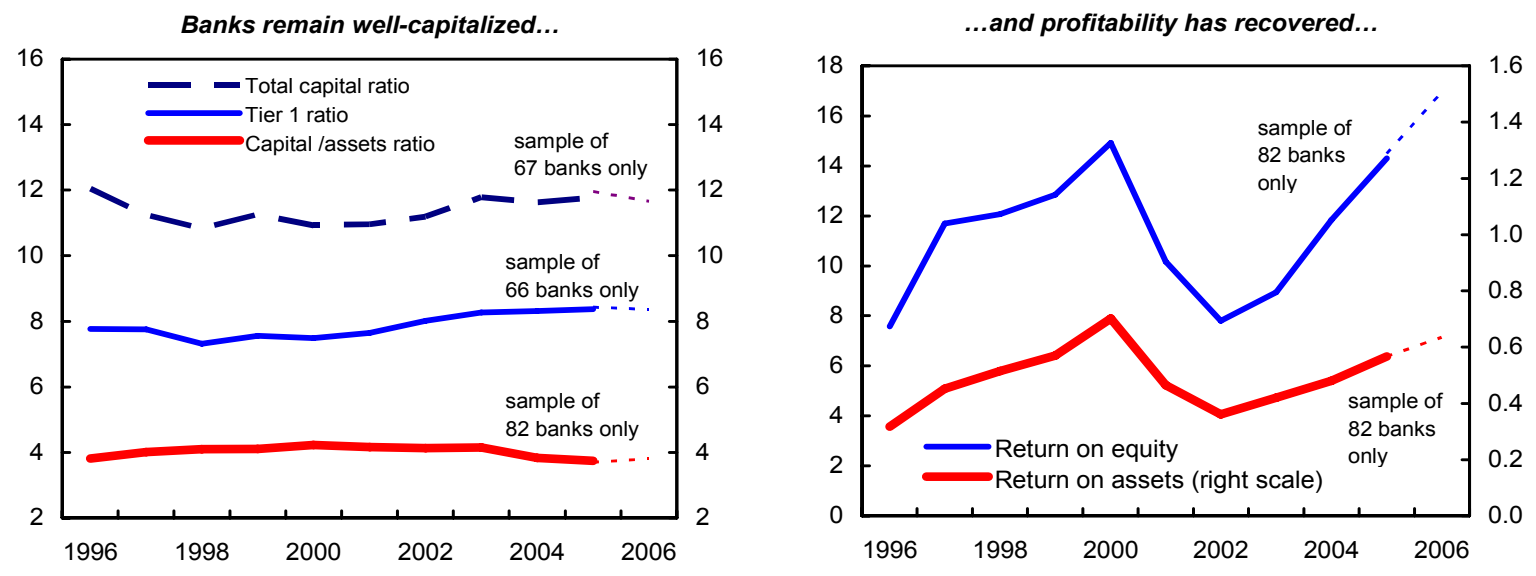

...helped by still healthy interest margins...
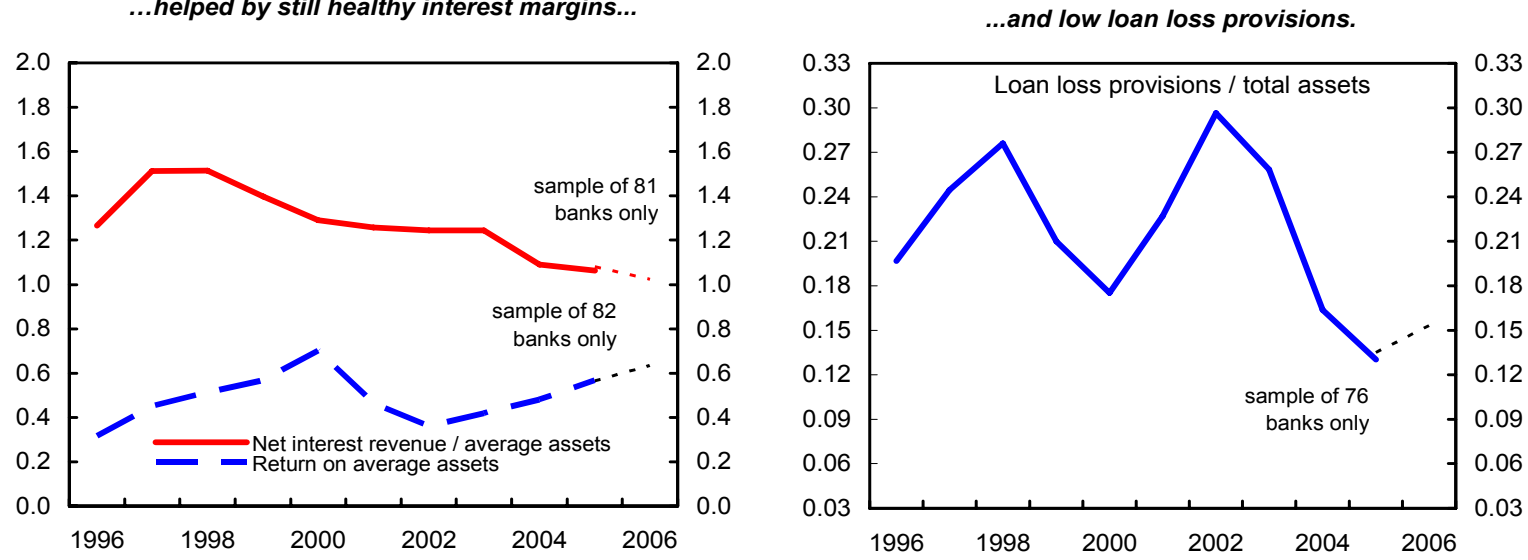

Rising revenues and cost cuts have combined to improve profits.
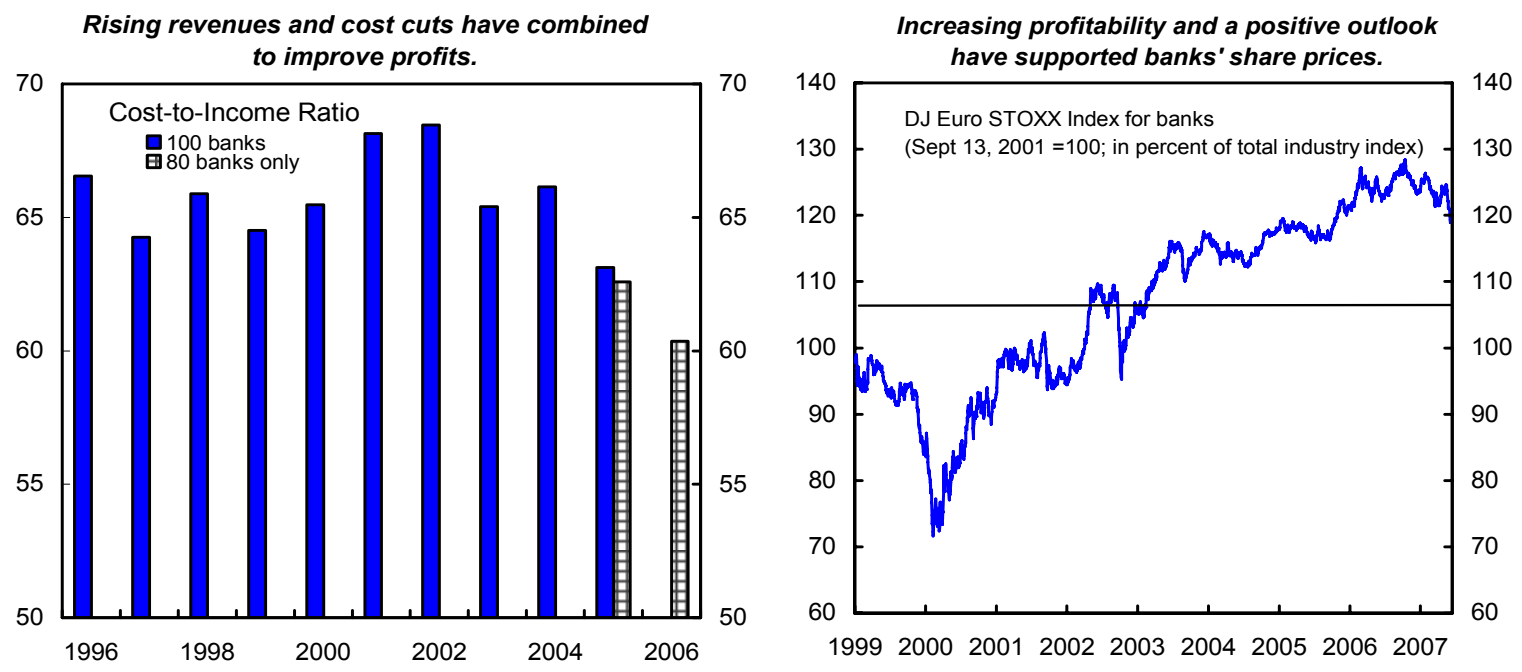

Sources: FitchIBCA database; Datastream; and Fund staff calculations. 
Figure 17. Euro Area: Leverage Ratios, 1999-2006

(Debt as a ratio to equity or net worth)

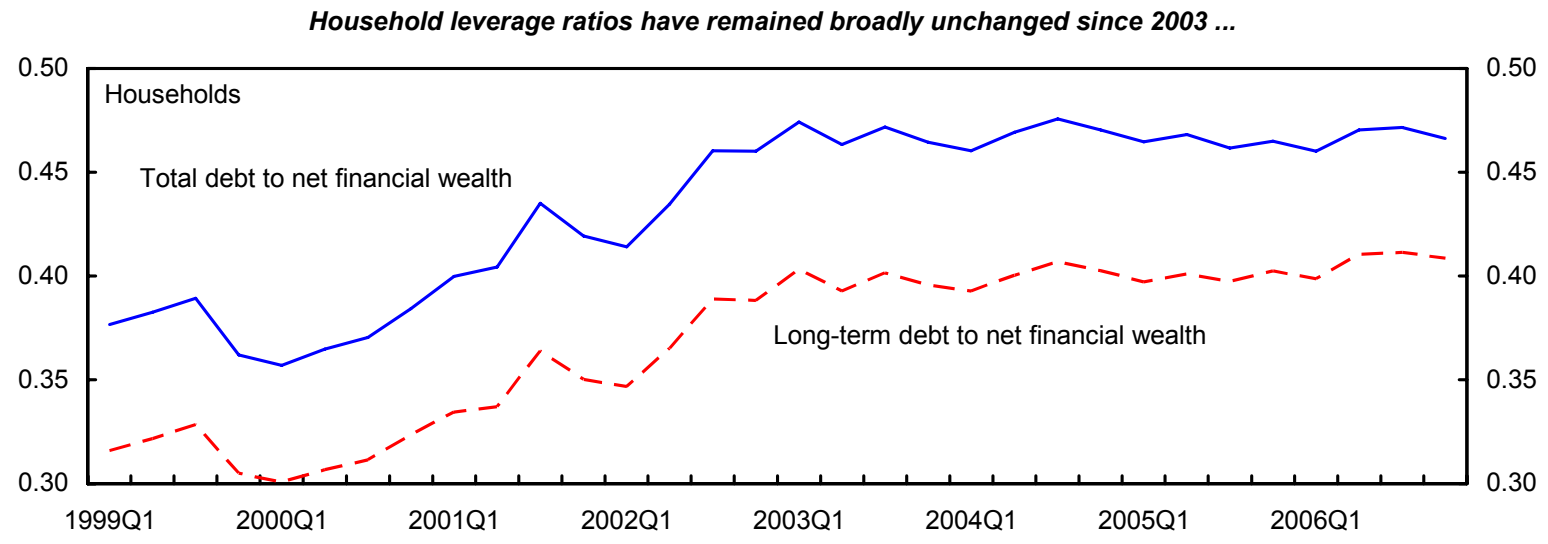

... while a process of de-leveraging continued in the non-financial enterprise sector...

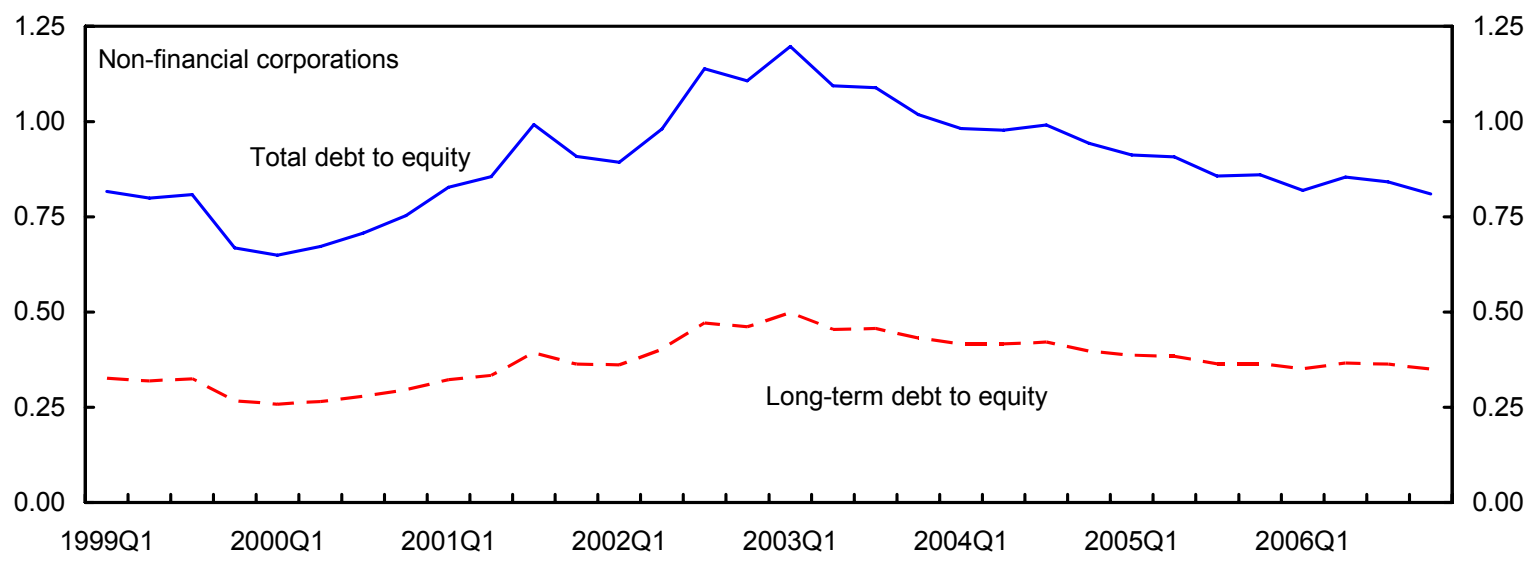

... as well as in the financial sector.

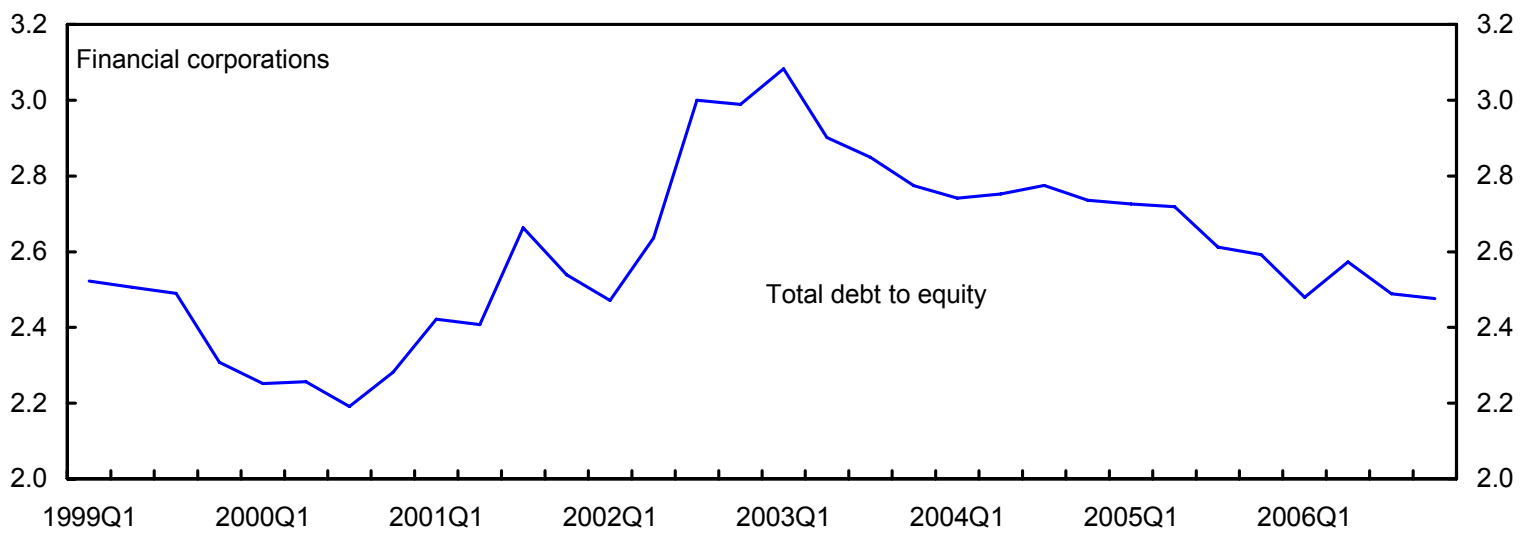

Sources: IMF staff calculations based on quarterly European sector accounts by the ECB and Eurostat. 
Figure 18. Euro Area: External Developments

(in billions of U.S. dollars; unless otherwise specified)
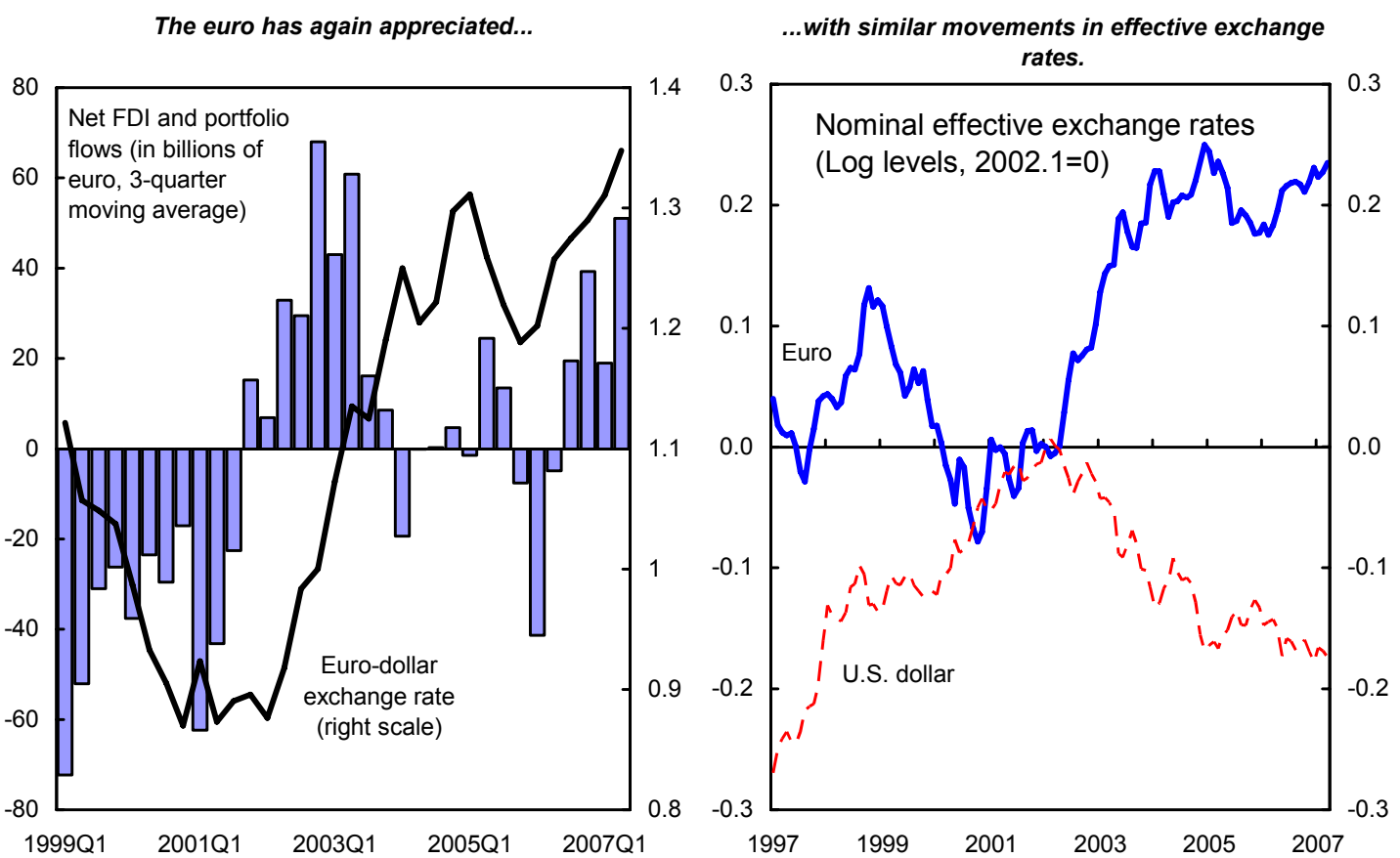

But the real value of the euro is still broadly aligned
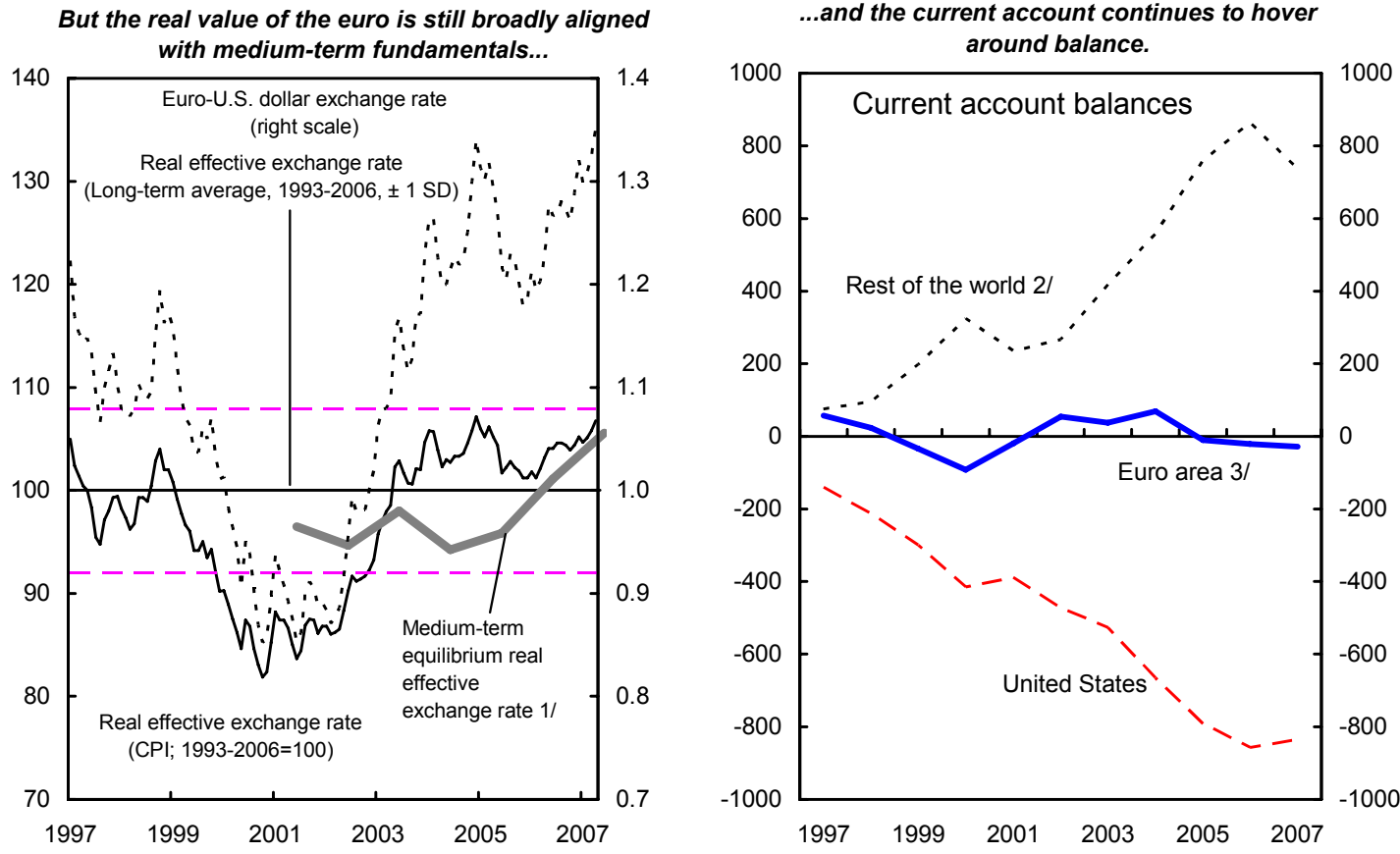

Sources: ECB; Haver Analytics; IMF, World Economic Outlook.

1/ Staff estimate, based on a time series estimate with stochastic trend, a macroeconomic balance approach, and an external sustainability assessment.

2/ Rest of the world calculated as residual (excludes global discrepancy).

3/ Excludes intra-area trade (ECB data). 


\section{APPENDIX-STATISTICAL ISSUES}

\section{Euro Area Policies}

Statistics for the euro area (and the EU-27) are produced by Eurostat and the ECB, generally on the basis of data reported by member states. These statistics are of sufficient quality, scope, and timeliness to allow effective macroeconomic surveillance. Nonetheless, gaps and weaknesses remain, and many of these are difficult to resolve given institutional and other complexities, including the changing composition of the euro area and EU. In spite of these complexities, important progress has been made over the past year, including in particular with the publication of quarterly euro area (i.e., "national") accounts per institutional sector. The accessibility of euro area data has also improved thanks to the launch of the ECB's Statistical Data Warehouse. ${ }^{13}$ Eurostat monitoring of member states' fiscal accounts is improving. Internationally comparable and higher-frequency financial soundness indicators, more housing market indicators, and improved statistics on non-bank financial intermediaries would be desirable. The IMF's Dissemination Standards Bulletin Board (DSBB) ${ }^{14}$ provides comprehensive information on the Euro area's statistical practices for the Special Data Dissemination Standard (SDDS) data categories.

- $\quad$ Following up on last year's release of annual euro area accounts per institutional sector, Eurostat and the ECB published an initial set of quarterly euro area and EU-27 accounts per institutional sector in June 2007, covering 1999:Q1 until 2006:Q4. New releases will henceforth follow on a quarterly basis, with a delay that is to be gradually reduced to 95 days. The new quarterly data will also allow better timeliness of annual data. Work on non-financial balance sheets per sector continues.

- A revised Nomenclature générale des Activités Economiques dans les Communautés Européennes (NACE) classification, NACE Rev. 2, will be introduced gradually from 2008 onwards, applying to 2008 data and beyond. Its introduction will affect a wide range of statistical series and cause structural breaks due to the limited scope for back-casting.

- A European Statistics Code of Practice was adopted in 2005 for Eurostat and the national statistical agencies, with a coverage that is largely the same as that of the IMF's Data Quality Assessment Framework. Self-assessments using the Code of Practice have taken place, and peer assessments are now ongoing. The Code puts

\footnotetext{
${ }^{13}$ Available at: http://sdw.ecb.int/.

${ }^{14}$ Available at: http://dsbb.imf.org/.
} 
forward, among other things, a need for professional independence of statistical authorities.

- National accounts data covering the pre-1995 period will remain unavailable for the foreseeable future, although Eurostat is working on the compilation of longer time series for some key indicators. NACE Rev. 2 is not expected to have major effects on aggregate economic statistics such as GDP. Efforts are underway to reduce differences in seasonal and working day adjustment methodologies between member countries.

- $\quad$ Structural indicators are being adapted to the requirements of the revamped Lisbonstrategy, with the retention of a set of 14 core indicators and the introduction of four new ones. In the area of short-term statistics, work is ongoing on better measuring output volumes of services and output prices. Publication of an euro area import price index is expected later this year, covering extra-area imports in goods. The Labor Force Survey is being expanded with more detailed information about the distribution of wages and a legal act providing for the compilation of data on job vacancies is being prepared. At present, data from member states are incomplete and not fully harmonized.

- A new emphasis on communications with respect to price statistics is being put in place by Eurostat, other European institutions, and the member states, and a new standard for quality adjustments of price statistics is being prepared. This new standard is expected to lead to more reliable quality adjustments and, together with the work of a center of excellence, greater convergence in adjustment methodologies between member states. A harmonized index of consumer prices at constant tax rates (HICP-CT) series should become available from 2008 onward for most EU member states. Some member states have not yet agreed to regular production of this index, and this may delay the compilation of euro area aggregates. Preliminary work is ongoing to better monitor administered prices, and work on housing prices is continuing, with the aim or producing an experimental euro area index by the end of 2007. A manual on house price statistics is being prepared.

- $\quad$ Analysis of asymmetries between balance of payments data reported by different member states continues to improve, both at the aggregate level by Eurostat and the ECB and between member states. While containing the problem, in particular at the aggregate level, the asymmetries cannot be expected to be eliminated altogether. Further progress will require increased harmonization of data collection and compilation practices, and changes to national confidentiality arrangements.

- $\quad$ All euro area countries and the ECB provide monetary statistics to the IMF through a "gateway" arrangement in which the data are channeled through the ECB. This 
arrangement guarantees the efficient transmission of monetary statistics to the IMF and reduces reporting burdens in euro area countries.

- Also, all EU countries participated in the IMF's Coordinated Compilation Exercise for Financial Soundness Indicators (FSIs). Data and metadata on a benchmark set of indicators of financial system soundness for end-2005 for all EU countries, but no aggregated data for the euro area and EU, have been posted on the IMF website. The aggregated FSIs for the euro area that were until 2005 published annually in the ECB's Banking Sector Stability Report, which were prepared using a different methodology, have been provisionally discontinued due to the staggered implementation of International Financial Reporting Standards (IFRS). The latest issue of the report includes only separate aggregations for IFRS and non-IFRS reporting EU member states. Euro area and EU aggregates will be reimplemented for end-2007 data when IFRS-compliant data will be required in all countries for supervisory reporting. The ECB's Financial Stability Review, which is published on a semi-annual frequency, includes a set of indicators covering only large, complex financial institutions given its focus on systemic developments. Overall, no comprehensive set of euro-area wide financial soundness indicators is available at present, and information on non-bank financial institutions is particularly scarce, in part due to limited information exchange between the relevant authorities.

- $\quad$ The recent entry of Slovenia in the euro area went smoothly from a statistical point of view. Going forward, European statistical authorities intend to focus efforts on maintaining data for only a selection of historical compositions of the euro area and EU. 


\section{INTERNATIONAL MONETARY FUND}

\section{EURO AREA POLICIES}

\section{Staff Report for the 2007 Article IV Consultation with Member Countries

\author{
Supplementary Information
}

Prepared by the European Department

Approved by Michael Deppler and Adnan Mazarei

July 20,2007

1. This supplement provides an update of economic and policy developments since the release of the staff report (7/10/07). The thrust of the staff appraisal remains unchanged.

2. Recent data indicate that economic activity remains buoyant (Table 1). Growth in 2007:Q1 was revised up modestly, to 2.8 percent on a quarterly annualized basis (3.1 percent over 2006:Q1). Industrial production data for May and purchasing managers' indices for manufacturing and services in June point to robust growth ahead.

3. Exports continue to show strong momentum. The latest foreign trade data suggest that euro-area (nominal) goods exports stood 9 percent and imports 5 percent above lastyear's levels during January-May 2007. Over the same period, the trade balance swung from a deficit of euro 20 billion ( 0.2 percent of GDP) to a surplus of euro 4 billion. The staff's March 2007 assessment suggested that the euro's real effective exchange rate was still broadly in line with fundamentals; since then the currency has appreciated by about 2 percent in real effective terms.

4. Headline and core inflation stayed at $\mathbf{1 . 9}$ percent in June. Capacity utilization continues to increase. Unemployment fell to 7.0 percent in May, the lowest level since the beginning of harmonized records. Labor cost indicators, however, suggest still contained wage increases. Inflation expectations have essentially moved sideways.

5. The ECB left interest rates unchanged at its July $\mathbf{5}$ meeting. Market participants expect further interest rate hikes in September and December, to $4 \frac{1}{2}$ percent by end year.

6. Pressures to slow fiscal adjustment are mounting. Since the staff report was finalized, key countries have loosened fiscal targets or tabled proposals to do so. 


\section{Table 1. Euro Area: Main Economic Indicators}

(in percent change)

\begin{tabular}{|c|c|c|c|c|c|c|c|}
\hline & 2002 & 2003 & 2004 & 2005 & 2006 & 2007 & 2008 \\
\hline \multicolumn{8}{|l|}{ Demand and Supply } \\
\hline Private consumption & 0.8 & 1.2 & 1.5 & 1.5 & 1.7 & 1.7 & 2.2 \\
\hline Public consumption & 0.8 & 1.2 & 1.6 & 1.6 & 1.7 & 1.7 & 2.2 \\
\hline Gross fixed investment & -1.5 & 1.1 & 2.3 & 2.6 & 4.8 & 5.8 & 4.2 \\
\hline Final domestic demand & 0.6 & 1.3 & 1.6 & 1.6 & 2.6 & 2.6 & 2.5 \\
\hline Stockbuilding 1/ & -0.3 & 0.2 & 0.3 & 0.0 & 0.1 & -0.1 & 0.0 \\
\hline Domestic Demand & 0.4 & 1.5 & 2.0 & 1.8 & 2.5 & 2.5 & 2.5 \\
\hline Foreign balance $1 /$ & 0.5 & -0.7 & 0.1 & -0.3 & 0.2 & 0.1 & -0.1 \\
\hline Exports 2/ & 1.7 & 1.1 & 6.8 & 4.2 & 8.2 & 5.9 & 5.7 \\
\hline Imports $2 /$ & 0.3 & 3.1 & 6.7 & 5.0 & 7.9 & 5.8 & 6.0 \\
\hline Real GDP & 0.9 & 0.8 & 2.0 & 1.5 & 2.8 & 2.6 & 2.5 \\
\hline \multicolumn{8}{|l|}{ Resource Utilization } \\
\hline Potential GDP & 2.0 & 1.9 & 1.9 & 1.9 & 2.0 & 2.1 & 2.1 \\
\hline Output gap & 0.1 & -1.0 & -0.9 & -1.3 & -0.6 & -0.1 & 0.2 \\
\hline Employment & 0.9 & 0.6 & 0.7 & 0.7 & 1.4 & 1.3 & 0.9 \\
\hline Unemployment rate $3 /$ & 8.2 & 8.7 & 8.8 & 8.6 & 7.8 & 7.0 & 6.9 \\
\hline \multicolumn{8}{|l|}{ Prices } \\
\hline GDP deflator & 2.6 & 2.1 & 1.9 & 1.9 & 1.8 & 2.1 & 1.9 \\
\hline Consumer prices & 2.3 & 2.1 & 2.1 & 2.2 & 2.2 & 2.0 & 2.0 \\
\hline \multicolumn{8}{|l|}{ Public Finance 4/ } \\
\hline General government balance & -2.6 & -3.1 & -2.8 & -2.5 & -1.6 & -1.0 & -1.1 \\
\hline General government structural balance & -2.6 & -2.6 & -2.4 & -1.9 & -1.3 & -0.9 & -1.0 \\
\hline General government gross debt & 68.2 & 69.3 & 69.8 & 70.5 & 68.8 & 66.7 & 65.4 \\
\hline \multicolumn{8}{|l|}{ Interest Rates } \\
\hline Short-term deposit rate & 3.3 & 2.3 & 2.1 & 2.3 & 3.1 & $\ldots$ & $\ldots$ \\
\hline Long-term government bond yields & 4.9 & 3.9 & 3.8 & 3.3 & 3.9 & $\ldots$ & $\ldots$ \\
\hline \multicolumn{8}{|l|}{ Exchange Rates } \\
\hline U.S. dollar per euro & 0.94 & 1.13 & 1.24 & 1.25 & 1.26 & $\ldots$ & $\ldots$ \\
\hline Nominal effective rate $(2000=100)$ & 105.1 & 117.6 & 122.0 & 121.7 & 122.6 & $\ldots$ & $\ldots$ \\
\hline Real effective rate $(2000=100) 5 /$ & 107.1 & 122.3 & 127.8 & 128.0 & 128.0 & $\ldots$ & ... \\
\hline \multicolumn{8}{|l|}{ External Sector $4 / 6$ / } \\
\hline Current account balance & 0.8 & 0.4 & 0.8 & 0.0 & -0.2 & -0.3 & -0.4 \\
\hline Trade balance $7 /$ & 1.8 & 1.4 & 1.3 & 0.6 & 0.3 & $\ldots$ & $\ldots$ \\
\hline \multicolumn{8}{|l|}{ Memorandum items 4/ 8/ } \\
\hline Current account balance & 0.7 & 0.5 & 1.1 & 0.3 & 0.0 & -0.3 & -0.5 \\
\hline Trade balance $7 /$ & 2.1 & 1.9 & 1.6 & 0.9 & 0.6 & 0.3 & -0.1 \\
\hline
\end{tabular}

Sources: IMF, World Economic Outlook; Eurostat, ECB Monthly Bulletin.

1/ Contribution to growth, in percentage points.

2/ Includes intra-euro area trade.

$3 /$ In percent.

4/ In percent of GDP.

5/ Based on normalized unit labor costs.

6/ Based on ECB data, which exclude intra-euro area flows.

7/ Data for goods.

8/ Calculated as the sum of individual countries' balances. 


\section{INTERNATIONAL MONETARY FUND}

EXTERNAL

RELATIONS DEPARTMENT
Public Information Notice (PIN) No. 07/89

FOR IMMEDIATE RELEASE

July 31,2007
International Monetary Fund $70019^{\text {th }}$ Street, NW

Washington, D. C. 20431 USA

\section{IMF Executive Board Discusses Euro Area Policies}

On July 25, 2007, the Executive Board of the International Monetary Fund (IMF) concluded the discussion of euro area policies. ${ }^{1}$

\section{Background}

The euro area economy is doing well on the heels of a supportive external environment and generally sound policies. Real GDP growth has been running around $2 \frac{1}{2}$ percent; fiscal deficits are markedly lower than a few years ago; and strong export growth, improving profitability and balance sheets, and accommodative financial conditions have fostered a broad-based upswing of investment and employment.

Capacity utilization indicators are moving up, with some already close to previous cyclical peaks. Thus far labor does not appear to be a major constraining factor. Amid supply sidedriven moderation, the cyclical response of wages appears to have diminished. Backward looking indicators show subdued wages through 2006 and wage settlements continue to surprise on the downside. While unemployment rates have fallen below the 2000 trough, equilibrium rates appear to have fallen further and labor force participation and population are on the rise. Key developments include the deregulation-enabled shift of employment toward part-time and temporary jobs; the rising labor force participation of women and older workers; high immigration; and more efficient welfare programs.

\footnotetext{
${ }^{1}$ Under Article IV of the IMF's Articles of Agreement, the IMF holds bilateral discussions with members, usually every year. A staff team visits the country, collects economic and financial information, and discusses with officials the country's economic developments and policies. On return to headquarters, the staff prepares a report, which forms the basis for discussion by the Executive Board. At the conclusion of the discussion, the Managing Director, as Chairman of the Board, summarizes the views of Executive Directors, and this summary is transmitted to the country's authorities.
} 
Since September 2006, headline inflation measured by the Harmonised Index of Consumer Prices (HICP) has been running in line with the European Central Bank's "close to but under" 2 percent target. Financial market-based measures, analysts expectations, and various indicators of inflation suggest that, adjusted for oil and administrative price as well as tax hikes, inflationary pressure has been mounting only gradually.

Fiscal policy performance was generally strong in 2006. Standard measures suggest that the area's cyclically-adjusted fiscal deficit fell by somewhat under 1 percentage point of GDP in 2006 - exceeding staff's $1 / 2$ percent of GDP benchmark for countries at a significant distance from close to balance or surplus. In general, higher-than-budgeted revenues have been allocated to debt reduction, even if not to the full extent by all countries.

In line with strengthening activity, the European Central Bank has raised the main policy rate eight times since December 2005 to 4 percent. Nonetheless, financial conditions are still on the accommodative side. The financial system is viewed as relatively healthy and financial market volatility as well as risk premia remain historically low, although there are some signs that the credit cycle is gradually turning.

The euro area's external setting is propitious. The area's external current account is broadly balanced and export growth has been dynamic. The euro's real effective exchange rate has appreciated by about 1 percent since the end of 2006 and is broadly unchanged from two and a half years ago.

Against this background, the staff projects above potential real GDP growth of around $2 \frac{1}{2}$ percent through 2008 . The risks to growth are generally small and to the upside in the short run but widening and moving to the downside over the medium run, mainly on account of external risks relating to oil prices, global current account imbalances, potential investor flight from risk, and US growth.

\section{Executive Board Assessment}

Directors welcomed the euro area economy's move from recovery to upswing. Against the backdrop of a broadly equilibrated external position and exchange rate, they expected real GDP growth to remain above potential over the near term and employment gains to stay healthy thanks in part to reforms to labor markets and welfare systems.

Directors observed that with rising resource utilization inflationary pressures could be expected to build gradually and some further monetary policy tightening might be required. The necessary magnitude of further tightening would have to depend on wages and the pricing behavior of firms and also on the extent to which reforms and demographics have improved labor supply and productivity growth. In addition, further tightening would hinge on the evolution of external risks to activity further out, including those related to global imbalances and the exchange rate, which are presently seen on the downside.

Directors considered that the external position of the euro area remains roughly in balance and that the real effective exchange rate of the euro continues to trade within range of the mediumterm equilibrium. They welcomed the broad-based structural reform efforts underway and 
underscored that their continued implementation, in line with the authorities' multilateral consultation commitments, will help strengthen prospects for an orderly resolution of global current account imbalances.

Directors welcomed the generally strong fiscal policy performances of 2006 and the announced intentions to reach medium-term fiscal objectives by 2010 at the latest. With a view to preparing for accelerated population aging soon after 2010, Directors encouraged the authorities of countries that have not yet reached these objectives to continue to lower their cyclically-adjusted fiscal deficits by at least $1 / 2$ percent of GDP per year, consistent with the rules of the Stability and Growth Pact. Given the good economic times, they considered it particularly important not to repeat past mistakes and loosen fiscal targets in response to abundant revenues. In this regard, they supported the trend toward strengthening national fiscal policy rules and governance mechanisms.

Looking forward, Directors observed that, while immediate prospects were strong, population aging was likely to prompt a significant slowing of potential growth. In this setting, they considered achieving a joint structural acceleration of productivity and labor force participation rates to be the fundamental challenge. They agreed that the Lisbon Strategy was beginning to play an important role and that the transparency and governance of National Reform Programs could usefully be strengthened further to that effect. Past labor market reforms had clearly paid off, leading to a significant strengthening of employment growth, consistent with the area commitments under the Multilateral Consultation. Achieving the same for productivity growth would require raising the contestability of national services markets. Hastening the implementation of the Services Directive would be a significant step in this direction.

Directors also viewed the integration of the markets for financial services as one of the most promising avenues for boosting Europe's productivity and growth performance. They advocated raising the contestability of national retail markets and deepening Europe's capital markets. Accordingly, they emphasized the need for a prompt implementation of the Markets in Financial Instruments Directive and welcomed steps to integrate national payments and securities clearing and settlement systems as well as ongoing work to facilitate crossborder bank mergers and acquisitions.

Directors agreed that a further strengthening of Europe's crossborder financial stability framework could help promote progress towards efficient and effective financial crisis prevention, reduce moral hazard, and avoid unnecessary risks for national taxpayers. Directors also agreed that establishing the foundation for a decentralized but more integrationcompatible financial stability framework required measures targeted at fostering cooperation, in particular in the area of supervision. Most Directors thought that this entailed an increased emphasis on joint responsibility and accountability, including mandates that call for minimizing the collective costs facing EU states from potential large cross-border financial institutions failures.

With trade having consistently been a boon to Europe's productivity performance, Directors emphasized the need for an ambitious conclusion to the Doha Round to boost the area's 
already high living standards. They therefore encouraged the authorities to resist protectionist pressures and agree to additional trade liberalization, in particular in agriculture.

It is expected that the next consultation on the euro area policies in the context of Article IV obligations of member countries will be held on the standard 12-month cycle.

Public Information Notices (PINs) form part of the IMF's efforts to promote transparency of the IMF's views and analysis of economic developments and policies. With the consent of the country (or countries) concerned, PINs are issued after Executive Board discussions of Article IV consultations with member countries, of its surveillance of developments at the regional level, of post-program monitoring, and of ex post assessments of member countries with longer-term program engagements. PINs are also issued after Executive Board discussions of general policy matters, unless otherwise decided by the Executive Board in a particular case. 


\section{Euro Area: Main Economic Indicators}

\begin{tabular}{|c|c|c|c|c|c|c|c|}
\hline & 2002 & 2003 & 2004 & 2005 & 2006 & 2007 & 2008 \\
\hline \multicolumn{8}{|l|}{ Demand and Supply } \\
\hline Private consumption & 0.8 & 1.2 & 1.5 & 1.5 & 1.7 & 1.7 & 2.2 \\
\hline Public consumption & 0.8 & 1.2 & 1.6 & 1.6 & 1.7 & 1.7 & 2.2 \\
\hline Gross fixed investment & -1.5 & 1.1 & 2.3 & 2.6 & 4.8 & 5.8 & 4.2 \\
\hline Final domestic demand & 0.6 & 1.3 & 1.6 & 1.6 & 2.6 & 2.6 & 2.5 \\
\hline Stockbuilding $1 /$ & -0.3 & 0.2 & 0.3 & 0.0 & 0.1 & -0.1 & 0.0 \\
\hline Domestic Demand & 0.4 & 1.5 & 2.0 & 1.8 & 2.5 & 2.5 & 2.5 \\
\hline Foreign balance $1 /$ & 0.5 & -0.7 & 0.1 & -0.3 & 0.2 & 0.1 & -0.1 \\
\hline Exports 2/ & 1.7 & 1.1 & 6.8 & 4.2 & 8.2 & 5.9 & 5.7 \\
\hline Imports 2/ & 0.3 & 3.1 & 6.7 & 5.0 & 7.9 & 5.8 & 6.0 \\
\hline Real GDP & 0.9 & 0.8 & 2.0 & 1.5 & 2.8 & 2.6 & 2.5 \\
\hline \multicolumn{8}{|l|}{ Resource Utilization } \\
\hline Potential GDP & 2.0 & 1.9 & 1.9 & 1.9 & 2.0 & 2.1 & 2.1 \\
\hline Output gap & 0.1 & -1.0 & -0.9 & -1.3 & -0.6 & -0.1 & 0.2 \\
\hline Employment & 0.9 & 0.6 & 0.7 & 0.7 & 1.4 & 1.3 & 0.9 \\
\hline Unemployment rate $3 /$ & 8.2 & 8.7 & 8.8 & 8.6 & 7.8 & 7.0 & 6.9 \\
\hline \multicolumn{8}{|l|}{ Prices } \\
\hline GDP deflator & 2.6 & 2.1 & 1.9 & 1.9 & 1.8 & 2.1 & 1.9 \\
\hline Consumer prices & 2.3 & 2.1 & 2.1 & 2.2 & 2.2 & 2.0 & 2.0 \\
\hline \multicolumn{8}{|l|}{ Public Finance 4/ } \\
\hline General government balance & -2.6 & -3.1 & -2.8 & -2.5 & -1.6 & -1.0 & -1.1 \\
\hline General government structural balance & -2.6 & -2.6 & -2.4 & -1.9 & -1.3 & -0.9 & -1.0 \\
\hline General government gross debt & 68.2 & 69.3 & 69.8 & 70.5 & 68.8 & 66.7 & 65.4 \\
\hline \multicolumn{8}{|l|}{ Interest Rates } \\
\hline Short-term deposit rate & 3.3 & 2.3 & 2.1 & 2.3 & 3.1 & $\ldots$ & $\ldots$ \\
\hline Long-term government bond yields & 4.9 & 3.9 & 3.8 & 3.3 & 3.9 & $\ldots$ & $\ldots$ \\
\hline \multicolumn{8}{|l|}{ Exchange Rates } \\
\hline U.S. dollar per euro & 0.94 & 1.13 & 1.24 & 1.25 & 1.26 & $\ldots$ & . \\
\hline Nominal effective rate $(2000=100)$ & 105.1 & 117.6 & 122.0 & 121.7 & 122.6 & $\ldots$ & \\
\hline Real effective rate $(2000=100) 5 /$ & 107.1 & 122.3 & 127.8 & 128.0 & 128.0 & $\ldots$ & $\ldots$ \\
\hline \multicolumn{8}{|l|}{ External Sector $4 / 6 /$} \\
\hline Current account balance & 0.8 & 0.4 & 0.8 & 0.0 & -0.2 & -0.3 & -0.4 \\
\hline Trade balance $7 /$ & 1.8 & 1.4 & 1.3 & 0.6 & 0.3 & $\ldots$ & $\ldots$ \\
\hline \multicolumn{8}{|l|}{ Memorandum items 4/ 8/ } \\
\hline Current account balance & 0.7 & 0.5 & 1.1 & 0.3 & 0.0 & -0.3 & -0.5 \\
\hline Trade balance $7 /$ & 2.1 & 1.9 & 1.6 & 0.9 & 0.6 & 0.3 & -0.1 \\
\hline
\end{tabular}

Sources: IMF, World Economic Outlook; Eurostat, ECB Monthly Bulletin.

$1 /$ Contribution to growth, in percentage points.

2/ Includes intra-euro area trade.

3/ In percent.

4/ In percent of GDP.

5/ Based on normalized unit labor costs.

6/ Based on ECB data, which exclude intra-euro area flows.

7/ Data for goods.

8/ Calculated as the sum of individual countries' balances. 


\section{Statement by Klaus Stein, Executive Director for Euro Area July 25, 2007}

In my capacity as President of EURIMF, I am pleased to submit this Buff statement on the Article IV consultation with the euro area. My statement reflects the common view of the euro area Member States and the European Community in their respective fields of competence.

The authorities of the euro area Member States welcome the IMF staff's assessment of economic developments and prospects in the euro area. While broadly concurring with the findings of the Fund, on some issues views differ, as I will outline in my statement. I will also update the Board on recent economic developments.

\section{Short-term economic outlook}

The euro area economy is in the second year of a robust economic recovery, growing at solid rates. The upturn is driven by strong growth of exports which benefit from continued favorable global demand conditions. On the domestic side, investment activity has been firming over several years and should give, despite a softening of construction investment in the course of the year, a substantial contribution to output growth also in 2007. Private consumption has shown some strengthening as well but remains weaker than in previous upswings. However, with unemployment having fallen to a level not seen in 25 years, rising consumer confidence should eventually feed into the spending behavior of households.

Short-term indicators point favorably to output growth at or above potential in the second and third quarter of this year. While hard data are somewhat mixed, especially those related to private consumption, survey indicators suggest that confidence remains high among both consumers and enterprises. For the year as a whole, output growth should therefore stay above $2 \frac{1}{2}$ percent. Looking ahead, the euro area economy is expected to grow further at a sustained rate also in 2008, as a moderation in capital spending should be largely compensated by stronger consumption growth. Although it is too early to have a definite view, the improved outlook is mostly due to a cyclical upturn. At the same time, there are signs that some structural factors may also be at work as well. 
The euro area authorities largely share the staff's view on real GDP growth in 2007 and 2008. We note that the discrepancy which existed a year ago regarding the projections for private consumption has largely disappeared. The authorities also broadly concur with the risk scenario put forward by the staff. In particular, over the medium term the risks are slightly tilted to the downside and related to the possibility of a sharper than expected slowdown in the United States, potential protectionist pressures, financial market risks, further unexpected oil price increases and the potential of a disorderly unwinding of global imbalances. In the short term, however, the risks to the outlook are broadly balanced.

\section{Monetary policy and the outlook for price stability}

The ECB broadly agrees with the Fund staff's assessment that some further monetary policy action is likely to be necessary to stabilize inflation rates below 2 percent, in line with its definition of price stability. After the increase in key interest rates in June the ECB's monetary policy is still on the accommodative side, given the continued positive economic environment in the euro area. The Governing Council of the ECB will continue to act in a firm and timely manner to ensure price stability over the medium term.

Turning to the outlook for price developments, annual HICP inflation was 1.9 percent in the first half of 2007. However, in assessing future inflation trends it is important to look beyond any short-term volatility in inflation rates, in particular as last year's volatility in energy prices is giving rise to significant base effects, which have and will strongly influence the short-term profile of annual inflation rates.

At the policy relevant medium-term horizon, the Governing Council of the ECB holds the view that the risks to price stability remain on the upside. In the Governing Council's view, with a high degree of resource utilization and continuously improving labor markets in the euro area economy, capacity constraints are emerging which could lead in particular to stronger than expected wage dynamics and profit margin developments. Such developments would pose significant risks to price stability. In addition, upside risks to price stability arise from increases in administered prices and indirect taxes beyond those anticipated so far, and the potentially pro-cyclical fiscal policy stance in some euro area countries. Further risks may arise from further unexpected oil price increases.

Cross-checking the outcome of the ECB's economic analysis with that of its monetary analysis confirms the existence of upside risks to price stability at medium to longer horizons. The underlying rate of monetary expansion remains strong, as reflected in continued rapid growth of the broad monetary aggregate M3 and the still high level of credit growth. Following several years of robust monetary growth and the continued vigor of money and credit expansion, liquidity in the euro area remains ample. In this environment, upside risks to price stability prevail at medium to longer-term horizons. Therefore, monetary developments continue to require very careful monitoring, particularly against the background of the current economic expansion and still strong property market developments. 
In this light, the Governing Council will continue to monitor closely all developments in order to ensure that risks to price stability over the medium term do not materialize and that inflation expectations in the euro area remain solidly anchored at levels consistent with price stability. Solid anchoring of inflation expectations is a prerequisite for monetary policy to make an ongoing contribution towards supporting sustainable economic growth and job creation in the euro area.

\section{Fiscal developments and fiscal policy}

The euro area authorities share the staff's assessment of the improved budgetary situation, including some uncertainty related to the sustainability of the recent tax revenue performance.

In 2006, the general government deficit in the euro area fell for the third consecutive year, while the debt ratio recorded its first decline since 2002. Taken at face value, the improvement seems to be structural. However, as rightly pointed out by the staff, since the buoyancy of tax revenues may reflect both permanent and temporary factors, the jury is still out on the actual determinants of the estimated improvement in the structural budget balance in 2006.

The authorities welcome the staff's overall positive assessment regarding the functioning of the reformed Stability and Growth Pact (SGP). In this context, it is important to emphasize that countries with excessive deficits have made significant structural efforts to correct their deficits within the deadlines established under the reformed SGP. At the same time, the authorities agree that the agreed rules of the preventive arm of the Pact should be fully implemented, and that further progress is needed to reach sound budgetary balances in the medium term.

The staff's focus on the necessity to reach the Medium Term Objectives (MTOs) fits well to the orientations for fiscal policies in euro area Member States adopted by the Eurogroup on April 20, 2007. The Eurogroup emphasized the need to make the preventive arm of the Pact work in the current good economic times by stepping up consolidation towards the MTOs and avoiding pro-cyclical loosening. This would create the necessary scope for the full working of the automatic stabilizers in less favorable economic times. It would also allow reducing debt levels and contribute to the sustainability of public finances.

The euro area authorities find interesting the staff's suggestions for strengthening the national fiscal policy rules and national governance mechanisms to improve the implementation of the preventive arm of the Pact and help to strengthen budgetary positions. The Commission has recently put forward a number of proposals aimed at improving the effectiveness of the preventive arm of the Pact. These proposals are being currently examined by the euro area authorities. In this context, it is worth noting that Member States already developed strategies to improve spending efficiency such as more use of performance information and of medium term budgetary frameworks. 


\section{Structural policies}

The euro area authorities share the staff's assessment of progress made in the area of structural reform. We are now close to the end of the first three-year cycle in the revised Lisbon strategy. In the coming months, policy directions for the next cycle covering the period 2008 to 2010 will be established.

As regards the functioning of the revised Lisbon strategy, experience suggests that the new governance based on a partnership between Member States and the EU is creating a greater sense of "national ownership" of objectives and commitments. The suggestions of the staff for greater transparency in reform commitments and for harnessing the synergies in reform efforts are timely and well considered. Considerable efforts are now being devoted to improve methods for evaluating National Reform Programs, the Lisbon Community Program, and their externalities. Moreover, a major element in ongoing reflections is how to achieve a better interaction between reform initiatives at national and EU level.

The most recent assessments of progress with structural reforms carried out by the Commission and the Council provide signs that many reforms are underway. Good progress has been made towards boosting $\mathrm{R} \& \mathrm{D}$ and innovation, improving regulation and enhancing the business environment, especially for small and medium-sized enterprises. Also, the shift to a knowledge-based economy appears to be well underway. If announced plans entailed in the National Reform Programs are implemented as intended, R\&D spending will rise to $2.8 \%$ of GDP by 2010, up from 1.9\% of GDP in 2005.

Also, important steps have been taken to reinforce the sustainability and the quality of public finances. Governments have been generally setting out appropriate measures to improve their budgetary positions and deal with projected increases in pension and health-care costs. Nevertheless, achieving sound finances in the medium to long term as well as raising the efficiency and effectiveness of public spending remain significant challenges.

Some reforms have started to deliver benefits, though many reforms are yet at an early stage and will need to be fully followed through to make a lasting economic impact. In this context, the authorities agree with the staff that market contestability in sheltered sectors, especially in services, needs to be improved. A successful and timely implementation of the Services Directive is essential for improving the regulatory environment in services. On the staff's suggestion that the coverage of the Directive be extended to cover professional services, the authorities clarify that although a series of services are excluded from the application of the Directive, it does apply to most professional services.

Analysis suggests that past structural reforms enacted by euro area Member States might have added a structural component to the recent cyclical upswing. There is evidence of structural improvement on the labor markets: structural rates of unemployment have declined since 2000, and there have been large and sustained increases in the employment rates of women and older workers. Labor productivity in the euro area is also experiencing a strong 
recovery. Nevertheless, the nature of this productivity pick-up is not fully certain. Although there are signs that it is not entirely cyclical, it is too early to draw confident conclusions.

\section{Financial sector issues}

The euro area authorities share the staff's view on the importance of the financial sector integration process for the region's growth performance. In order to better understand the productivity gap in financial services (ex insurance), it would be helpful to have more details on the staff's research, including the impact of potential measurement discrepancies. Financial integration has been an EU policy priority since 1998 and now forms an integral part of the Lisbon strategy as a means to deliver a more productive use of capital and higher output potential.

Stimulated by regulatory reform and the euro introduction, the process of EU financial integration is well underway, in particular in wholesale markets. Measures of the Financial Services Action Plan (FSAP) are almost fully transposed by Member States, but the staff rightly emphasizes the crucial role of supervisors and the Commission in ensuring their consistent implementation. In this context, the functioning of the Lamfalussy process is currently under review, and possible improvements may be discussed later this year. Further, in accordance with the principle of Better Regulation, the Commission has launched an external study on the evaluation of the FSAP policies. Regarding ongoing work, the major initiatives highlighted by the staff reflect the priorities set in the White Paper on Financial Services Policy for the period 2005-2010, while the Green Paper on Retail Financial Services published early this year has confirmed the Commission's commitment to targeted measures in the retail area.

With regards to macro-stability risks, euro area authorities remain optimistic on the financial sector's capacity to absorb adverse shocks, while acknowledging risks associated with a turning of the credit cycle. The authorities also agree with the staff's recommendations that ensuring the adequacy of supervisory structures is crucial as financial integration progresses.

Building on previous analysis and the outcome of crisis simulation exercises, a report on developing EU financial stability arrangements is just being finalized by an Ad Hoc Working Group established after the informal Ecofin meeting in Helsinki in September 2006. The main challenges in this respect are to develop cooperation and tools for prevention, management and resolution aimed at the minimization of overall costs in the event of a potentially systemic cross-border crisis and providing appropriate incentive structures for all involved parties.

There is also ongoing work within the FSC on the challenges for the current supervisory framework. In this context, the euro area authorities welcome the staff's analysis and suggestions as an input to the ongoing debate, but warn against a too alarmist tone which in our view fails to acknowledge the developments of the past years, both at the legislative level and in regard to the enhancement of cooperation and coordination arrangements of the crisis 
management.

\section{Euro area integration}

The euro area authorities emphasize the open character of the euro area enlargement process within a rules-based framework, as reflected in the recent decision on euro adoption by Cyprus and Malta on January 1, 2008. While authorities subscribe to the position that real income catching-up is not a separate convergence criterion, they stress the importance of achieving nominal convergence in a sustainable manner, with the assessment involving both backward- and forward-looking elements. It implies that countries should not rely on one-off measures or a temporary downward shock to meet the criterion only during a short time frame. As reported by the staff, euro area authorities underscore the key role of strong policies in preparation for euro adoption. In particular, fiscal and structural policies should be orientated towards ensuring a successful long-term performance under monetary union.

\section{International economic relations}

As noted by the staff, the euro area's contribution to the resolution of global imbalances - as agreed in the context of the multilateral consultations - is part of the more broadly based Lisbon Strategy for Growth and Jobs. Also for domestic reasons, the euro area authorities are therefore firmly committed to its implementation.

It is important, however, that other participants of the multilateral consultations also deliver on their commitments and that countries that did not directly participate in the consultations contribute to the adjustment effort needed for an orderly correction of global imbalances. The Fund can continue to play a very useful role in the process through its monitoring, both in the context of the Article IV consultations and in the context of its regional and multilateral surveillance.

Regarding trade policy, the euro area authorities share the importance attached by the staff to an ambitious conclusion of the Doha Round. Throughout 2006 and 2007, the EU continued to play a key role in the efforts to push forward the negotiations. In particular, the EU was instrumental in the re-launch of the negotiations in early 2007 - after a 6 months suspension of the talks. Despite the difficulties encountered during negotiations, it remains the EU's firm intention to ensure its successful conclusion.

The EU has lately launched a new generation of carefully chosen bilateral free trade agreements with Asean countries, South Korea and India, which should help tackle some non-tariff barriers and step up the EU's engagement with rapidly growing Asian economies. The authorities concur with the staff's view that the free trade agreements should not be substitutes for an ambitious liberalization under the Doha Development Agenda. Indeed, they are not. They are designed to be complementary to the multilateral trade liberalization. The EU's priority is to ensure that any new free trade agreement is a stepping stone for, rather than a stumbling block to, progressive liberalization within the WTO system. 